\title{
Väestöliitto
}

Elina K. Einiö

\section{DETERMINANTS OF INSTITUTIONAL CARE AT OLDER AGES IN FINLAND}

Finnish Yearbook of Population Research XLV 2010 Supplement

The Population Research Institute, Helsinki, Finland 
Elina K. Einiö

\section{Determina nts of Institutional Care at Older Ages in Finland}

Finnish Yearbook of Population Research XLV 2010 Supplement

\section{$\varangle$ Väestöliitto}

The Population Research Institute, Helsinki, Finland In collaboration with The Finnish Demographic Society 


\title{
FINNISH YEARBOOK OF POPULATION RESEARCH XLV 2010 SUPPLEMENT
}

\author{
Advisory Board \\ HELKA HYTTI \\ SEIJA ILMAKUNNAS \\ OSMO KONTULA \\ SEPPO KOSKINEN \\ MAURI NIEMINEN \\ IRMA-LEENA NOTKOLA \\ ANNA ROTKIRCH \\ MATTI SIHTO \\ KARRI SILVENTOINEN \\ ISMO SÖDERLING \\ STINA FÅGEL (secretary) \\ Editor in Chief \\ ISMO SÖDERLING \\ Editorial Assistant \\ MIKA TAKOJA \\ ISBN 978-952-226-046-8 (paperback) \\ ISBN 978-952-226-047-5 (PDF) \\ ISBN 978-952-226-066-6 (PDF) \\ ISSN L-1796-6183 \\ ISSN 1796-6183 (print) \\ ISSN 1796-6191 (online)
}

\footnotetext{
The Population Research Institute Väestöntutkimuslaitos

Väestöliitto, The Family Federation of Finland

(Kalevankatu 16 B) PO Box 849, FIN-00101 Helsinki, Finland

Telephone +358-9-228 050, Fax +358-9-612 1211

E-mail:pop.inst@vaestoliitto.fi

http://www.vaestoliitto.fi
}

The Yearbook is abstracted/indexed in Popline and Sociological Abstracts All articles of the journal are peer-reviewed 


\section{CONTENTS}

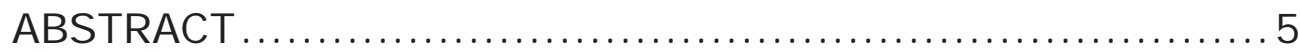

LIST OF ORI GINAL PUBLICATIONS ......................... 6

1 I NTRODUCTION .......................................... 7

2 BACKGROUND AND CONCEPTUAL FRAMEWORKS .......... 9

2.1 Background and framework in social sciences .......... 9

2.2 Framework in health-service research ................... 11

2.3 Application and criticism .................................13

2.4 Reformulated framework ............................... 14

3 LITERATURE REVIEW................................. 15

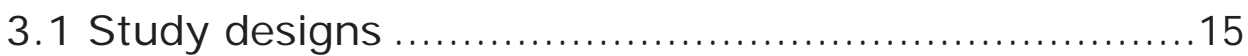

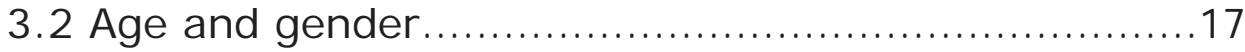

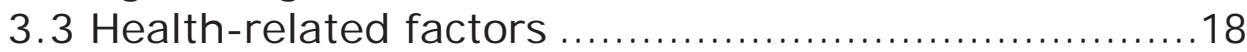

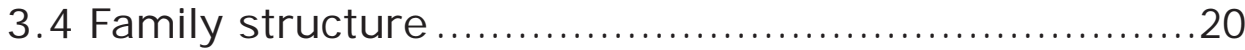

3.5 Socio-economic resources ................................ 22

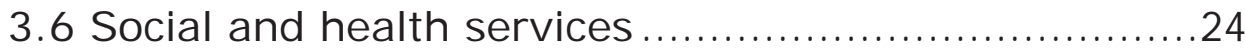

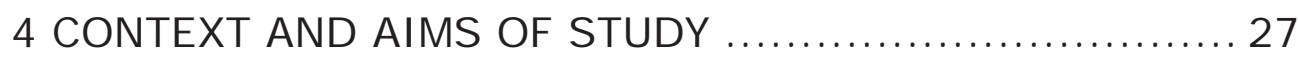

4.1 Institutional care in Finland $\ldots \ldots \ldots \ldots \ldots \ldots \ldots \ldots \ldots \ldots \ldots \ldots \ldots \ldots \ldots \ldots$

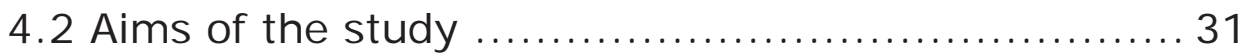

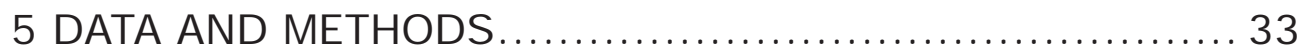

5.1 Data sources ................................................. 33

5.2 Data protection ............................................. 33

5.3 Study population and period .............................. 33

5.4 Definition of long-term institutional care ...................34

5.5 Definition of the independent variables ................... 35

5.6 Statistical methods ....................................... 39

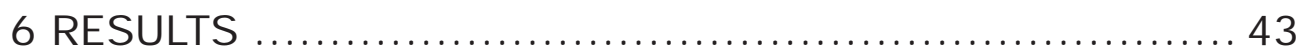

6.1 Characteristics of the study population...................43

6.2 Age and gender and institutional care .....................45

6.3 Chronic medical conditions and institutional care .....48

6.4 Socio-economic factors and institutional care...........49

6.5 Income and institutional care .............................. 51

6.6 Spouse and institutional care ............................. 52

6.7 Institutional care after the death of a spouse ...........54 
7 DISCUSSION............................................... 57

7.1 Discussion of the main determinants....................... 57

7.1.1 Chronic medical conditions.......................................................57

7.1.2 Household income ...............................................................

7.1.3 Other socio-economic factors ...................................................62

7.1.4 Having and losing a spouse .....................................................65

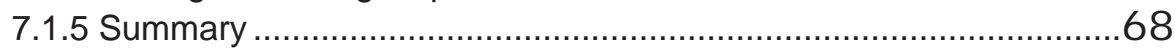

7.2 Methodological considerations ..........................69 69

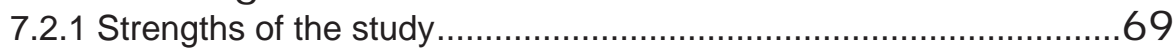

7.2.2 Limitations of the study ...........................................................

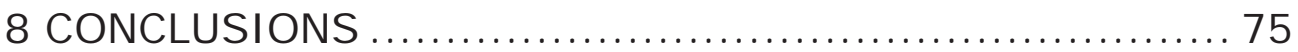

8.1 I mplications for future research ....................... 75

8.2 I mplications for policy .................................. 77

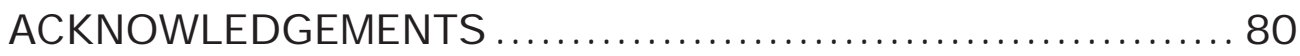

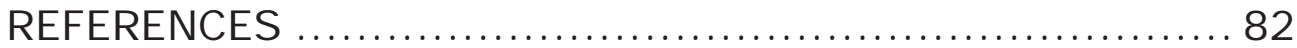

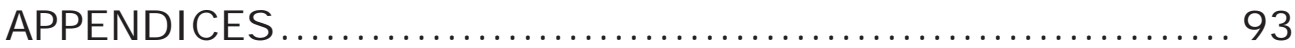

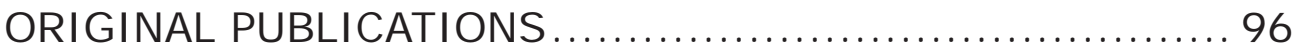




\section{ABSTRACT}

With growing pressure from an ageing population on social and health-care use and expenditure, it is of major policy importance to analyze the reasons for admission to long-term institutional care at older ages. Although there is increasing evidence that cognitive and functional disabilities are not the only major risk factors, and that the social situation and the lack of family members play an important role in explaining admissions, further research is needed. There is a lack of evidence on the effects of a spouse's death, and their magnitude and duration are unknown. In addition, previous findings on how income is associated with institutional care are inconsistent, and results on poor housing are seldom available. Furthermore, there is little systematic evidence showing how chronic medical conditions other than dementia affect the risk of admission in the general older population.

This study used population-based register data on Finnish older adults aged 65 and over $(n=280,722)$ to analyse individual-level determinants of admission to long-term institutional care from January 1998 to September 2003. The main focus was on how chronic medical conditions, household income and other socio-economic factors, living with a spouse, and the death of a spouse were associated with admissions. Cox proportional hazard regression models were used.

The results of the study indicated that dementia, Parkinson's disease, stroke, depressive symptoms, other mental-health problems, hip fracture, and diabetes were strongly associated with an increased risk of admission when socio-demographic confounders and co-morbid conditions were controlled for (Nihtilä et al. 2008). It was also shown that older men and women in the lowest household-income quintile group were more likely to be admitted to institutional care than those in the highest group, when age, first language, and area characteristics were accounted for. Controlling further for living arrangements and other socio-economic and chronic medical conditions markedly reduced these income differences in admission, but they still remained significant. Poorly equipped housing and being a renter were associated with an increased risk of admission, and the possession of a car and living in a detached house with a decreased risk in these same multivariate models. Having a lift in an apartment house was not associated with admission (Nihtilä and Martikainen 2007). The results further showed that the lower risk of admission among those living with a spouse compared to those living alone or with others was only partly attributable to and mediated through favorable socio-economic, housing and medical conditions (Nihtilä and Martikainen 2008b). Moreover, this study 
was the first to establish that the death of a spouse strongly increases the risk of admission, the excess risk being highest during the first month following the death and decreasing over time in both genders (Nihtilä and Martikainen 2008a). In showing a particularly high risk immediately after bereavement, the study provides indirect evidence of an association between the loss of social and instrumental support and the risk of institutional care. Overall, it seems that the need for long-term institutional care depends not only on the ageing of the population but also on the future prevalence and severity of chronic medical conditions associated with admission, and on older people's income, housing conditions and spousal care.

\section{LIST OF ORIGINAL PUBLICATIONS}

This thesis is based on the following articles referred to in the text in italics.

I. Nihtilä, E. K., Martikainen, P. T., Koskinen, S. V., Reunanen, A. R., Noro, A. M., Häkkinen, U. T. (2008): Chronic conditions and the risk of long-term institutionalization among older people. European Journal of Public Health, 18 (1):77-84.

II. Nihtilä, E., Martikainen, P. (2007): Household income and other socioeconomic determinants of long-term institutional care among older adults in Finland. Population Studies, 61(3):299-314.

III. Nihtilä, E., Martikainen, P. (2008b): Why older people living with a spouse are less likely to be institutionalized: the role of socioeconomic factors and health characteristics. Scandinavian Journal of Public Health, 36(1):35-43.

IV. Nihtilä, E., Martikainen, P. (2008a): Institutionalization of older adults after the death of a spouse. American Journal of Public Health, 98(7): $1228-1234$.

These articles are reproduced with the kind permission of their copyright holders. 


\section{I NTRODUCTION}

The number and proportion of older people is rising. In Finland the proportion of people aged 65 years and over is expected to increase from the current 16 percent in 2006 to 26 percent in 2030 (Statistics Finland 2007). Although most older people live independently at home they use a disproportionally large proportion of social and health services, including most inpatient care in health centers and fifty percent in somatic specialized care (Official Statistics of Finland 2003). In addition, the fastest growing age group comprises those aged 85 and over, who currently constitute 1.8 percent of the total population and will constitute 6.0 percent in 2040 (Statistics Finland 2007). Despite their small numbers, this oldest age group accounts for half of the care in old people's nursing homes (Official Statistics of Finland 2007). The net expenditure on long-term care in institutions is high (Hujanen 2003), and the overall need for such care is unlikely to diminish given the ageing of the older population. It is thus of particular relevance in terms of policy planning to identify population characteristics that influence the need for institutional care and thus to target other social and health services in order to delay or prevent it. Furthermore, the vast majority of older people themselves think that living at home and receiving services there is the best living arrangement for those in need for care (Vaarama et al. 1999).

The aim of the Finnish old-age policy is to promote functional capacity and support independent living among older people, so that as many as possible will continue to live at home and in a familiar environment. Institutional care and housing services are available, however, for those who can no longer cope living at home (Ministry of Social Affairs and Health 2008a). The quantitative target set in 1996 for increasing the proportion of people aged 75 and over living at home up to 90 percent was mostly reached in 2002 (Ministry of Social Affairs and Health 1996; Official Statistics of Finland 2003). The current national target is to increase this to 91-92 percent by 2012 (Ministry of Social Affairs and Health 2008b). However, with growing pressure from an ageing population on social and health-care use and expenditure it is of major interest to understand how older people who go into institutions differ from those who continue living at home in terms of demographic, socio-economic and health-related characteristics.

Although earlier studies, mostly from the United States (Gaugler et al. 2007), indicate that functional and cognitive impairments are not the only major risk factors with regards to admission into institutional care at older ages, and 
that the lack of family members, especially of a spouse, plays an important role further research is needed. There is a lack of evidence on how a spouse's death affects the risk of admission, inconsistent evidence on the role of income and housing conditions, and little systematic, longitudinal evidence on the effect of chronic medical conditions other than dementia (Aguero-Torres et al. 2001 ) in the general older population. Using internationally unique registerbased data on Finnish adults aged 65 and over, this study aims at analysing demographic, socio-economic and health-related determinants of admission to long-term institutional care between January 1998 and September 2003. The focus is on the role of chronic medical conditions, household income and other socio-economic factors, and having and losing a spouse in explaining the risk of admission. The quality or consequences of institutional living fall beyond the scope of the study. 


\section{BACKG ROUND AND CONCEPTUAL FRAMEWORKS}

\subsection{Background and framework in social sciences}

Peter Townsend (1962) was one of the first researchers in sociology to systematically analyze admissions to old-age institutions in the Last Refuge. He wanted to identify the social reasons for admission, to explore the nature and quality of institutional care, and to discover the effects of institutional living upon old people themselves in order to find out whether long-stay institutions for the old were necessary in modern society, and if so what form they should take. He studied institutional residents in England and Wales in the late 1950s and early 1960s, his aim being to explain why older persons gave up independent living at home and were admitted to institutions where they lost some of their privacy and self-determination.

Townsend (1962) considered social and environmental circumstances essential in understanding institutional admission. However, his starting point was the most proximate reason for admission: incapacity of self-care. He categorized the activities necessary for self-care into four groups: 1) activities that are always or nearly always performed by the individual if he or she is able to do them; 2) activities that may be done by others even if the individual is able to do them; 3) faculties that have to be employed in social communication; 4) tasks that are necessary only if the individual suffers from some special disabling condition. The first category includes mobility and personal care, the second house-care, the third seeing, hearing, organizing thoughts, and speaking, and the fourth the activities necessary to overcome special handicaps, such as taking medication or following special diets. When the capacity to perform these different activities weakens, the likelihood of admission to an institution is likely to increase. However, Townsend offered no explicit hypotheses covering the type of incapacity of self-care that would increase the risk of admission the most.

In addition to incapacity of self-care, Townsend (1962) considered also social and environmental circumstances to be potential reasons for admissions, focusing in particular on the family, social isolation, homelessness and financial insecurity. The question commonly raised in Britain was, whether older people were in institutions because their families would not look after them. This has been a concern in many other societies as well. According to Pitkänen (1994), the increase in institutional care has often been regarded as a consequence of change in family functions, especially the diminishing role 
of younger generations in caring for older people, although there has been little historical evidence on the use of old-age institutional care. Furthermore, Arber and Ginn (1991) summarised that in the literature on care-giving in both the United States and Britain, caring for older people has primarily been regarded as work done by daughters for their parents, and that care provided by spouses has received less attention.

Freedman (1996) studied the impact of families on the use of institutional care in her analyses of nursing-home admissions in the United States. She identified three different interrelated ways in which family members might influence admissions: 1) family members could give personal care directly to the older person; 2) family members could provide assistance in obtaining formal community-based services; and 3) family ties could have a beneficial impact on the well-being and health of the older person, and thus indirectly affect the risk of admission. Townsend (1962), however, underlined the importance of social isolation among older people who did not have family members or friends. $\mathrm{He}$ considered the lack of social relationships, conflicts in them, and the inability of family members to provide care to be important in determining admission to institutions. He attributed social isolation to never having had close family members or friends (continuing isolation), losing them due to death or for some other conclusive reason (sudden desolation), or the weakening of the relationships on account of separation or infirmity (diminishing frequency of social relationships). These three different ways to social isolation may be difficult to distinguish in practice, but they may shed light on the social reasons for admission (Townsend 1962, 288). Widowhood could be regarded as one of the most common forms of sudden desolation at older ages.

Potential reasons for admission to old-age institutions could also be characterised as lack of different types of resources that may increase the likelihood of admission. Resources for preventing institutional fall into three different interrelated categories: health resources, material resources and caring resources. Originally Arber and Ginn (1991) created this resource triangle to explain dependency in old age as an unwelcome stage of life. For some older people, however, institutional care could be a compensatory environment that helps them to cope with everyday life.

According to Arber and Ginn (1991), health resources include the ability to provide own self-care and care for others, material resources include income, assets, housing and car ownership, and caring recourses include access to carers in the household and the community, from one's own financial resources 
and from the state. The absence of any of these types of resources is a constraint on the well-being of the older person and may increase the risk of admission to an institution. Arber and Ginn did not mention any of these three resource domains as a predominant reason for dependency in old age but treated them as equally important. Although sometimes recognized, social-sciences frameworks do not specifically hypothesize about interrelations between different resource domains or social circumstances that may affect the use of institutional care.

\subsection{Framework in health-service research}

Several studies analyzing the reasons for admission to institutional care in old age (Greene and Ondrich 1990; Wolinsky et al. 1992; Tomiak et al. 2000) apply Ronald Andersen's conceptual framework, which considers the use of health services to be a function of predisposing, enabling and need factors (Andersen 1968). According to the original framework, created in the United States in the 1960s, families' use of formal health services is a function of their predisposition to use services, their ability to obtain services and their need for such services. It focuses on the family as the unit of analysis, the assumption being that family members often decide together whether care is necessary, and whether it should be provided by the family or the formal health-care system (Andersen 1968). Although originally considering the family to be the main decision-making unit, Andersen shifted to the individual as the unit of analysis when developing the framework further (Andersen and Newman 1973; Andersen 1995). Moreover, the original framework took the use of health services as an indicator of family members' behavior rather than a product of the health-care system (Andersen 1968).

In the original framework, predisposing factors referred to characteristics that affected the propensity of family members to use services but were not directly related to the need for care or ability to gain access to care. Predisposing factors included family composition (e.g., age, gender, family size, marital status), social structure (e.g., employment, social class, occupation), and health beliefs (e.g., value of health services, knowledge of diseases) (Andersen 1968). Predisposing factors pre-date need factors, and as Andersen (1995) argued later they may be exogenous, especially some demographic characteristics (Andersen 1995). Enabling factors were the means that made the services available to family members, and included family resources (e.g., income, savings, insurance) and community resources (e.g., residence, region, physician/hospital bed-population ratio). Need factors represented the most immediate reason for health-service use, including illness among family 
members (e.g., symptoms, overall health level) and their response to it, e.g., seeing a doctor (Andersen 1968). However, a revised model from the $1970 \mathrm{~s}$ characterized illness according to perceived and evaluated need, the original need indicator of response being abolished because it measured a dimension rather than a predictor of use (Aday and Awe 1997). Furthermore, enabling factors originally referred mostly to the ability to obtain health services, not to the ability to avoid them, as the framework was created to explain the use of hospital, physician and dental services (Andersen 1968), and not specifically the use of services that people might want to avoid such as long-term institutional care. Although the Andersen framework is the most commonly used conceptual framework for analyzing nursing-home admissions, it does not focus specifically on the nature of institutional living when exploring the potential reasons. Admission is regarded as a regular health service that old people might need.

Within the framework of the 1960s the use of health services was considered to be a function of individual or family behavior (Andersen 1968). However, in the revised framework of the 1970's, the original predisposing, enabling and need factors were reformulated as principal individual determinants, and societal determinants (technology, norms) and health services system features (resources and organization) were introduced as important aggregate determinants of the use of health services (Andersen and Newman 1973; Aday and Awe 1997). However, predisposing, enabling and need factors are still the most commonly used concepts from Andersen's framework in empirical studies of the determinants of institutional care (Greene and Ondrich 1990; Wolinsky et al. 1992; Tomiak et al. 2000).

Andersen (1995) argued later, after having developed and revised the framework over several decades, that it was meant to both predict and explain the use of health care. The predisposing, enabling and need component could be regarded as making an independent contribution to the prediction of use. Furthermore, according to Andersen, the framework could also specify hypothesized causal pathways between the different predictors and the use of health services (Andersen 1995; Aday and Awe 1997). However, this option to find causal pathways has rarely been taken up in studies examining factors related to the use of institutional care. 


\subsection{Application and criticism}

Although widely used in health-service research, the Andersen framework is largely ignored in medical sociology. There may be numerous reasons for this. Research in the latter field, for example, often explores how certain structural aspects of society, including social class, the economy and the culture, are related to the health of the population, and there may be no need to go into people's health beliefs and motivations. Moreover, a number of criticisms could be offered of the Anderson framework as well. The criticisms are often related to the definition and measurement of the major predictors and indicators of health-service use, and to the specification and testing of the hypothesized relationships (Aday and Awe 1997). The usefulness of Andersen's major concepts is limited because they are not exclusive and could incorporate the same variables simultaneously. For example, a person's social situation, such as living with a spouse, could be regarded as both a predisposing and an enabling factor, which makes the empirical testing of the relationships between them impractical. Furthermore, in sociological terms dependency in old age or the need for institutional care is often attributed to a combination of health, social and financial problems (Townsend 1962; Arber and Ginn 1991), and Andersen's reduction of these need factors to health problems seems to underestimate the role of difficult social and financial circumstances.

Although, the Andersen framework does take into account the role of health beliefs, including beliefs about the severity of the health problems and whether moving to an institution is necessary in the view of the individual, family members or health-care professionals, it is more useful in analyzing attitudes towards institutional care rather than real admissions as it is often difficult or impossible to know who made the final decision about the admission. Nevertheless, the Andersen revised framework from the 1970s is of major importance in that it incorporates features of the health-care system that are essential in explaining trends or area differences in admissions (Andersen and Newman 1973; Aday and Awe 1997). In this study, the usefulness of the Andersen original framework lies in its clarity in terms of focusing on health problems as the most proximate individual-level reasons for institutional care as admission rarely takes place without them. However, in both the Andersen (1968) and the Arber and Ginn (1991) frameworks need factors/health resources category is very general and normally incorporates all kinds of health problems. 


\subsection{Reformulated framework}

A reformulated framework comprising elements of those used in social-science and health-service research is introduced in order to enhance understanding of the individual-level determinants of admission to institutional care in old age (Figure 1). Health-related factors are further classified as more distant (e.g., diseases, accidents) and proximate (e.g., functional and mental disabilities) health-related factors. A somewhat similar distinction has been used in analyzing mortality at older ages (Martelin 1994). Functional or mental disabilities often constitute the immediate cause and requirement for admission into an institution, whereas diseases are likely to precede and to cause disabilities. In this reformulated framework demographic factors, family structure, and socio-economic resources are considered more distant determinants that are likely to affect admission, indirectly through health or more directly through preventing or promoting the admission of people with health problems. Demographic factors refer mainly to age and gender, family structure mainly to the availability of family support, socio-economic recourses to income, social class, education, housing conditions and car ownership, and formal caring resourses at home to access to formal carers and support services in the community. The aim in this is to clarify the role of different individual-level factors in affecting the risk of admission into institutional care and to suggest a causal ordering of some of them. The objective is to shed further light on previous results and guide the discussion. This framework will also guide the analyses of the Finnish data that form the basis of this study.

Figure 1. The key factors related to the use of institutional care on individual level

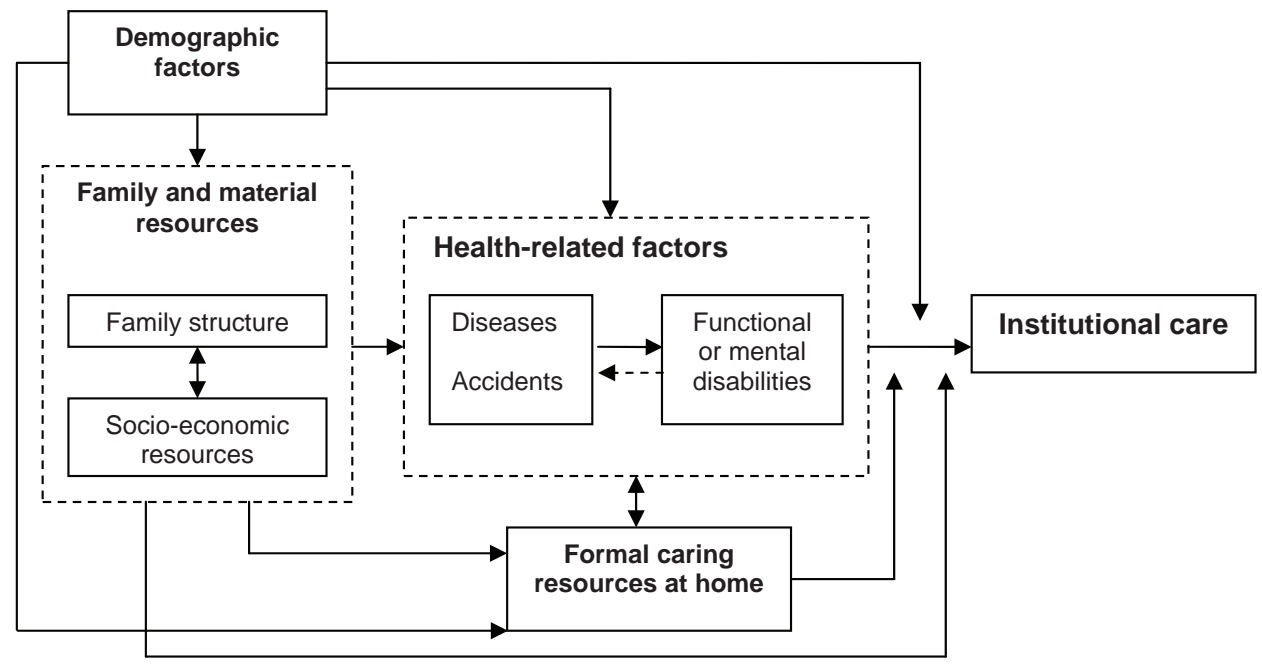




\section{LITERATURE REVIEW}

\subsection{Study designs}

Despite the large number of longitudinal studies analyzing admission to institutional care at older ages, few use data that are nationally or regionally representative of general older populations. Most nationally-representative longitudinal studies are from the United States (Speare et al. 1991; Steinbach 1992; Wolinsky et al. 1992; Coward et al. 1996; Couch and Kao 1998; Banaszak-Holl et al. 2004), England and Wales (Grundy 1992; Grundy and Glaser 1997; Breeze et al. 1999; Grundy and Jitlal 2007), and a few recent ones from Australia (Giles et al. 2007) and Finland (Häkkinen et al. 2008; Martikainen et al. 2009). In addition, some studies (Cohen et al. 1986; Lakdawalla and Schoeni 2003; Harris and Cooper 2006) are considered representative of older Americans because the sampling frames are based on Medicare insurance that covers almost all of those aged 65 and over in the United States (Lakdawalla and Schoeni 2003).

There are also a few longitudinal regional studies on the determinants of institutional care: for Manitoba, Canada (Shapiro and Tate 1988; Mustard et al. 1999; Tomiak et al. 2000), and for local areas in the United States (Branch and Jette 1982; Foley et al. 1992; Jette et al. 1992; Salive et al. 1993; Freedman 1996; Russell et al. 1997; Russell et al. 1997), England (Hancock et al. 2002), Sweden (Aguero-Torres et al. 2001), Finland (Nuotio et al. 2003), Germany (Klein 1996), the Netherlands (Puts et al. 2005), and China (Woo et al. 2000). Some regional studies represent older people in urban areas (Aguero-Torres et al. 2001; Puts et al. 2005), and others focus on rural areas (Russell et al. 1997). The Finnish regional studies in this field cover the older population in the areas of Helsinki (Valvanne 1992), Tampere (Nuotio et al. 2003), and Kuusamo (Anttila 1989). However, the majority of longitudinal studies analyzing the risk factors for admission are based on selected rather that general samples, including disease-specific samples (for a review of determinants in dementia see Gaugler et al. 2009), or samples selected according to various other direct or indirect health criteria, such as samples of those older people with some (Hanley et al. 1990; Newman et al. 1990; Liu et al. 1991; Pearlman and Crown 1992; Liu et al. 1994) or high (Garber and MaCurdy 1989; Greene and Ondrich 1990) level of functional dependency, or samples of older people receiving formal services at home (Kivelä 1985). 
The literature review for this study was mostly based on population-based national or regional studies that had a follow-up of admission to institutional care. Other longitudinal studies on selected samples were cited if they were well known or if no similar population-based results were available. Studies using disease-specific samples were excluded. Population-based cross-sectional studies were occasionally cited, in particular when similar longitudinal studies were not available, but were not systematically used because they simultaneously reflect both the risk of admission and the length of stay, and the determinants cannot normally be measured prior to admission.

Longitudinal studies from the United States and Canada mostly analyze admission to nursing homes. Similarly, some studies from Australia and Europe cover stays in nursing and residential homes (Hancock et al. 2002; Puts et al. 2005; Giles et al. 2007), and others from Europe also include long-stays in hospitals (Grundy and Jitlal 2007) or stays in mental hospitals (Aguero-Torres et al. 2001). These differences across studies may reflect national or regional practices in the provision of institutional care for older people. With a few exceptions (Liu et al. 1994), most North American studies do not distinguish between short- and long-term stays in nursing homes (Gaugler et al. 2007).

The results of existing studies are mostly based on multivariate models, either logistic (Cohen et al. 1986; Shapiro and Tate 1988; Speare et al. 1991; Foley et al. 1992; Steinbach 1992; Wolinsky et al. 1992; Coward et al. 1996; Grundy and Glaser 1997; Breeze et al. 1999; Mustard et al. 1999; Aguero-Torres et al. 2001; Giles et al. 2007; Grundy and Jitlal 2007) or proportional-hazards regression models (Freedman 1996; Tomiak et al. 2000; Hancock et al. 2002; Nuotio et al. 2003; Banaszak-Holl et al. 2004). These are mostly multivariate models, in which various demographic, socio-economic and health-related factors are simultaneously controlled for in order to obtain independent predictors of institutional care. These so-called independent determinants of nursing-home admission in the United States are summarized in a meta-analysis by Gaugler et al. (2007) and a synthesis by Miller and Weissert (2000). The meta-analysis is less biased in terms of health selection as it mostly summarizes studies using general samples of older people. 


\subsection{Age and gender}

The association between age and the risk of institutional care is well established. Numerous studies have shown that the older people are, the higher is the likelihood of being admitted to institutional care. In a longitudinal study of older Canadians in Manitoba, Mustard et al. (1999) indicated that the over80 s were 20 times more likely to go into nursing home during the follow-up period than the 60-69-year olds. Furthermore, most studies show that the association between age and the risk of institutional care persists even after adjustment for control variables, such as various socio-demographic and health characteristics (Branch and Jette 1982; Speare et al. 1991; Foley et al. 1992; Steinbach 1992; Coward et al. 1996; Tomiak et al. 2000; Woo et al. 2000; Nuotio et al. 2003). This could imply that advanced age is related to general fragility, which causes dependency but which is difficult to measure on the population level. Similarly, Speare et al. (1991) argue that it is not clear whether the independent effect of age is attributable to unmeasured aspects of health and disability that correlate with age or to norms about care for older people that are more supportive of institutional care as age increases.

Gender differences in institutional care are observed in most population-based cross-sectional (Arber and Ginn 1991; Carriere and Pelletier 1995; AgueroTorres et al. 2001; Desesquelles and Brouard 2003; Festy and Rychtarikova 2008; National Center for Health Statistics 2009) and longitudinal studies (Woo et al. 2000; Martikainen et al. 2009) that report them. It has been shown that women are more likely than men to reside and enter institutional care at older ages. For example, a longitudinal study of Finns over 65 years of age showed that women were 40 percent more likely than men to be admitted to institutional care during a six-year follow-up (Martikainen et al. 2009). However, gender differences are usually assumed to be due to the fact that women are older and more likely to be widowed (Grundy 1992; Klein 1996), because of higher male mortality rates and a higher male age at marriage. In a study of older Swedes living in an urban district of Stockholm, Agüero-Torres et al. (2001) indicated that gender differences in residing and entering institutional care were not significant after adjustment for age. Similarly, the gender differences in admission found in the Finnish study were entirely due to the fact that women were older and more likely to live alone (Martikainen et al. 2009). However, the net effects of gender identified in multivariate models vary. It seems that if older women were similar to men with regard to various socio-demographic, economic and health characteristics they would have a lower risk of admission in Finland (Martikainen et al. 2009) and in Manitoba, 
Canada (Mustard et al. 1999), a lower or the same risk in the United States (Gaugler et al. 2007), the same risk in Australia (Giles et al. 2007) and HongKong, China (Woo et al. 2000), but a higher risk in England and Wales (Grundy and Jitlal 2007). However, these results are not entirely comparable given the methodological differences, and the excess risk of institutional care observed among men, other things being equal, is usually relatively small.

\section{3 Health-related factors}

Despite numerous methodological differences various studies have produced broadly similar results with regard to some health-related reasons for admission to institutional care. It has been shown in several longitudinal studies that functional dependency (Branch and Jette 1982; Shapiro and Tate 1988; Greene and Ondrich 1990; Pearlman and Crown 1992; Steinbach 1992; Wolinsky et al. 1992; Coward et al. 1996; Tomiak et al. 2000; Aguero-Torres et al. 2001) and cognitive impairment (Branch and Jette 1982; Shapiro and Tate 1988; Greene and Ondrich 1990; Pearlman and Crown 1992; Coward et al. 1996) are associated with an increased risk of admission. These associations have been observed both in older populations in general (Branch and Jette 1982; Shapiro and Tate 1988; Steinbach 1992; Wolinsky et al. 1992; Coward et al. 1996; Tomiak et al. 2000; Aguero-Torres et al. 2001), and among older people with health problems (Greene and Ondrich 1990; Pearlman and Crown 1992). Functional dependency in this context usually refers to limitations in activities of daily living, ADL, or to instrumental activities of daily living, IADL. Both of which may reflect different aspects of bad health, including physical and mental disabilities, although they measure the capability to perform somewhat different tasks. ADL cover basic functions, such as eating, dressing, bathing, going to the toilet, maintaining continence, and moving, whereas IADL cover more complex functions such as shopping, handling finances, and cooking without assistance.

Previous studies have consistently shown that the more limited older people are in ADL (Shapiro and Tate 1988; Steinbach 1992; Wolinsky et al. 1992; Coward et al. 1996; Tomiak et al. 2000; Aguero-Torres et al. 2001; Banaszak-Holl et al. 2004) the higher is their risk of being take into institutional care. For example, Steinbach (1992) found in a study of people over 70 years of age living in the United States that those with one or two ADL limitations were 2.8-times more likely and those with three or more limitations were 4.5-times more likely to be admitted to an institution than those with no limitations, after controlling for other factors. However, there is little systematic evidence distinguishing the role of different ADL limitations in predicting admission. One reason for this may be the very high correlations between different types of ADL limitations, 
which complicate the estimation of their independent effects. However, Nuotio et al. (2003) found in a study of Finns over 60 years of age living in the city of Tampere that urge incontinence significantly increased the risk of institutional care among men, independently of all other factors including some other ADL limitations. In addition, the effects of IADL limitations seemed somewhat similar than those of ADL limitations in the studies that reported them: older people with more limitations were more likely to be taken into institutional care (Branch and Jette 1982; Coward et al. 1996; Banaszak-Holl et al. 2004). In a study of people over 75 years of age living in the United States in the 1990's, Banaszak-Holl et al. (2004) reported that those with one or more IADL or ADL dependencies were twice as more likely to be admitted to a nursing home than those with no dependencies, once socio-demographic and other medical conditions had been controlled for. On the other hand, Gaugler et al. (2007) reported in a meta-analysis from the United States that the presence of IADL dependencies was much less important in predicting admission than ADL dependencies. However, previous results on whether sight or hearing defects increase the risk of admission at older ages are somewhat inconsistent (Branch and Jette 1982; Tomiak et al. 2000; Hancock et al. 2002; Giles et al. 2007), but such effects appear at best to be relatively small (Giles et al. 2007).

Cognitive impairments (Branch and Jette 1982; Shapiro and Tate 1988; Coward et al. 1996), and dementia in particular, are known to predict admission to institutional care. Dementia has been shown to increase the risk (Jagger et al. 2000) independently of other medical conditions (Eaker et al. 2002; Banaszak-Holl et al. 2004) and functional dependency (Tomiak et al. 2000; Aguero-Torres et al. 2001; Banaszak-Holl et al. 2004; Bharucha et al. 2004). In a study of older Swedes over 75 years of age living in an urban district of Stockholm, Agüero-Torres et al. (2001) found that all types of dementia, including Alzheimer's disease, vascular dementia, and dementia of other etiology, strongly increased the risk of admission to institutional care. Furthermore, Banaszak-Holl et al. (2004) argued that the effect of dementia on nursing-home admission went beyond limitations in ADL and IADL, indicating that dementia had other consequences affecting admission, apart from increasing the number of functional dependencies. This could be related to the fact that dementia is highly burdensome to caregivers (Dunkin and Anderson-Hanley 1998), which could strengthen their intentions to find institutional care for the person concerned. Furthermore, according to Couch and Kao's (1998) longitudinal study of Americans over 70 years of age in the mid-1980s, dementia in combination with functional limitations strongly predicted nursing-home use. 
Although the effects of ADL and IADL limitations and dementia are rather well documented, the evidence on the effects of other chronic diseases and medical conditions on the risk of institutional care is meagre. Population-based crosssectional studies indicate than neurological diseases in general (Liu and Tinker 2001) and some specific neurological diseases such as Parkinson's disease (Berger et al. 2000) and stroke (Schmidt et al. 2000) are associated with living in an institution. These results are likely to be related to the severity of the functional consequences of these medical conditions. However, there is little evidence on the effects of other chronic diseases among older populations in general, and the effects of different diseases have seldom been studied simultaneously. Gaugler et al. (2007) carried out a meta-analysis of in the United States based on multivariate Cox regression models and indicated that diabetes, high blood pressure, cancer, stroke, and falls predicted nursing-home admission. However, previous results on whether certain other medical conditions, such as a hip fracture for example, predict admission are still inconsistent (Tomiak et al. 2000; Aguero-Torres et al. 2001).

\subsection{Family structure}

Interest in understanding the role of family members in reducing the risk of institutional care has been longstanding and research has mainly concentrated on the existence of a spouse or children (Freedman 1996). In an early cross-sectional study of new residents in old-age institutions in England and Wales, Townsend (1965) showed that older persons who were not married, and especially the never-married, were overrepresented in institutions when compared with the general older population. Since then several longitudinal studies have consistently shown that living without a spouse or alone is strongly associated with an increased risk of admission to institutional care (Grundy 1992; Grundy and Glaser 1997; Breeze et al. 1999). Furthermore, some studies indicate that after controlling for different socio-demographic factors and baseline health status, living alone still raises the risk of institutional care among older people in general (Branch and Jette 1982; Steinbach 1992; Wolinsky et al. 1992; Grundy and Jitlal 2007), and among older people with functional disabilities (Greene and Ondrich 1990; Liu et al. 1991; Yaffe et al. 2002). Steinbach (1992) found in his study of people over 70 years of age living in the United States in the mid-1980s that those living alone were 80 percent more likely than those living with a spouse to be admitted to institutional care, independently of other factors. These results are interpreted to indicate the importance of the social and instrumental support provided by a spouse in reducing the need for institutional care. However, there are few studies investigating whether older people with a spouse are also 
advantaged in having better economic, housing and health conditions that could partly explain the lower risk of admission.

Over four decades ago Townsend (1965) observed that older people without living children were overrepresented in institutions compared with the general British older population. Similarly, early cross-sectional studies from the United States indicated that childless women were more likely to reside in institutions than women with at least one (Dolinsky and Rosenwaike 1988) or two everborn children (Soldo 1981). A similar protective effect of children has been found in cross-sectional studies in France (Desesquelles and Brouard 2003). Furthermore, Grundy and Jitlal (2007) found in a recent longitudinal study of people over 65 years of age conducted in England and Wales that childless women were approximately 35 percent more likely to reside in an institution ten years later than those with children, even independently of other sociodemographic characteristics and limiting long-term illness. However, evidence from longitudinal studies conducted in the United States is somewhat inconsistent in that some indicate significant (Salive et al. 1993; Coward et al. 1996) and others insignificant (Speare et al. 1991) effects of having children. Freedman (1996) argued that it was essential to distinguish between sons and daughters in assessing the role of children in reducing the risk of institutional care. In a study of older Americans in New Haven, Connecticut, Freedman (1996) found that having at least one daughter reduced the risk of nursing-home admission among both genders, whereas having a son seemed to reduce the risk only among the women. Freedman also examined the association between having siblings and the risk of admission, and indicated that older people with at least one sibling had a lower risk than those without any.

Losing family members is suggested to play a major role in increasing the risk of moving to an institution at older ages. Townsend (1962) reported that many residents in old-age institutions gave similar reasons for being there: 'A wife died or went into hospital, a son was killed, and a daughter emigrated'. Although people's own perceptions of reasons for moving into an institution may be closely related to losing family members, there are few empirical studies analyzing how the death of a family member affects the risk of moving to an institution.

One study from the United States indicated that becoming widowed during the prospective follow-up was associated with an increased risk of nursinghome admission, but the recency of widowhood, measured retrospectively at the time of the baseline interviews, was not (Wolinsky and Johnson 1992). 
However, this latter result may to be misleading, especially if the effect of widowhood is short-term, and a large proportion of those who were recently widowed had already moved to an institution before the baseline interviews. There are currently no known large-scale prospective studies testing whether the effect of a spouse's death on entry into institutional care varies according to the duration of widowhood, and the existence and the magnitude of these effects are unknown. However, more extensive research on mortality (Young et al. 1963; Parkes et al. 1969; Mellström et al. 1982; Kaprio et al. 1987; Jagger and Sutton 1991; Schaefer et al. 1995; Martikainen and Valkonen 1996a; Martikainen and Valkonen 1996b; Manor and Eisenbach 2003) leads one to expect that the recently bereaved are more likely to be admitted to institutions than those who are currently married, and that the excess risk of admission is highest immediately after the death of the spouse and decreases over time.

\subsection{Socio-economic resources}

According to Mustard et al. (1999), the North American literature on the risk factors for nursing-home entry has found no strong evidence that a lower socioeconomic status was a determinant of institutional care at older ages. They argued that this was puzzling as most previous studies consistently showed that lower measures of socio-economic status such as household income and level of education were associated with higher mortality and morbidity, and lower functional status. This is not so puzzling, however, as most studies on risk factors for nursing home admission report only the net effects of income, after various other demographic, socio-economic, medical and functional statuses are controlled for, but do not report the crude or age-adjusted associations. The effect of income is likely to have disappeared in many studies after controlling for other factors including medical and functional status. A lower income could, nevertheless, increase admission risk through various health factors, but routine adjustment for them in the multivariate models is likely to underestimate these effects. The expected inverse relationship between income and institutional care might be observed in more studies if crude or age-adjusted figures were reported.

Although Mustard et al. (1999) showed that older people with a lower income had a higher likelihood of nursing-home admission in Manitoba, Canada, even independently of demographic, socio-economic and health characteristics, several other studies report different results. Numerous longitudinal studies from the United States (Speare et al. 1991; Steinbach 1992; Salive et al. 1993) and another study from Manitoba, Canada (Tomiak et al. 2000), and a regional 
study from England (Hancock et al. 2002) suggest that income has no effect on the risk of admission to institutional care after other socio-demographic and health characteristics are controlled for. In contrast, some other studies from Australia (Giles et al. 2007) and the United States (Lakdawalla and Schoeni 2003) indicate that the risk of admission decreases as income rises, independently of other factors including health conditions. These results suggest that income has an effect that goes beyond that of health.

However, there are not many studies examining in detail what health conditions mediate the effect of income on institutional care, and to what extent. Furthermore, there are no currently available studies investigating whether the inverse association between income and institutional care is explained by factors that could be considered to precede income, such as living arrangements and other socio-economic characteristics, and mediated through poor housing. Older people on a low income may be less likely to live in well-equipped houses with washing facilities and central heating, and this may complicate living in the community especially when disabilities arise. Furthermore, those with a lower income may also be disadvantaged in terms of buying community-based services in order to delay or prevent the need for institutional care.

Although Townsend (1962) argued as long ago as in the early 1960s that poor housing conditions, particularly homelessness and housing conditions that severely restrict living at home when disabilities appear, were important in explaining admission to old-age institutions, empirical results based on longitudinal studies are still scarce. He found in his cross-sectional study that a lack of piped water had been more common among the new institutional residents who formerly lived alone than among the general British older population who lived alone. However, according to a longitudinal study that started in former West Germany in the mid-1980s, a lack of a flush toilet or central heating was not a significant predictor of entering an institution in old age (Klein 1996).

Previous studies have used various other measures of socio-economic status, aside from income and poor housing, to determine whether wealth reduces the risk of admission into institutional care. The most consistent results refer to home ownership, which was shown to be associated with a reduced risk of admission, independently of other socio-demographic characteristics, among older adults in England and Wales (Grundy 1992; Grundy and Glaser 1997; Breeze et al. 1999), and even independently of health conditions among older adults in Manitoba, Canada (Tomiak et al. 2000), and among older adults with functional limitations in the United States (Garber and MaCurdy 1989; 
Greene and Ondrich 1990; Liu et al. 1991; Headen 1993; Greene et al. 1995). In contrast, findings on the effect of education are less consistent (Wolinsky et al. 1992; Mustard et al. 1999; Tomiak et al. 2000; Giles et al. 2007). Studies on the association between the possession of a car and entering institutions at older ages are mainly from England and Wales, and mostly indicate a reduced risk of institutional care (Breeze et al. 1999).

\section{6 Social and health services}

There is a general assumption that receiving formal, paid services at home reduces the risk of being admitted to institutional care at older ages. Empirical evidence is mostly inconsistent, however. Some studies from the United States indicate that older people with functional limitations in receipt of formal care at home have a higher risk of admission into institutional care, even when sociodemographic and health characteristics are controlled for (Newman et al. 1990; Liu et al. 1991). These unexpected results could reflect the fact that fragile older people are likely to receive community-based formal care first and then to move into institution. Despite the control for certain health and family characteristics however, the empirical results could nevertheless be biased by unmeasured confounders, such as general fragility or insufficient family support, which increase both the use of community-based formal services and the use of institutional care. Furthermore, even studies on people with dementia have not produced consistent results concerning the effects of service use on the risk of nursinghome admission (Gaugler et al. 2009). In fact, few population-based studies in this field find any significant effects of service use (Coward et al. 1996).

Although the supply of institutional care is one of the most important societal determinants of the likelihood of moving into institutions, the evidence is meagre. One study from England and Wales indicated that the overall risk among older people of moving into institutions was higher in 1981-1991 than in 1971-1981, partly because of the large increase in the supply of publicly provided institutional care (Grundy and Glaser 1997). Moreover, there are very few studies on how the organization of alternative community-based services affects the likelihood of entering institutional care. In a Canadian cross-sectional study, Carrière and Pelletier (1995) analyzed policies that were specific to different provinces and put forward some hypotheses on how they could affect the likelihood of residing in institutions in old age. Although there were large differences in institutionalization rates between the provinces, there were no empirical evidence that the likelihood of residing in an institution was lower in provinces in which the policies favored alternative community-based services (Carrière and Pelletier 
1995). Because of the difficulty of quantifying the supply of care most studies do not explicitly incorporate it into empirical analyses. This decision is unlikely to substantially bias the results of studies that do not focus on changes or regional differences in the use institutional care. 



\section{CONTEXT AND AIMS OF STUDY}

\subsection{Institutional care in Finland}

\section{Use of institutional care}

Institutional care has traditionally been relatively high among older people in Finland since the early 1930s. Although there were practically no old-age institutions in the country before the 1870s, numerous alms-houses (vaivaistalo) were rapidly established after the turn of the century following the Poor Relief Law (köyhäinhoitolaki) that came into force in 1922, which gave the municipalities the responsibility for providing institutional care. Those who moved into these new institutions were mainly older people. Only 1.6 percent of people aged 65 and over lived in alm-houses in 1900 compared to 2.7 percent in 1913, but by 19325.6 percent were living in these municipal homes (kunnalliskoti), rising to 5.8 percent in 1965 (Pitkänen 1994). These institutions later focused on old-age care and were turned into nursing homes for older people (vanhainkoti) (Rintala 2003). Nowadays, long-term institutional care for older people is provided mostly in nursing homes, service homes with 24-hour care, and health centers, and rarely in other hospitals such as psychiatric hospitals (Figure 2).

The use of institutional care started to decrease in the 1980s. Almost 7.3 percent of people aged 65 and over resided in long-term care institutions in 1981 (Noro 1998), compared to only 5.7 percent in 1991 and 5.3 percent in 2001. The decrease was most prevalent between the mid-1980s and the mid1990s. However, interpretation of the most recent trend depends on whether service homes providing 24-hour care are regarded as institutions, as in this study, in which case the overall usage of institutional care in older Finns has been rather stable in the 2000s. If these new housing services are excluded, the overall usage of institutional care among older people seems to have somewhat decreased (Figure 2).

Institutional care underwent a structural change between the 1990s and the 2000s, when the proportion of older adults living in service houses increased and the proportion in nursing homes decreased (Official Statistics of Finland 2002). The increase in service housing with or without 24 -hour care is related to the funding system, which favored this form of services for older people (Official Statistics of Finland 2003) and service housing seems to have replaced part of the care in nursing homes (Official Statistics of Finland 2002). Service homes with 24-hour care are regarded as institutions in this study, but ordinary 
service homes without 24-hour care, in which staff is not always available are excluded. The use of long-term inpatient care in health centres has remained rather stable since the early 1990s, but long-term care in other hospitals has somewhat decreased (Figure 2).

Long-term care in nursing and service homes is classified as social care, and long-term care in health centers and hospitals as health care. The provision of both social and health services for older people is the responsibility of the municipalities, which purchase some of them from private-sector providers (Official Statistics of Finland 2003). Long-term care in health centers and nursing homes is mostly publicly provided whereas care in service homes is often privately operated. Clients in public nursing homes accounted for over 85 percent of all nursing-home residents in the 1990s and the 2000s (derived from Noro 1998; Official Statistics of Finland 2006; Official Statistics of Finland 2008a), and the corresponding figure for service homes with 24-hour care was under 40 percent in 2005 (derived from Official Statistics of Finland 2006). No corresponding figures for older clients in health centres or hospitals were available, but these institutions are known to be mostly public, especially those that provide long-term inpatient care. The average age of new older clients admitted to long-term institutional care was 81.3 years in nursing or service homes with 24-hour care, and 82.6 years in health centers in 2001 (Official Statistics of Finland 2007). 
Figure 2. The proportion and number of people aged 65 and over in different long-term-care institutions, Finland, 1981-2006

\section{Proportion (\%)}

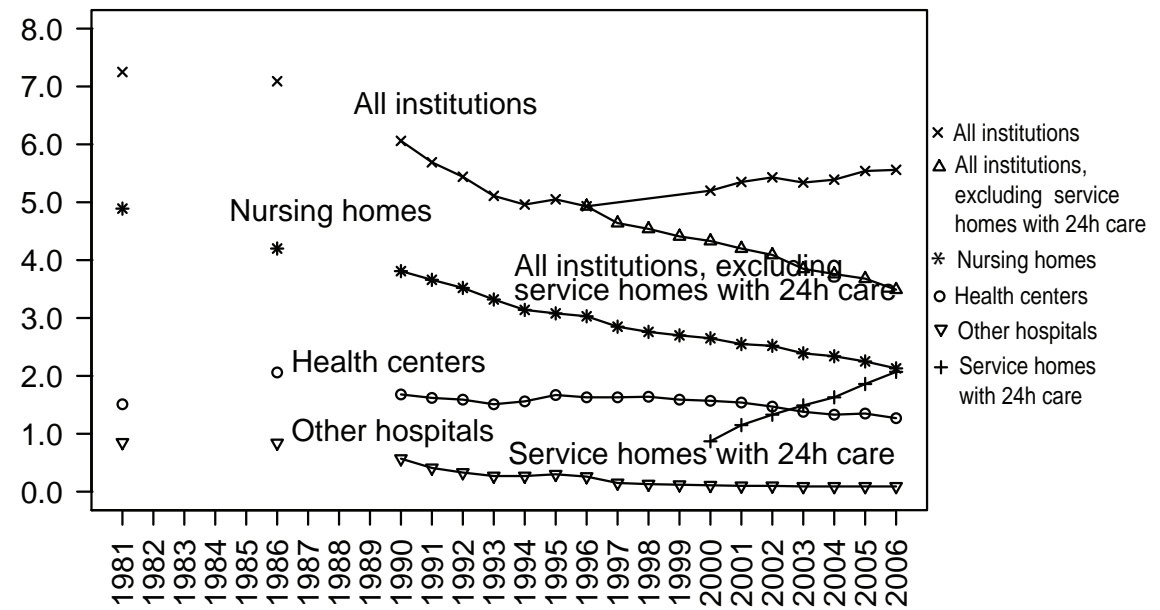

\section{Number of people}

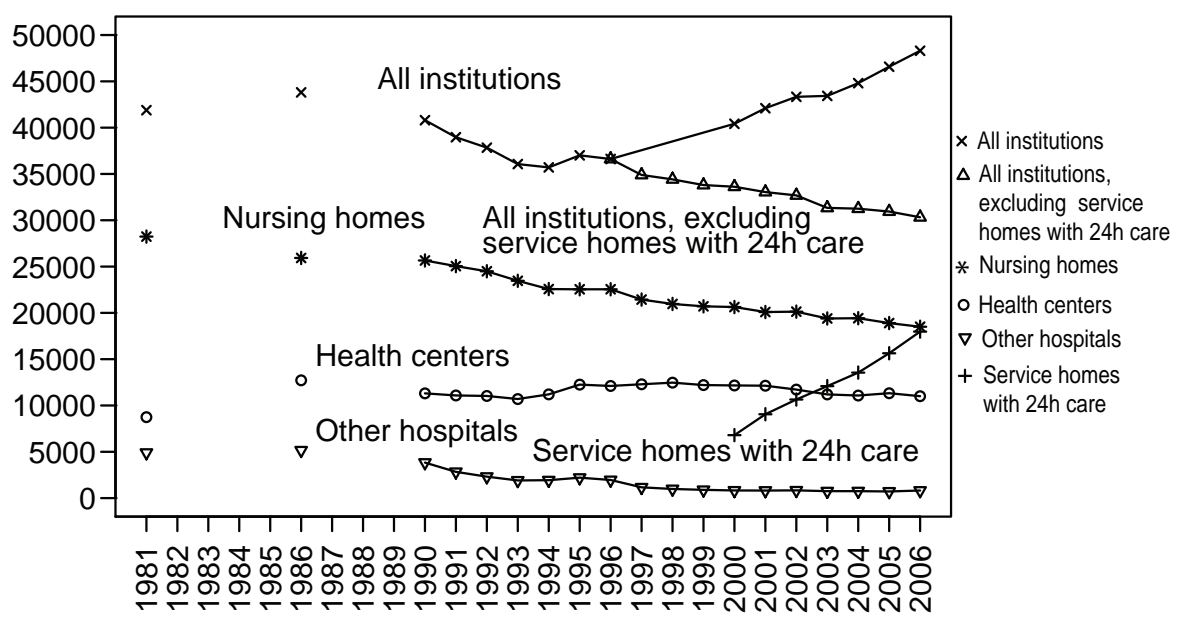

Source: For institutional care in 1981 and 1986 (Noro 1998), 1990-1994 (Nikiforov and Salmela 1995; Official Statistics of Finland 2008b), 1995-2006 (Official Statistics of Finland 2008b; Unpublished health care registers by STAKES), for population 1990-2006 (Statistics Finland 2008). 


\section{Cross-country comparisons}

Comparisons of institutionalization rates in old age across countries vary according to the period of time chosen and the institutions included. For example, the proportions of institution residents of all people aged 65 and over were similar in Finland (5.2 percent in 2000; Figure 2) and the United Kingdom (5.1 percent in 2000; OECD 2005), but lower in the United States (4.3 percent in 1999; National Center for Health Statistics 2009). However, the low figure for the United States only included nursing homes, whereas those for Finland and the United Kingdom also included institutional care in hospitals. Excluding long-term hospital care figures for 2000 would have been lower in Finland (3.5 percent; Official Statistics of Finland 2008b) and England (4 percent; Bajekal 2002). However, excluding hospital care for Finland gives a biased overall picture, because a high proportion of old-age institutional care is provided in health centers. Similar comparisons among selected Nordic countries indicate a lower rate of residency in various care institutions among people aged 65 and over in Finland than in Sweden (7.9 percent in 2000) or in Norway (6.0 percent in 2000; OECD 2005). Although comparisons between countries might provide a general overview of whether the care culture leans more towards institutional care or home-based care, they should be made with caution for several reasons. As mentioned above, the figures are likely to include different kinds of institutions, they are not adjusted for age structure of the older population, and very low figures may partly reflect the poor quality of information on institutional care.

\section{Regulations covering institutional care}

In Finland, institutional care for older people who can no longer live at home is usually managed and provided by the local municipality. Although the provision of social and health services is the responsibility of the municipalities there was no separate legislation covering services for older people at the time of this study (Official Statistics of Finland 2007). Neither the municipalities nor the state had a legal obligation to care for older people unless the danger to their life or health was obvious (Meriläinen et al. 1994). However, in principal institutional care and housing services are available to those who can no longer cope at home (Ministry of Social Affairs and Health 2008a). Admissions into institutional care are judicially based on older people's approval. People are taken into a care institution against their will only for certain specific reasons such as mental-health problems, intellectual disabilities, and severe and healththreatening drug abuse. These compulsory admissions are very rare at older ages, however (Meriläinen et al. 1994). 
User charges for long-term care in institutions are regulated and related to disposable income, up to a maximum of 80 percent. At the time of this study, clients were allowed to keep a minimum of 20 percent of their personal income, and at least a certain fixed amount for personal use if it was very low (Ministry of Social Affairs and Health 2003). Property ownership did not affect the charges, unless it provided income (e.g., proceeds from selling or renting). People in short-term institutional care paid fixed daily charges. Institutional care, like most social and health services, is mainly funded by public money, in other words municipal and state taxes (Official Statistics of Finland 2003). User charges account for a rather small proportion of the net expenditure of long-term institutional care, less than 20 percent in nursing homes for older people (Official Statistics of Finland 2007).

\subsection{Aims of the study}

The purpose of this study was to analyze the demographic, socio-economic and health-related determinants of admission into long-term institutional care at older ages. The focus was mostly on individual-level determinants. The role of formal, paid services provided at home were not analysed (Figure 1). This study used register-based data on people aged 65 years or older who were living in the community at the beginning of the study period and were followed for admission into long-term institutional care mostly from January 1998 to September 2003. The main aims of the study were to assess:

1. Which chronic medical conditions were most strongly associated with the risk of admission to institutional care, after controlling for socio-demographic confounders and co-morbid conditions (Nihtilä et al. 2008)

2. How education, social class, housing conditions, and the possession of a car were associated with the risk of admission, after controlling for age first and secondly for socio-demographic and chronic medical conditions (Nihtilä and Martikainen 2007)

3. Whether the higher risk of admission among those with a lower income was attributable to or mediated through living arrangements and other socio-economic, housing and chronic medical conditions (Nihtilä and Martikainen 2007)

4. Whether the lower risk of admission among those living with a spouse was attributable to their favorable socio-economic, housing and medical situation (Nihtilä and Martikainen 2008b)

5. How the death of a spouse and the time since bereavement affected the risk of admission (Nihtilä and Martikainen 2008a) 



\section{DATA AND METHODS}

\subsection{Data sources}

The register-based data were based on a 40-percent individual-level sample of the total Finnish population aged 65 and over on 31 December 1997 (301,263 persons). The study population was born in 1887-1932. The sample was drawn from a population registration database maintained by Statistics Finland using simple random sampling. These data are collected annually from different administrative records to provide labour-force statistics. They cover all persons living in Finland and provide detailed demographic and socio-economic information. This baseline sample, which was linked with the study persons' and their spouses' dates of death, was further linked with information on institutional care and previous hospital diagnoses provided by the National Research and Development Centre for Welfare and Health, STAKES, and with information from medication registers provided by the Social Insurance Institution.

\subsection{Data protection}

This study follows generally approved data-protection guidelines and ethical regulations in the use, reporting, and designing of the data. The data linkage was carried out at Statistics Finland using personal identification codes, which were removed before the data were handed over to the researchers at the Department of Sociology, University of Helsinki. Permission to use the anonymous data was obtained from all three registration authorities that provided it: Statistics Finland, STAKES and the Social Insurance Institution (TK 53-57604 and TK 53-499-05). In order to minimize the risks of indirect recognition of the individuals, the data contained no detailed information on the area of residence, such as the municipality.

\subsection{Study population and period}

Those who were already in institutions for long-term care (5.86 percent) or who for some other reason were not living in a private household at baseline on 31 December 1997 (0.96 percent) were excluded from the data. As a result the effective study sample, which was representative of the total Finnish older population living in the community, consisted of 280,722 persons. These people were followed for first entry into long-term institutional care or death mainly from 1 January 1998 to 30 September 2003. During this time, 35,940 persons 
were taken into long-term institutional care, and 49,254 died without being admitted into long-term institutional care. In the analyses of bereavement, the follow-up time was shorter, from 1 January 1998 to 31 December 2002, due to the unavailability of later dates of spousal death.

\subsection{Definition of long-term institutional care}

\section{Institutions}

Institutions included 1) hospitals and health centres and 2) old-age nursing homes and similar places. Places similar to nursing homes referred to service homes with staff on duty 24 hours a day. Service homes without 24-hour care were excluded. Both public and private institutions were included. Institutions for those with mental handicaps were excluded from the dependent variable, because they were not considered old-age institutions. People in these institutions were also excluded from the population-at-risk because they were not living in the community.

The information on institutional care was based on the annual client censuses and the discharge registers of health care (hospitals and health centers) and social care (nursing and service homes with 24-hour care). The censuses included information on people who were residing in institutions at the end of every year between 1997 and 2003, and the discharge data covered people who had left the institution each year between 1997 and 2003. Both the client censuses and the discharge data were used in order to minimize possible under-coverage in nursing and service homes (for more details on coverage see Nihtilä and Martikainen 2007).

\section{Long-term care}

A care episode in an institution was considered long-term if it lasted for over 90 days or was confirmed by a long-term care decision. The length of stay was calculated using arrival, departure and census dates. One care episode could comprise one stay or several successive stays in different institutions. The stays were considered successive if the preceding one ended on the same day as the next one started. The whole care episode was considered long-term if the over-90-days criterion was met or if any of the stays within the episode was subject to a long-term care decision. Long-term care decisions are usually made by social or health-care professionals when it seems that institutional living is permanent or long-lasting. The over-90-days criterion was used for the sake of consistency as it is traditionally applied by the National Research and Development Centre for Welfare and Health, STAKES. 


\section{Date of admission}

The date of the first admission into long-term institutional care during the follow-up was used to form the dependent variable. The admission date was available for all clients who were on record as residing in an institution. The date of departure was used to calculate the over-90-days criterion. For the clients who did not have a departure date the latest known date of being in an institution at the end of the year was used instead in order to calculate the length of the care episode. This is likely to have somewhat underestimated the length of these episodes and thus somewhat underestimate the overall number of people taken into long-term care. The follow-up period for admission into long-term institutional care ended on 30 September 2003. After that it was impossible to apply the over-90-days-criterion because the departure dates were available only until 31 December 2003. Occasionally, when clients were recorded as being in several institutions at the same time, if the stays overlapped entirely or in part, the earliest admission dates and the latest departure dates were used.

\subsection{Definition of the independent variables}

The independent variables were age, first language, living arrangements, region of residence, level of urbanization, household income, education, occupationbased social class, home ownership, house type, level of equipment in the dwelling, the possession of a car, and eighteen chronic medical conditions. The independent variables were mostly measured at baseline or prior to it, with the exception of bereavement, which was measured during the follow-up and was only used in the fourth sub-study. The variables used in each sub-study are shown in the appendices (Appendices 1-3). Separate analyses were usually carried out for men and women.

Age

Age was divided into one-year age groups $(65, \ldots, 98,99+)$ and added to the statistical models as separate dummies in the three first sub-studies and as a continuous variable in the fourth sub-study.

\section{First language}

The subject's first language was categorized as Finnish, Swedish, and other.

\section{Education}

The three educational categories were based on the highest educational qualification or degree: tertiary education, intermediate education (corresponding to upper-secondary or post-secondary non-tertiary education), and basic 
education or less (corresponding to lower-secondary education or less). The data did not separate primary education from lower-secondary education.

\section{Social class}

The occupation-based social-class categories were: upper white-collar, lower white-collar, worker specialized, worker non-specialized or specialization unknown, farmer, other self-employed, and others and unknown. Retired persons were categorized according to their last occupations and positions, and former housewives were categorized mainly according to the former social class of the head of the household.

\section{Household disposable income}

Household disposable income per consumption unit was used to measure income, which comprised all annual taxable income received by household members including wages, capital income, pensions, unemployment benefits and other taxable income transfers. All taxes and certain social-security payments such as income, capital, municipal, and church taxes, and health-insurance and pensioninsurance payments were subtracted from household income. Disposable income was then adjusted for the number of persons in the household, with the first member weighted as 1.0 unit and any other as 0.7 of a unit. This procedure corresponds to the OECD equivalence scale of weighting income in the household (OECD 1982), except for children, who are weighted as adults because of the data restrictions. Weighting children in this way did not affect our results because there are few children in the homes of Finnish older people. Income was divided into quintile groups, the cut-off points calculated from the combined data for elderly men and women (e.g., Nihtilä and Martikainen 2007; Nihtilä et al. 2008; Nihtilä and Martikainen 2008b). The cut-off points of annual household disposable income in euros were the following: 1st quintile $(0-6,942.38), 2$ nd quintile $(6,942.39-$ $8,100.00)$, 3rd quintile $(8,100.01-9,588.24)$, 4th quintile $(9,588.25-12,117.65)$, 5 th quintile (over 12,117.66). The information on disposable income originated from the Tax Administration register.

\section{Housing conditions}

Three categories of home ownership were used: owners, renters, and others or unknown, and the following of types of housing: detached house, semidetached house, apartment house with a lift, apartment house without a lift, and other. Dwellings were categorized as well equipped, poorly equipped, or very poorly equipped. A dwelling was regarded as well equipped if it had all of the following: piped water, connection to a sewer, hot water, a flush toilet, washing facilities (shower/bath/sauna), and central or fixed electric heating. It was poorly equipped if it lacked washing facilities or central or fixed electric 
heating, and very poorly-equipped if it lacked piped water, connection to a sewer, hot water, or a flush toilet.

\section{Possession of a car}

The possession of a car was an individual rather than a household characteristic. The information recorded was whether the individual possessed a car or not; this information was lacking for residents of the Åland Islands $(0.55$ percent).

\section{Region of residence}

Region of residence was categorized into 20 official regions (NUTS 3 level of the official EU area classification), with the exception of the region of Uusimaa, which was divided into three parts: 1 . Helsinki, 2. the rest of the metropolitan area including Espoo, Vantaa and Kauniainen, and 3. the rest of Uusimaa. The Åland Islands were combined with Southwest Finland. The region of residence and the level of urbanization were adjusted in the analyses to control for broad differences between the areas in the supply of and access to institutional care (Nihtilä and Martikainen 2007; Nihtilä et al. 2008; Nihtilä and Martikainen $2008 b$ ). Region of residence only was used to control for the supply in analysing the effects of bereavement (Nihtilä and Martikainen 2008a).

\section{Level of urbanization}

The home municipality was characterized as urban, semi-urban or rural. The urbanization level was based on the proportion of people living in different built-up areas and the population of the largest built-up area. The municipality was categorized as urban if at least 90 percent of the population lived in builtup areas and the largest built-up area had at least 15,000 residents, as semiurban if 60-90 percent lived in built-up areas and the largest built-up area had $4,000-15,000$ residents, and as rural if under 60 percent lived in built-up-areas and the largest built-up area had under 15,000 residents or if 60-90 percent lived in built-up areas and the largest built-up area had under 4,000 residents. A built-up area was defined as a group of houses with at least 200 residents, the distance between the houses not normally exceeding 200 meters.

\section{Living arrangements}

The living-arrangement categories were based on information on marital status, household size, family type, and status within the family. The three categories in sub-study III were: living with a spouse with or without others, living alone, or living with persons other than a spouse. These categories were chosen in order to allow for the possibility of obtaining emotional and instrumental support from a spouse or other persons within the household. 
A spouse was defined as a marriage or cohabiting partner of the opposite sex. The seven living-arrangement categories used in sub-studies I-II were: living with a spouse, living alone and being married, living alone and being widowed, living alone and being divorced, living alone and never having been married, and living with others.

\section{Bereavement}

Bereavement was measured during the follow-up from January 1998 to December 2002. A person was considered bereaved if the spouse, i.e. a marriage or cohabiting partner of the opposite sex, had died at least one day prior to his or her own date of institutionalization or death. The time since the bereavement was, for the most part, divided into seven categories: $0-1$ months (1-30 days), 1-2 months (31-60 days), 2-6 months (61-180 days), 6-12 months (181-360 days), 12-24 months (361-720 days), 24-36 months (721-1,080 days), over 36 months (over 1,081 days).

\section{Chronic medical conditions}

Eighteen dichotomous indicators of chronic medical conditions were used in order to control for health status at baseline: cancer, diabetes, dementia, psychosis, depressive symptoms, other mental-health disorders, Parkinson's disease, other neurological diseases, heart disease, stroke, chronic asthma or other similar chronic obstructive pulmonary diseases, other respiratory diseases, arthritis, osteoarthritis, hip fracture, other conditions related to accident or violence, other hospital diagnoses, and other chronic diseases. The persons studied were categorized as having a medical condition if it appeared in at least one of the following sources: 1) registers showing the principal cause of hospitalization in1996-97; 2) registers showing the right to reimbursement for drug costs under the Special Refund Categories for certain diagnosed chronic conditions in 1997; and 3) registers of prescription medication in 1996-97. The data on the principal cause of hospitalization was based on the Tenth Revision of the International classification of diseases (STAKES 1999), that on the right to reimbursement for drug costs under the Special Refund Categories was based on the Finnish disease classification of the Social Insurance Institution (Social Insurance Institution of Finland 1998), and that on purchases of prescription medication was based on the Anatomical Therapeutic Chemical Classification (National Agency for medicines 1997; National Agency for medicines 1998). The detailed definitions of the chronic medical conditions are given elsewhere (Nihtilä et al. 2008, Appendix). 


\subsection{Statistical methods}

\section{Kaplan-Meier survival estimates}

The Kaplan-Meier survival estimator (Kaplan and Meier 1958), which is a common nonparametric method for analyzing censored survival data, was used to describe the probability of not being admitted to institutional care during the follow-up. The data was presented by estimating the cumulative survival curve (Christensen 1987; Dickman 2004) that showed the probability of not being admitted to institutional care as a function of the follow-up time. The Kaplan-Meier estimate of the cumulative survival function at time $t$ is:

$\hat{S}(t)= \begin{cases}1 & \text { if } t<t_{1} \\ \prod_{t_{i} \leq t}\left(1-\frac{d_{i}}{l_{i}}\right) & \text { if } t \geq t_{1}\end{cases}$

where $d_{i}$ is the number of admissions to institutional care occurring at time $t_{p}$ and $l_{i}$ the number of persons at risk. Censoring referring mostly to deaths in this study does not affect the $S(t)$ estimate but decrease the number of persons at risk the next time admissions occur (Dickman 2004).

The Cox regression model

Cox proportional hazards regression models were used to estimate the determinants of first admission to long-term institutional care during the follow-up. Cox regression model is a widely used semi-parametric model for carrying out multivariate analyses of censored survival data (Cox 1972; Christensen 1987; Dickman 2004). Cox model is classified as semi-parametric as it carries no assumptions about the distribution of the survival times. However, it assumes that the hazards of any two subgroups are proportional over time, i.e. the ratio between the hazards is constant at any time t. The hazard at time $t$ is assumed to be:

$\lambda(t ; \mathbf{x})=\lambda_{0}(t) \exp \left(\beta_{1} x_{1}+\ldots+\beta_{k} x_{k}\right)$,

where $x_{1}, \ldots, X_{k}$ are explanatory variables, $\beta_{1}, \ldots, \beta_{k}$ regression coefficients, and $\lambda_{0}(t)$ the baseline hazard component. The Cox model provides estimates of regression coefficients but not of the baseline hazard. From the regression coefficient $\beta$ of a variable it is possible to estimate the relative risks, called hazard ratios, of admission to institutional care between the different categories of that variable, all other variables being held constant. 
All independent variables except for the death of a spouse were considered time-invariant variables measured at baseline or prior to it. The death of a spouse and time since bereavement were considered time-varying covariates and measured during the follow-up.

\section{Research strategy}

In order to enhance understanding of the relationship between income and institutional care, other variables were categorized as explanatory, mediating, and control variables (Nihtilä and Martikainen 2007). Explanatory variables were factors that might explain the inverse association between income and institutional care (living arrangements, education, social class), and that were likely to precede and influence income. Mediating variables were factors that might mediate the effect of income on institutional care because income was likely to precede them (home ownership, housing conditions, car, chronic medical conditions). The control variables (age, language, region, level of urbanization) were confounders that were of no substantive interest, and they were adjusted for before the effect of income on institutional care was analyzed. The modelling strategy was to add all the explanatory and mediating factors separately to the basic Cox model, which already included the control variables, in order to analyze in detail how this changed the relative admission risks according to income. The causal associations between income and other socio-demographic factors and medical conditions could nevertheless have been conceptualized in a somewhat different way. All the explanatory, mediating, and control variables were simultaneously added to the model at the final stage. The reduction in percentage was calculated from the hazard ratios of the basic and adjusted models according to the following formula: (HR_basic - HR_adjusted) / (HR_basic - 1)*100. However, the associations between various other socio-economic factors and the risk of admission were assessed on age-adjusted models first and then on fully adjusted multivariate models (Nihtilä and Martikainen 2007). Analyses were conducted separately for men and women because of the interactions for age-adjusted risks of admission were found between gender and most of the socio-economic determinants including education, social class, home ownership, and the possession of a car.

The analyses of the role of living with a spouse were also based on estimating nested models (Nihtilä and Martikainen 2008b). Other independent variables were added to the basic model sequentially, one after the other. The order of the variables was determined by their hypothetical order in the life-course of a typical individual: education, social class, income, home ownership, house type, housing conditions, car, and chronic medical conditions. A model was 
compared with the previous one in order to determine whether the lower risk of admission among those living with a spouse could be explained by or mediated through socio-economic factors, housing and medical conditions. The percentage reduction was calculated from the hazard ratios, as mentioned above. Analyses were performed for men and women separately because the effect of having a spouse was found to be stronger among men than women.

The modelling strategy in analyzing the effect of different chronic medical conditions on the risk of institutional care and on the competing risk of death without institutional care was mainly based on fully adjusted multivariate models (Nihtilä et al. 2008). In order to assess the risk of institutionalization, subjects were censored at the time of death or at the end of the follow-up if not previously admitted into institutional care, and in order to assess the risk of death without institutionalization subjects were censored at the time of admission or at the end of the follow-up. The hazard ratios for the different medical conditions obtained from these separate Cox models were compared in order to assess which medical conditions were more strongly associated with institutional care than with death without institutional care. Analyses were conducted separately for men and women as the unadjusted probability of receiving institutional care is known to be higher among older women than men.

The modelling strategy used in analysing the effect of the death of a spouse on the risk of institutional care was based on fully adjusted multivariate models (Nihtilä and Martikainen 2008a). The death of a spouse and the time since bereavement were used as time-varying covariates, whereas the control variables were considered time-invariant. 



\section{RESULTS}

\subsection{Characteristics of the study population}

The study population comprised of 108,474 (39\%) men and 172,248 (61\%) women aged 65 years and over at baseline (Nihtilä and Martikainen 2007; Nihtilä et al. 2008; Nihtilä and Martikainen 2008b). The distribution of the study population by gender and all socio-demographic and area characteristics are presented in the appendices (Appendices 1-3).

Men were younger than women (Figure 3), and were more likely to have had a higher education, and to have been upper white-collar workers, to be homeowners, to live in a detached house and to possess a car (Appendices 1-3). One of the most unevenly distributed characteristics was living arrangements: 72 percent of older men lived with their spouse or partner and 22 percent lived alone compared to 36 and 50 percent of women respectively. The prevalence of chronic medical conditions seemed to be somewhat more evenly distributed, although there was a higher prevalence of depressive symptoms among women (Appendices 1-3)

The proportion of people who were admitted into long-term institutional care between January 1998 and September 2003 is presented by gender and sociodemographic and health-related characteristics in the appendices (Appendices 1-3). Women were more likely than men to be admitted to institutional care: 15 percent of women and 10 percent of men were admitted during the follow-up. By age group, four percent of the 65-69-year-olds were taken into institutional care, eight percent of the 70-74-year-olds, 16 percent of the 75-79-year-olds, 27 percent of the 80-85-year-olds, 37 percent of the 86-89-year-olds and 45 percent of the over-90-year-olds. The mean and median age at admission was 80 years among men, 83 among women, and 82 for both genders together. Figure 4 shows the age distribution at the time of admission by gender.

The study population in the analyses of institutional care after the death of a spouse comprised 140,902 persons who were living in private households with a spouse, including a married spouse (96.4\%) and a non-married partner (3.6\%), at baseline in 1997 (Nihtilä and Martikainen 2008a). Seven percent of men and 21 percent of women lost their spouse due to death during the follow-up from January 1998 to December 2002. 
Figure 3. The number of people in the study population by gender and age at baseline

Men

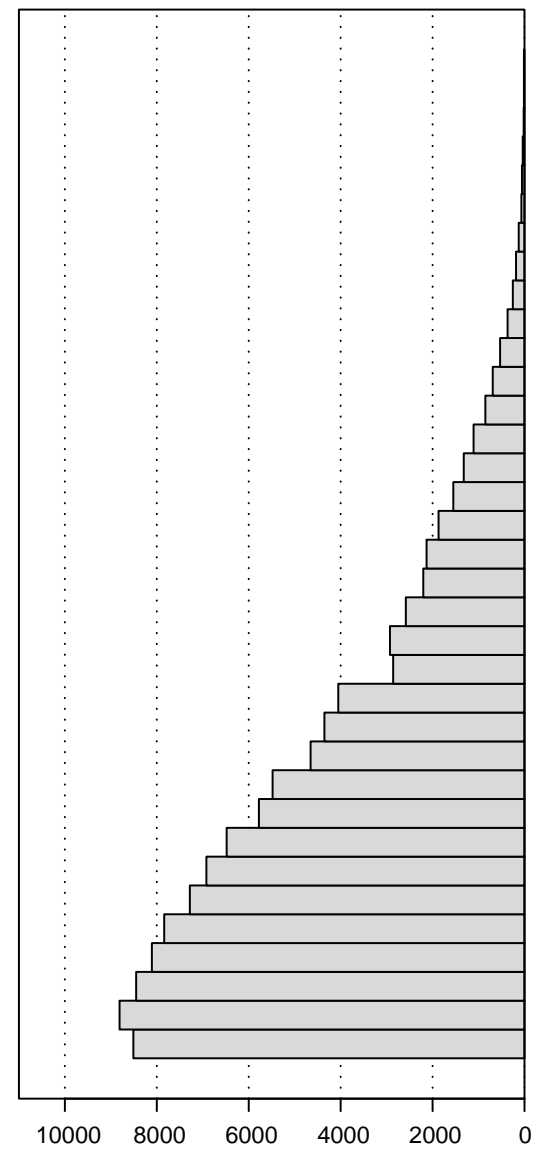

Number of study population
Women

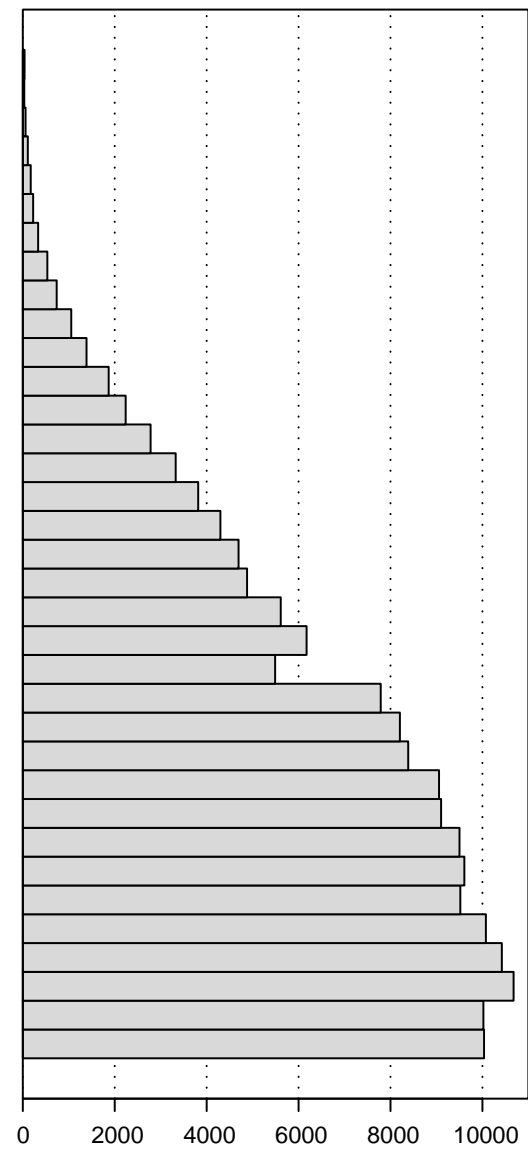

Number of study population 
Figure 4. The number of people admitted into institutional care in the study population by gender and age at admission

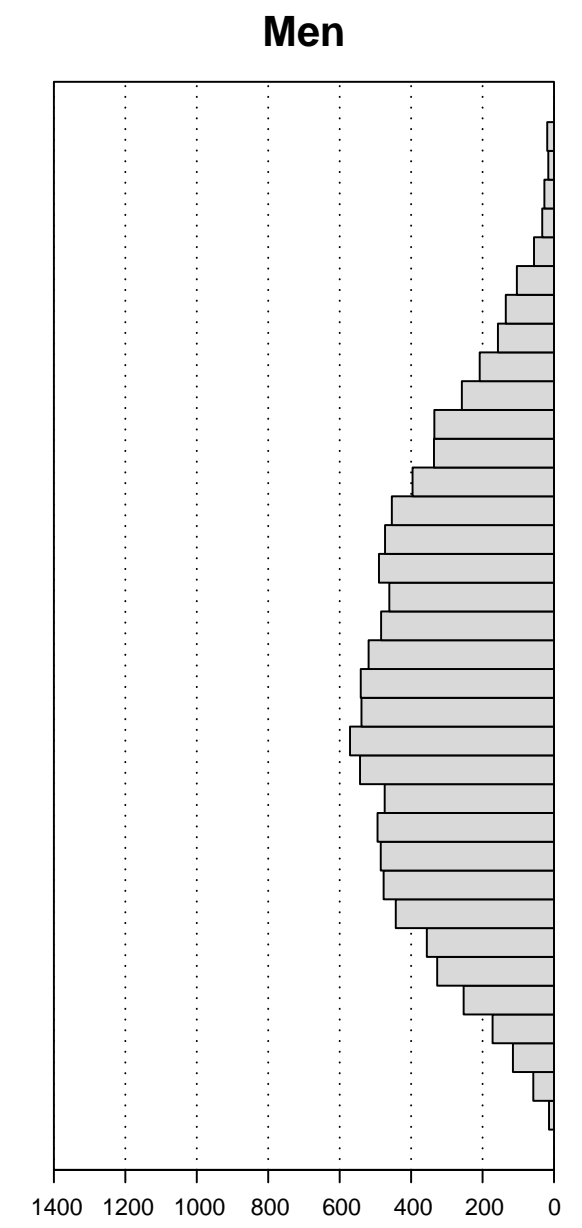

Number of study population entering institution

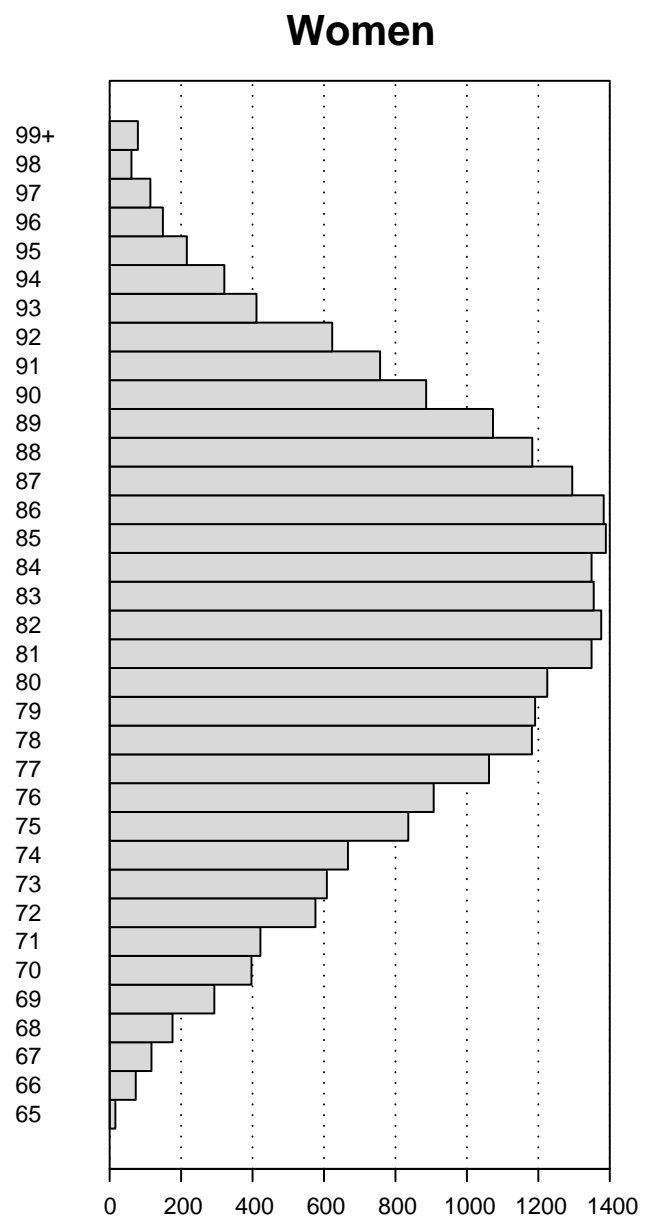

Number of study population entering institution

\subsection{Age and gender and institutional care}

The probability of not being taken into institutional care was 0.89 in men and 0.84 in women at the end of the follow-up period. It decreased dramatically with age, and the age pattern was relatively similar for men and women (Figure 5). The probability of not being admitted was almost the same for both genders in the two youngest age groups of 65-69 and 70-74 years, whereas the unadjusted gender differences were more explicit in the older age groups, in that the probability of not being admitted was clearly higher among men than women. 
Overall, the results obtained from the unadjusted Cox models, showed that older women aged 65 and over at baseline were 40 percent more likely than older men to be taken into long-term institutional care during the follow-up (Martikainen et al. 2009). The relative gender differences disappeared when age and living arrangements were controlled for, however. Furthermore, there was a five-percent higher relative risk of admission into institutional care among men than women when all other socio-demographic and health characteristics were controlled for. 
Figure 5. Probability of not being admitted into institutional care by gender and age between January 1998 and September 2003, people aged 65 and over at baseline in December 1997, Finland

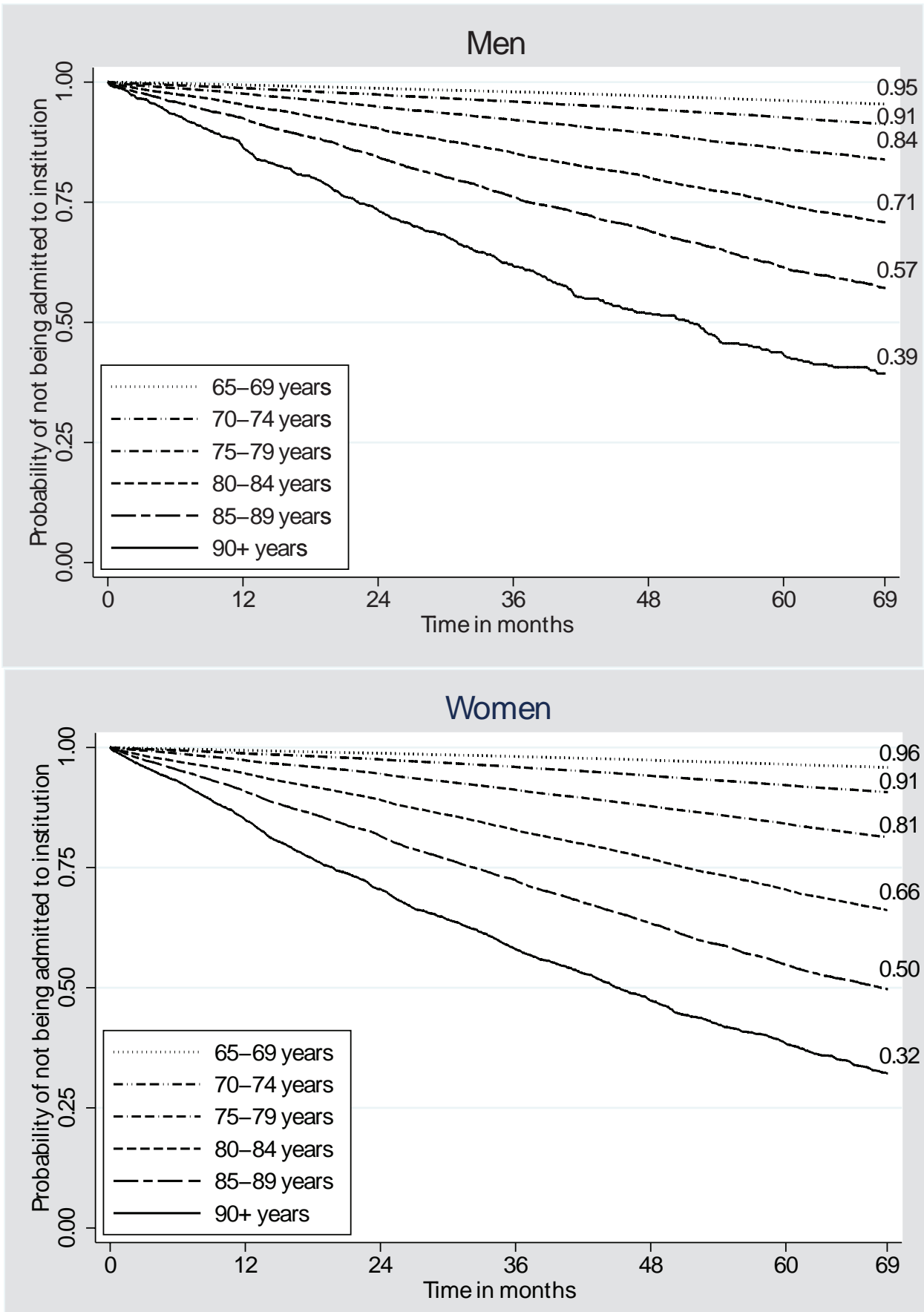




\subsection{Chronic medical conditions and institutional care}

Parkinson's disease was, after dementia, the strongest predictor of admission into institutional care, followed by stroke, mental-health problems, hip fracture, and diabetes in both genders (Nihtilä et al. 2008). These conditions raised the risk by 50 percent or more for both men and women (Figure 6). Furthermore, other conditions related to accidents or violence, arthritis, other neurological diseases, cancer, respiratory diseases other than asthma, other hospital diagnoses, heart disease, and other chronic diseases raised the risk of institutional care. Chronic asthma was associated with institutional care only among men. Osteoarthritis was not associated with institutionalization.

Dementia, Parkinson's disease, psychosis, depressive symptoms, other mentalhealth disorders, and stroke were more strongly associated with the relative risk of institutionalization than with the relative risk of death without institutionalization when socio-demographic confounders and co-morbid conditions where controlled for.

Figure 6. Relative adjusted institutionalization rates and mortality rates without institutionalization by chronic medical conditions, men and women aged 65 and over

Men

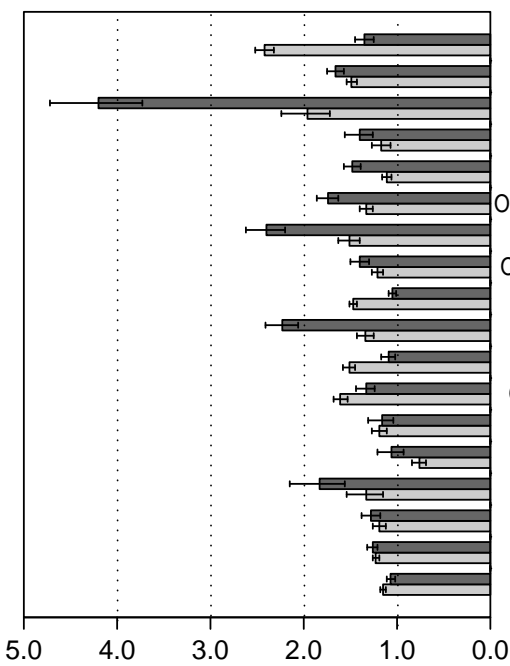

Hazard ratio, reference (1.00) not this disease
Women

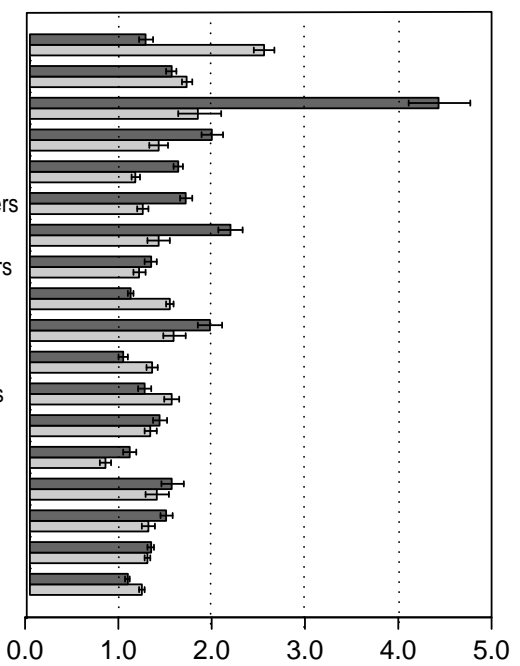

Hazard ratio, reference (1.00) not this disease

Institutionalization

Mortality without institutionalization

Source: Nihtilä et al. (2008), Figure 1 


\section{4 Socio-economic factors and institutional care}

Various socio-economic measures were mostly inversely associated with institutional care, following adjustment for age alone (Nihtilä and Martikainen 2007). The higher was the level of education, the lower was the risk of admission into institutional care. Furthermore, upper white-collar workers, home-owners, and people who possessed a car had a lower risk of admission (Table 1). The associations with these socio-economic measures were significantly stronger among men than among women ( $\mathrm{p}$-value<0.05). Male renters were 90 percent more likely, and female renters 40 percent more likely than owner-occupiers to be admitted to institutional care independently of age. In addition, those living in a detached house were less likely to be admitted than those living in other types of housing. Having a lift in the apartment house was not associated with institutional care.

The socio-economic differences in institutional care were mostly reduced among both genders following simultaneous adjustment for all other variables. The association between institutional care and poor housing conditions became apparent when other factors were controlled for. Among both men and women, living in poorly equipped housing and being a renter were associated with an increased risk of admission, whereas the possession of a car and living in a detached house were associated with a decreased risk, independently of other factors. Education was associated with admission among men only. A higher occupation-based social class was no longer associated with a lower risk of institutional care, once other factors were controlled for. However, among older men, farmers were somewhat less likely than the self-employed to be admitted during the follow-up. 


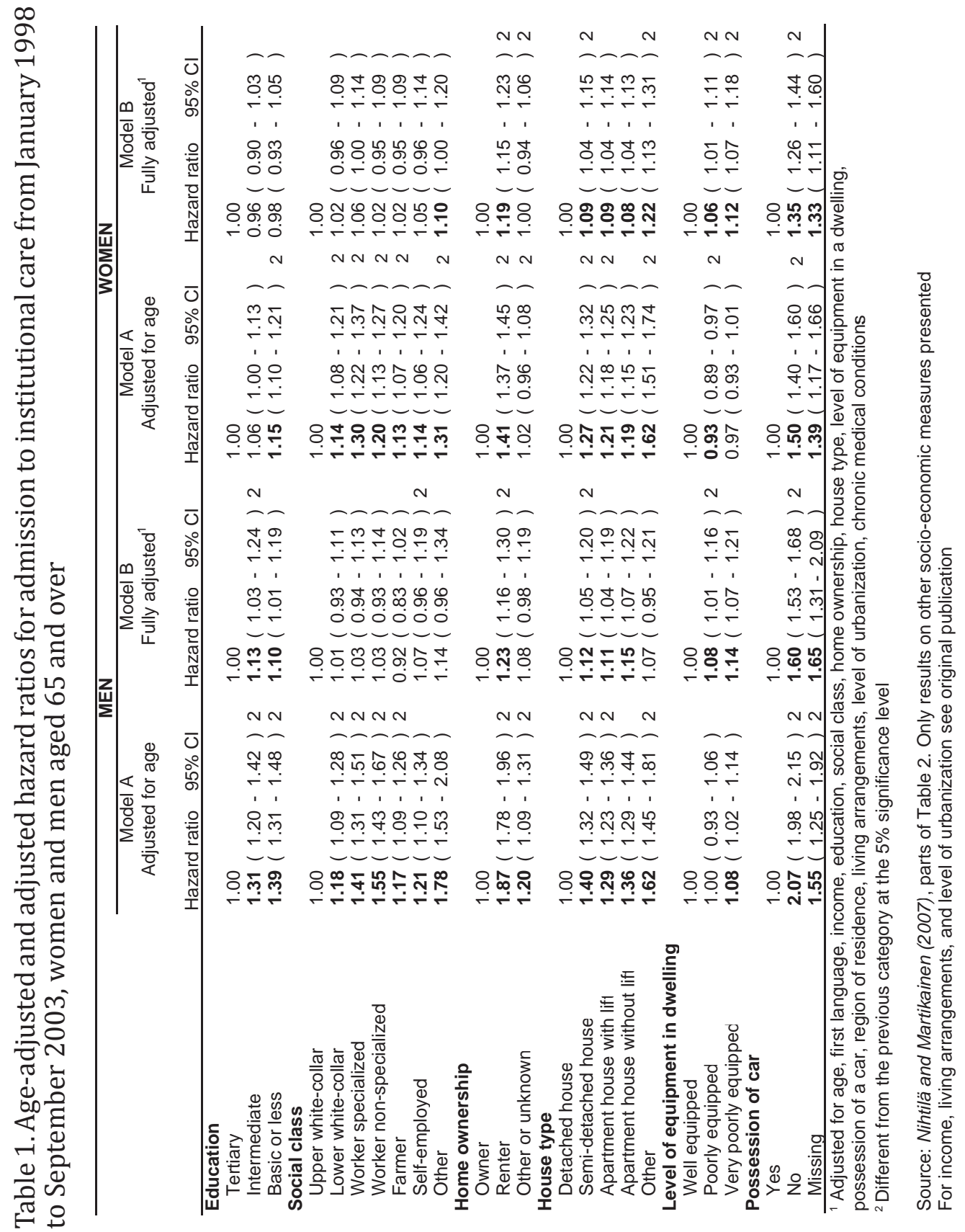




\subsection{Income and institutional care}

The findings showed that household income was inversely associated with institutional care (Nihtilä and Martikainen 2007). Men in the lowest income quintile group were 59 percent more likely, and women in the lowest quintile group 35 percent more likely to be admitted into long-term institutional care than those in the highest income group after age, first language, region of residence and level of urbanization were controlled for (Figure 7). Controlling further for other socio-demographic characteristics and medical conditions reduced these differences by 78 and 59 percent, respectively.

Figure 7. Hazard ratios (and $95 \%$ confidence intervals) for admission to institutional care by level of household income obtained from two different Cox models, men and women aged 65 and over, Finland, January 1998-September 2003
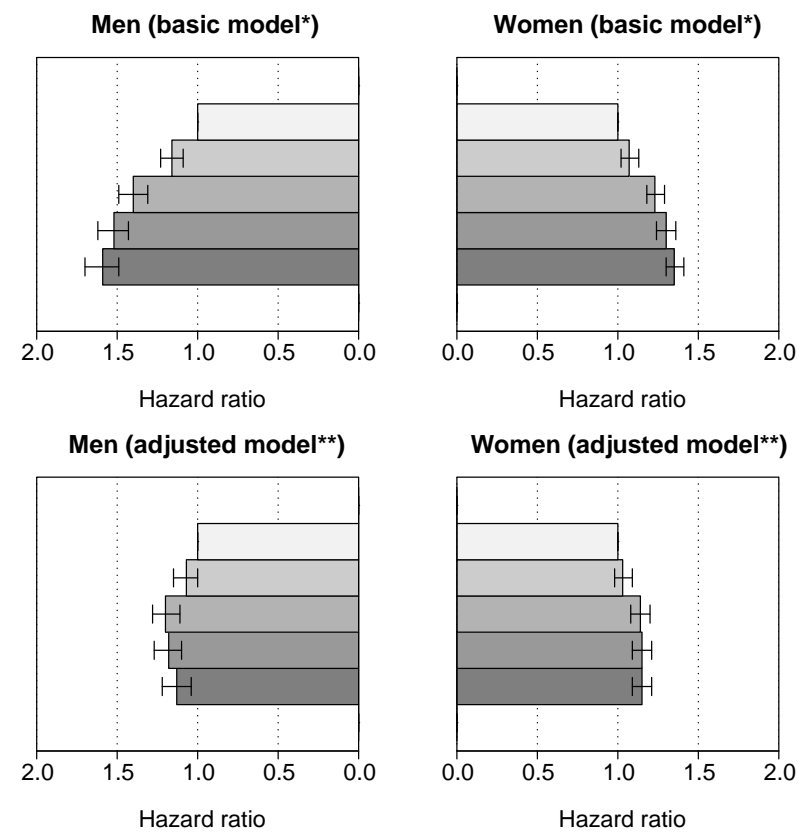

Household income
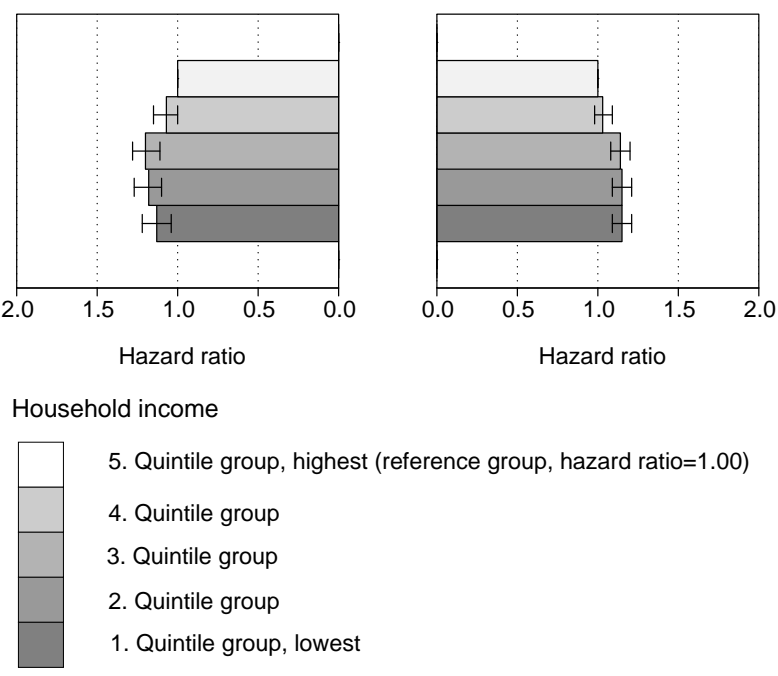
5. Quintile group, highest (reference group, hazard ratio=1.00)
4. Quintile group
3. Quintile group
2. Quintile group
1. Quintile group, lowest

* Basic model includes age, first language, region of residence, level of urbanization

** Adjusted model includes age, first language, region of residence, level of urbanization, living arrangements, education, social class, home ownership, house type, house equipment level, possession of a car, chronic medical conditions Source: Nihtilä and Martikainen (2007), part of Table 3 
These results imply that income differences were partly attributable to the fact that those with a low income were less likely to live with a spouse and more likely to have a lower education and socio-economic position, and mediated through not owning a home, having poor housing conditions, not having a car, and having certain chronic medical conditions (see Nihtilä and Martikainen 2007, Table 3). The most important medical conditions that mediated the effect of income on institutional care were psychoses and other mental-health problems for men and psychoses and diabetes for women. However, a high household income was still associated with a lower risk of institutional care: older people within the three lowest quintile groups were between 13 and 20 percent more likely to be admitted to institutional care than those in the highest quintile group, once other socio-demographic and health conditions were controlled for (Figure 8).

\section{6 Spouse and institutional care}

Living with a spouse was associated with a reduced risk of institutional care in both genders (Nihtilä and Martikainen 2008b). Among men, those living alone had a 70 percent higher and those living with other persons a 56 percent higher risk of entering institutional care than those living with a spouse, independently of age, region of residence and urbanicity. The corresponding figures for women were 29 and 21 percent (Figure 8, model 1).

About 35 percent of the lower risk among men living with a spouse compared to those living alone was explained or mediated by different socio-economic factors, housing conditions, and chronic medical conditions including depressive symptoms (Figure 8, model 8 vs. 1). The corresponding figure for women was 43 percent. Among women, almost the same factors explained the lower risk of institutional care for those living with a spouse compared to those living alone, with the exception that women with a spouse were not clearly advantaged in terms of education or having less chronic medical conditions.

Overall, the differences in institutional care between those living with a spouse and those living with other persons did not clearly attenuate after adjustment for all other factors simultaneously (model 8 vs. 1). This is related to the fact that the differences were exacerbated after adjustment for household income and house type (model 4 vs. 3, and model 6 vs. 5). However, in both genders, the differences were attenuated following adjustment for education, social class, home ownership, and chronic medical conditions. The main medical conditions in terms of explaining the differences were psychosis and other mental-health problems, excluding depressive symptoms, and conditions related to accidents or violence among men, and psychoses among women. 
When all other factors were controlled for, men living alone still had a 45 percent and men living with other persons a 51 percent higher risk of admission than men living with a spouse. The corresponding figures for women were 17 and 21 percent. The protective effect of having a spouse was thus significantly stronger among men than among women ( $\mathrm{p}$-value $<0.001$ ).

Figure 8. Hazard ratios (and $95 \%$ confidence intervals) for admission to institutional care by living arrangements obtained from different Cox models, men and women aged 65 and over, Finland, January 1998-September 2003
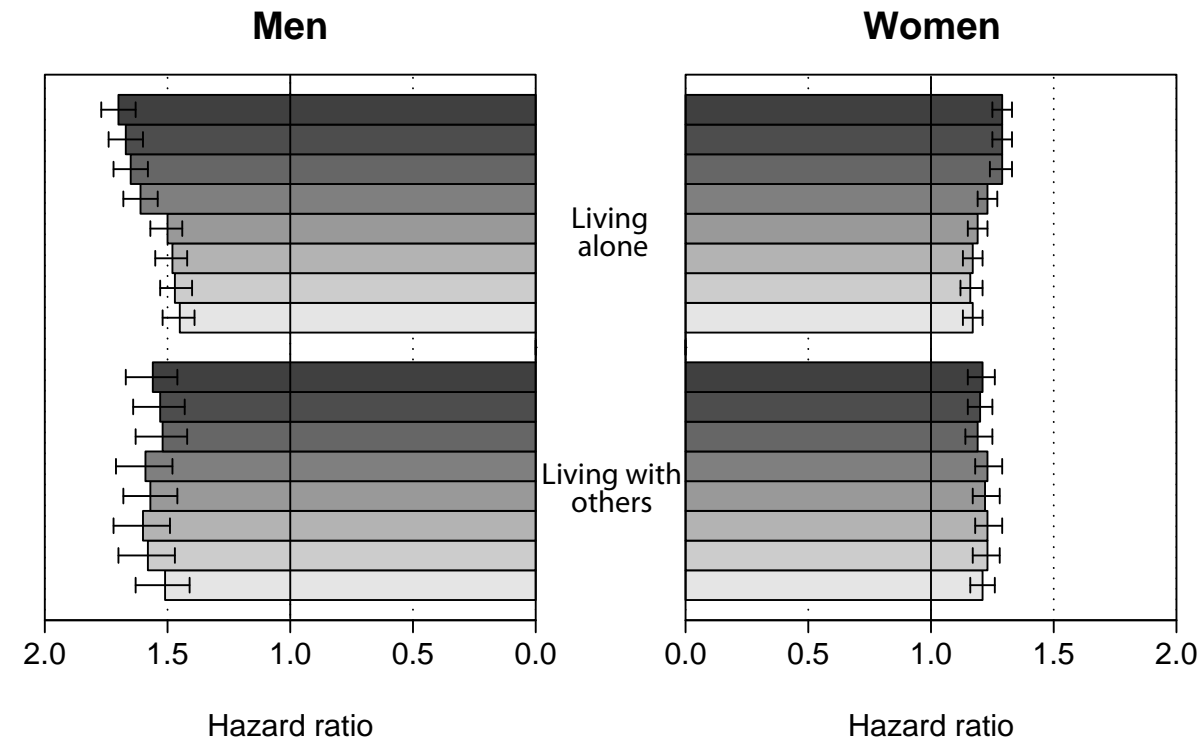

Living with a spouse as reference group (hazard ratio $=1.00$ )

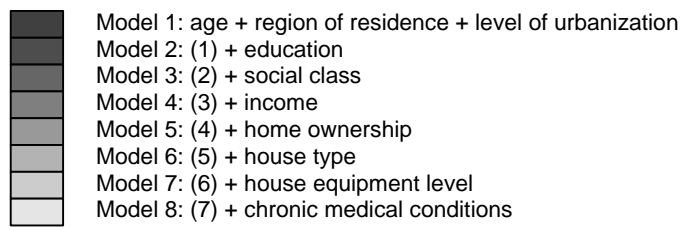

Source: Nihtilä and Martikainen (2008b), Table II 


\subsection{Institutional care after the death of a spouse}

The death of a spouse increased the risk of institutional care among both genders. Men bereaved during the five-year follow-up were 71 percent more likely to enter institutional care than those still living with a spouse, independently of age, region of residence, education, household income, and chronic medical conditions (Nihtilä and Martikainen 2008a). The corresponding figure for women was 49 percent. The excess risk of moving to an institution was highest during the first month following the spouse's death: 231 percent among men and 262 percent among women (Figure 9). This excess risk decreased over time, dropping to around 40-50 percent among men and 20-30 percent among women one year after bereavement. The relative effect of the duration of bereavement on moving to an institution did not significantly vary according to the level of education or income. 
Figure 9. Adjusted hazard ratios and 95\% confidence intervals of institutionalization in relation to duration of bereavement (not bereaved: hazard ratio=1) among men and women 65 years and older living with a spouse at the beginning of the follow-up study: Finland, 1998-2002.

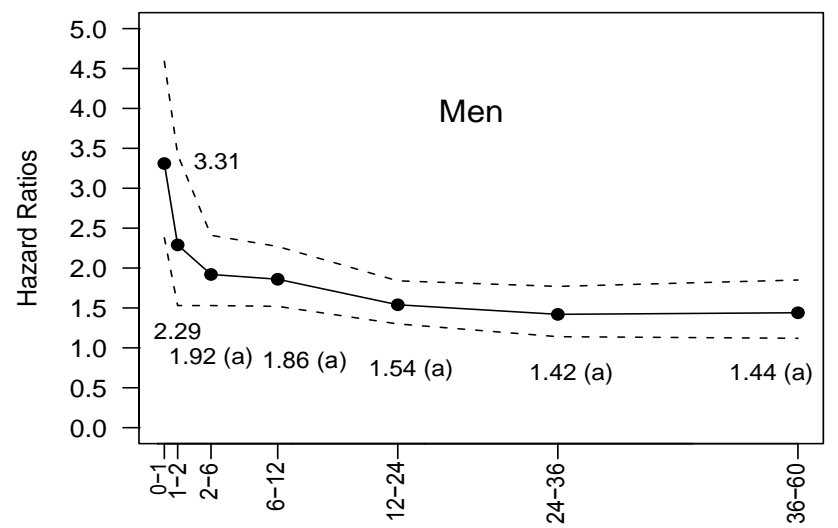

Time Since Spouse's Death, Months

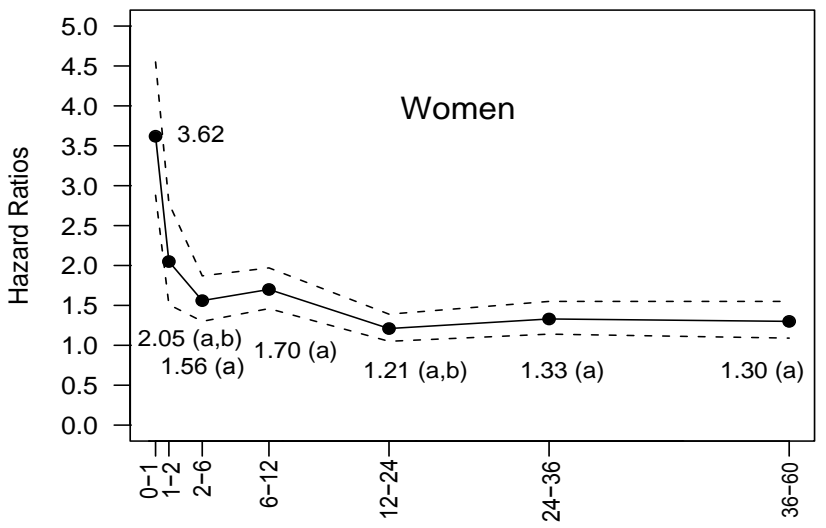

Time Since Spouse's Death, Months

Note: Models included age, region of residence, education, household income, and chronic medical conditions. Difference from duration category of 0 to 1 months at the $5 \%$ significance level (a); difference from previous duration category at the $5 \%$ significance level (b)

Source: Nihtilä and Martikainen 2008a, Figure 1 



\section{DISCUSSION}

\subsection{Discussion of the main determinants}

\subsubsection{Chronic medical conditions}

The results of the study indicated that dementia, Parkinson's disease, stroke, depressive symptoms, other mental-health problems, hip fracture, and diabetes raised the risk of long-term institutional care by 50 percent or more among both genders, independently of socio-demographic confounders and comorbid conditions (Nihtilä et al. 2008). Because of the large number of study subjects followed for admission to institutional care, many other chronic conditions were also significant predictors of admission, although these effects were less than 50 percent.

This population-based longitudinal study strengthens the evidence of the association between Parkinson's disease and living in an institution that has been previously reported in cross-sectional studies (Woo et al. 1994; Rockwood et al. 1996; Berger et al. 2000). Furthermore, the finding that stroke increased the risk of admission is somewhat similar to the results of some earlier studies from the United States (Banaszak-Holl et al. 2004; Gaugler et al. 2007), but differs from those of a Canadian study suggesting that stroke increases the risk only among men, after socio-demographic and other health characteristics, including functional disabilities are controlled for (Tomiak et al. 2000). However, Tomiak et al. (2000) analyzed nursing-home admissions after controlling for functional disability, and this could have underestimated the effect of stroke or cerebrovascular accident, which is likely to cause functional disability. However, the results of our study confirm those of earlier longitudinal studies showing that dementia markedly increases the risk of admission to institutional care (Jagger et al. 2000; Tomiak et al. 2000; Aguero-Torres et al. 2001; Banaszak-Holl et al. 2004).

The finding that diabetes increased the risk of admission corresponds with the results of some earlier studies (Banaszak-Holl et al. 2004; Gaugler et al. 2007), but seems to differ from those of others (Tomiak et al. 2000) indicating that diabetes had no effect when socio-demographic confounders and other health characteristics, including functional disabilities were controlled for. However, these results are not fully comparable in that most studies control for the presence of functional disabilities at baseline that might be caused by diabetes. However, our results confirm the few earlier findings suggesting that 
mental health problems are associated with institutional care at older ages, independently of socio-demographic confounders and other health problems (Tomiak et al. 2000; Banaszak-Holl et al. 2004). However, the finding that depressive symptoms increased the risk of institutional care in both genders partly differs from the results of a previous regional study from Tampere, Finland indicating significant effects in only among elderly men, independently of some socio-demographic factors and other health characteristics (Nuotio et al. 2003).

Earlier evidence on the effect of hip fracture is inconsistent: some studies indicate that it increases the risk of institutional care (Aguero-Torres et al. 2001) and others indicate no significant effects (Tomiak et al. 2000). Aguero-Torres et al. (2001) found in their study of Swedes over 75 years of age living in an urban district of Stockholm that those with a history of hip fracture were over twice as likely to move to an institution during the three-year follow up than those with no hip fracture after socio-demographic factors and health characteristics were controlled for. Our sub-study (Nihtilä et al. 2008) supports this Swedish result that hip fracture markedly increases the risk of institutional care. Somewhat similarly, American meta-analyses have indicated that falling predicts institutional admission, albeit weakly (Gaugler et al. 2007). However, it is likely that hip fractures and stroke, which may cause major functional disabilities at older ages, are stronger determinants of admission to institutional care than the previous literature (Tomiak et al. 2000; Aguero-Torres et al. 2001; Gaugler et al. 2007), and even the Finnish results suggest (Nihtilä et al. 2008). First, as mentioned earlier, routine adjustment for functional disability in the previous studies is likely to have underestimated the effects of diseases and accidents that cause functional disability (Figure 1). This was not a problem in our sub-study, however, because functional disabilities could not be directly measured in the register-based data. Secondly, the history of stroke and hip fracture was mostly measured among older people living in the community at baseline and the baseline sample is likely to have excluded people with the most severe forms of stroke or hip fracture that caused immediate hospitalisation leading to longer periods in institutions. The effects may thus be underestimated.

The results of the study also indicated that mental-health problems (psychosis, depressive symptoms, and other mental health problems) and certain specific neurological disorders (dementia, Parkinson's disease, and stroke) were more strongly associated with the relative risk of institutional care than with the relative risk of death without institutional care, independently of 
socio-demographic confounders and comorbid conditions (Nihtilä et al. 2008). The fact that these conditions affected institutionalization more strongly than mortality without institutionalization could be related to several things. Mental-health problems and neurological disorders tend to have a long-termdisability impact on older individuals and these medical conditions, especially dementia (Dunkin and Anderson-Hanley 1998) and stroke (Draper et al. 1992), are thus known to be highly burdensome to the informal caregiver. This could strengthen older individuals' and their caregivers' resolve to find an alternative to home care. Furthermore, older people with severe memory problems may be given priority admission into institutional care by health-care professionals, judging their actions or speech to be irrational and their capability of performing daily routines to be weak, even though such conditions may not necessarily be life-threatening.

\subsubsection{Household income}

This study showed that household income was inversely associated with the risk of admission to long-term institutional. Men in the bottom income quintile group were 59 percent more likely, and women in the bottom group 35 percent more likely to be admitted into institutional care than those in the top quintile group, independently of age, first language, region of residence and level of urbanization. The income differences were partly explained by the fact that those with a low income were less likely to live with a spouse, and more likely to have had a lower education or to be in a lower occupation-based social class, and were mediated by not owning a home, having poor housing conditions, not having a car, and having certain chronic medical conditions such as psychoses and other mental-health problems among men, and psychoses and diabetes among women. The effect of income remained significant for both genders, however, other things being equal. The independent association of income with admission corresponds with the results of some earlier population-based studies (Mustard et al. 1999; Lakdawalla and Schoeni 2003; Giles et al. 2007), but differs from those of others (Speare et al. 1991; Steinbach 1992; Salive et al. 1993; Tomiak et al. 2000).

Although previous studies have produced inconsistent results on its independent effect (Speare et al. 1991; Foley et al. 1992; Steinbach 1992; Salive et al. 1993; Mustard et al. 1999; Tomiak et al. 2000; Lakdawalla and Schoeni 2003; Giles et al. 2007), low income is indicated to be associated with institutional care in research reporting crude or age-adjusted associations (Steinbach 1992; Mustard et al. 1999). Steinbach (1992) argued in his study of people over 70 
years of age living in the United States in the 1980s that annual family income below 5,000 American dollars was predictive of institutional care in singlevariable models but not in multivariate models, once socio-demographic and health conditions were controlled for. The figures obtained from the singlevariable logistic regression models were not shown, however, and the magnitude of these associations thus remains unknown. Somewhat similarly, in a study of people over 65 years of age living in three different communities, Foley et al. (1992) found that in general nursing-home occupation was highest among people with an annual income of below 5,000 American dollars and those whose income was not known. However, the effect of low self-reported income persisted only in Iowa and Washington County but not in East Boston, Massachusetts, or in New Haven, Connecticut, once other socio-demographic and health conditions were accounted for. By way of contrast, having conducted a national study of people over 65 years of age covered by Medicare insurance in the 1990s, Lakdawalla and Schoeni (2003) suggested that low income increased the risk of nursing-home admission in the United States, other things equal.

Similarly, it was found in an Australian study covering a nine-year period that people over 75 years of age with an annual household income of below 12,000 Australian dollars were twice as likely as those with a higher income to be in a nursing home care, independently of other factors (Giles et al. 2007). Our Finnish study produced somewhat smaller independent effects of household income: over a period of almost six years people aged 65 and over in the three lowest income quintile groups were between 13 and 20 percent more likely to be taken into institutional care than those in the highest group (Nihtilä and Martikainen 2007). However, these results are not fully comparable due to methodological differences (e.g., logistic vs. proportional-hazards regression). In a more comparative study design of people over 75 years of age living in the market town and surrounding area of Melton Mowbray in Leicestershire, England, Hancock and colleagues (2002) suggested that income had no independent effect on admission to care homes.

To conclude, the independent effects of income have been found to be significant in Australia (Giles et al. 2007), inconsistent in the United States (Speare et al. 1991; Foley et al. 1992; Steinbach 1992; Salive et al. 1993; Lakdawalla and Schoeni 2003) and Manitoba, Canada (Mustard et al. 1999; Tomiak et al. 2000), and insignificant in Leicestershire, England (Hancock et al. 2002). The variation could be attributable to various factors, including numerous methodological differences in the studies. First, the data used in most of them were 
collected largely via interviews, either directly with the older respondent or with a proxy, and income information is thus missing for a large number of participants. The American regional study conducted by Foley et al. (1992) lacked income information on between 12 and 23 percent of the participants due to respondent refusal, proxy interviewing or otherwise unknown income. Similarly, 14 percent of the participants in the British regional study conducted by Hancock et al. (2002) did not report their income, the non-response being associated with cognitive impairment and home-ownership. This could explain why the independent effect of income on care-home entry was not significant. Secondly, the variation in the studies could be related to the definition of institutional care. Most of those conducted in North America analyze nursing-home admission but do not normally distinguish between long- and short-term care. It may be that a low income is a stronger determinant of long-term than of short-term nursing-home care because the latter may be more likely to include rehabilitation after hospitalization, which may not be strongly related to lower income. Thirdly, the definition of the control variables, especially health characteristics, used in the multivariate models limit comparisons across studies. It may be that those studies using good measures of various health aspects, including both chronic medical conditions and functional limitations, tend to show no independent effects of income (Tomiak et al. 2000). Income could, however, have an effect on institutional care through chronic conditions and functional status, but this does not show in the multivariate models.

Aside from the effects on health and functioning, a higher income could make it easier for people to buy community-based services, and thus to delay or prevent the need for institutional care. The unexplained or so-called independent effects of income observed in many studies (Mustard et al. 1999; Lakdawalla and Schoeni 2003; Giles et al. 2007) could be partly related to this purchasing potential. The relationship between income and admission into institutional care could also be related to different national practices in providing institutional care and other services for older people according to their socio-economic or family status. It has been suggested that nursing-home admission in the United States could be influenced by eligibility for Medicaid, which covers health-care costs for low-income people (Grundy 1992; Himes et al. 2000). Older people needing care in institutions are usually expected to pay it unless or until their income is low enough to qualify for payment through Medicaid. Only short-term nursing-home care for older people with acute conditions is paid for through Medicare programme for older people (OECD 2005). However, Mustard et al. (1999) found that a low income increased the risk of nursing-home entry in the Canadian province of Manitoba, where 
the older population is universally insured and there are no income-related barriers to nursing-home care. Somewhat similarly, Finland offers universal coverage of long-term institutional care, which is mostly funded from general taxation, and user chargers constitute only a minority of the net expenditure, about 20 percent in nursing homes for older people (Official Statistics of Finland 2007). At the time of this study, long-term institutional care was provided mostly in nursing homes and health centers, and user charges were related to personal disposable income, up to a maximum of 80 percent (Ministry of Social Affairs and Health 2003). Clients were allowed to keep a minimum of 20 percent of their personal income, and a certain fixed amount for personal use if it was very low. High-income older people and their families could thus have an economic incentive to avoid long-term institutional care if the absolute level of charges was very high, and thus may prefer buying home-help services or receiving less intensive care in service homes without 24-hour care. This could partly explain the lower risk of admission among high-income older people in Finland.

\subsubsection{Other socio-economic factors}

This study provided evidence of an association between various measures of higher socio-economic status and a lower risk of admission into institutional care at older ages (Nihtilä and Martikainen 2007). The findings indicated that the level of education, occupation-based social class, home ownership, house type and the possession of a car were significantly associated with the risk of institutional care, independently of age. These socio-economic differences were mostly reduced when other socio-demographic and chronic medical conditions were controlled for. However, being a renter and living in poorly equipped housing increased the risk of admission, whereas the possession of a car and living in a detached house decreased it, independently of socio-demographic and medical conditions. A higher education was independently associated with a lower risk of admission only among men. A lower occupation-based social class was no longer associated with a higher risk, once other factors were controlled for. Having a lift in the apartment house was not associated with institutional care in any of the models.

The association of being a renter with a higher risk of institutional care corresponds with the results of most earlier national studies from England and Wales (Grundy 1992; Grundy and Glaser 1997; Breeze et al. 1999) and the United States (Coward et al. 1996), but differs from those of a recent Australian study showing that home ownership had no independent effect (Giles et al. 
2007). Furthermore, a regional study of people over 75 years of age living in Melton Mowbray, England, reported that renters were over 30 percent more likely than home owners to be taken into care homes, independently of demographic, socio-economic and health characteristics (derived from (Hancock et al. 2002)). Similarly, according to our study of Finns over 65 years of age, being a renter increased the risk of admission by 23 and 19 percent among men and women respectively (Nihtilä and Martikainen 2007). In these cases (Hancock et al. 2002; Nihtilä and Martikainen 2007) home ownership could be considered a measure of property and wealth that is not entirely accounted for by other socio-economic measures such as income. Home ownership could also facilitate return back to the community after short-term institutional care and thus prevent the care episode from becoming long-term. Other studies from Finland (Martikainen et al. 2009) and the United States (Greene et al. 1995) suggest that home ownership is associated with returning back to the community from institutional care. Although Hancock et al. (2002) argued that home ownership may reduce the risk of institutional care in England because home owners are reluctant to sell their homes and use the proceeds to pay for their care, this is unlikely to be the underlying explanation in Finland, where user charges for long-term institutional care are related to disposable income, and the sale of property is not required in order to pay the user charges.

One of the strongest socio-economic determinants in this study seemed to be the possession of a car: older men without a car had a 60 percent higher risk of admission into institutional care compared to those with a car, when other socio-demographic and chronic medical conditions were accounted for (Nihtilä and Martikainen 2007). The corresponding figure for women was 35 percent. These results are somewhat similar to earlier findings from England and Wales showing an association between having a car in the household and a reduced risk of institutional care (Breeze et al. 1999). Having a car gives access to a geographically wider social network (Arber and Ginn 1991) and eases weekly routines such as shopping, and may thus help older people to maintain their independence. Benefits of a car require, however, the means to maintain it. In the Finnish study, however, the possession of a car was an individual rather than a household characteristic. Besides measuring mobility and socio-economic position, having a car is thus likely to measure indirectly an individual's health. People with functional disabilities or poor eyesight are likely to give up driving, and even their car if their driving licence is revoked on health grounds. Furthermore, having a car seemed to predict admission among men as well as some chronic diseases, such as diabetes (Nihtilä et al. 2008). 
This study showed that very poor housing conditions such as the lack of piped water, sewer, hot water or a flush toilet were significant determinants of admission to institutional care, after socio-demographic and chronic medical conditions were controlled. This is somewhat similar to the finding of Townsend's cross-sectional study indicating that a lack of piped water had been more common among new institutional residents who used to living alone than among the general older British population who were living alone (Townsend 1962). However, the Finnish results differ from those of a previous longitudinal study indicating that the lack of a flush toilet or central heating was not a significant predictor among older people in former West Germany (Klein 1996). The Finnish study, however, suggested that living in a very poorly-equipped dwelling raised the risk of institutional care by 12-14 percent, and living in a poorly equipped dwelling, lacking washing facilities or central or fixed electric heating, by 6-8 percent (Nihtilä and Martikainen 2007). These results indicate that good housing resources are important in reducing the need for institutional care among older Finns. Furthermore, living in a detached house was found to be associated with a lower risk of admission, independently of other sociodemographic characteristics and medical conditions. Living in a detached house could be an indicator of many different things in Finland, however: 1) good socio-economic position, especially in urban areas; 2) living in a prosperous area in which detached houses are the norm; and 3) even an indirect indicator of being physically active enough to be able to maintain a detached house with all the gardening, snow work and other maintenance jobs involved. These indirect and unmeasured socio-economic, area and health characteristics could explain the association between living in a detached house and a low institutionalization rate to some extent. Thus the detached house may not be such an important resource in itself in protecting older people from moving to institutions.

This study showed no evidence of an association between having a lift in the apartment house and a reduced risk of institutional care. This was unexpected, and could be related to the choices of apartment houses made according to unmeasured functional disabilities. Older people with disabilities might choose to live in building with a lift, or on the ground floor if no lift is available. However, without data on changes in residential moves and functional status this hypothesis cannot be verified. In the absence of similar population-based longitudinal studies on the effect of a lift it was not possible to compare this finding with those of previous studies.

In this study, a high level of education was associated with a decreased risk of admission into institutional care only among men, after socio-demographic 
and chronic medical conditions were controlled for (Nihtilä and Martikainen 2007). This runs contrary to the results of a Canadian study suggesting an association between a high education and a decreased risk of admission only among women, independently of socio-demographic and health-related factors (Tomiak et al. 2000). However, according to another Canadian study a high education was independently associated with a decreased risk of nursinghome admission, but separate results for men and women were not available (Mustard et al. 1999). Furthermore, some earlier studies from the United States indicated no effect of education on nursing-home admission when socio-demographic and health-related factors were controlled for (Cohen et al. 1986; Wolinsky et al. 1992).

\subsubsection{Having and losing a spouse}

This study showed that older people living with a spouse were less likely to be admitted into institutional care than those living alone or with persons other than a spouse, independently of age, region of residence and level of urbanization (Nihtilä and Martikainen 2008b). The lower risk of admission among men living with a spouse compared to those living alone was partly attributable to a higher education, occupation-based social class, household income, home ownership, house type, better housing conditions, and a lower likelihood of having depressive symptoms. Almost the same factors explained the lower risk among women living with a spouse, with the exception that they were not clearly advantaged in terms of education or having less chronic conditions than those living alone. Women living alone still had 17 percent higher and women living with persons other than a spouse 21 percent higher risk of admission than those living with a spouse, after other factors were accounted for. The corresponding figures for men were as high as 45 and 51 percent.

Different mechanisms are thought to explain the lower risk of admission among those living with a spouse. Having a spouse may have beneficial effects on mental and psychical health (Ross 1995), and may reinforce positive health behaviors (Joung et al. 1995), thus indirectly affecting the need for institutional care. The former assumption corresponds with the results of this study: Finnish men living with their spouse were less likely to have depressive symptoms than men living alone, and this in part reduced their risk of admission. In addition, those living with a spouse may have better financial and housing conditions, which could facilitate living in the community. Correspondingly, in this study, a higher income and favorable housing conditions partly explained the lower risk of admission among men and women living with a spouse compared with those living alone. 
However, controlling for socio-economic, housing and medical conditions explained and mediated only 35-43 percent of the higher risk of admission among those living alone compared to those living with a spouse, and much less among those living with persons other than a spouse. Having a spouse seemed to have a major independent role in preventing and delaying admission that could not be entirely reduced to other socio-demographic and health-related factors. This finding corresponds with the results of earlier studies showing that living alone or without a spouse is a major risk factor for moving to an institution at older ages (Branch and Jette 1982; Steinbach 1992; Wolinsky et al. 1992; Grundy and Jitlal 2007). These unexplained, protective effects of a spouse are likely to be related to receiving help with domestic and personal self-care tasks that decrease the need for institutional care. This is line with the results of earlier studies showing that the majority of married older people with disabilities receive help with these tasks from their spouse (Evandrou et al. 1986; Katz et al. 2000). The provision and receipt of spousal care is often based on longstanding co-residence and reciprocity (Arber and Ginn 1991), but may still require the renegotiating of duties and rights between the spouses (Mikkola 2009). Although intensive spousal caring changes the routines of everyday life, it is nevertheless likely to become part of a couple's normal life furthering the aim of living together as long as possible (Mikkola 2009). Although other family members may also be carers, if they live in another household they normally spend much less time for informal caring than co-resident carers, especially spouses (Arber and Ginn 1991). However, the provision of spousal care should not be taken for granted as both spouses may become frail and be unable to care for each other.

This study also showed that the death of a spouse markedly increased the risk of admission to institutional care for both genders (Nihtilä and Martikainen 2008a). The admission risk was about 70 and 50 percent higher, respectively, among the recently bereaved men and women compared with their counterparts still living with a spouse when age, education, income, region of residence, and medical conditions at baseline were controlled for. The excess risk was highest during the first month after bereavement, being over three-fold among both men and women, and decreased over time to stabilize at around 20-50 percent excess after one to five years. These findings could not be compared with the results of previous studies as there are no other large-scale prospective studies analyzing admission to institutional care in relation to the duration of widowhood. However, the results are similar to findings reported in mortality studies showing a larger immediate effect of bereavement that decreases over time (Young et al. 1963; Mellström et al. 1982; Bowling 1987; 
Kaprio et al. 1987; Jagger and Sutton 1991; Martikainen and Valkonen 1996a; Martikainen and Valkonen 1996b; Martikainen and Valkonen 1998; Lusyne et al. 2001; Manor and Eisenbach 2003). It has been found that the recently bereaved have a higher risk of death, especially from alcohol-related diseases, suicide, and other accidents and violence (Martikainen and Valkonen 1996b), than the currently married. In Finland, however, the immediate excess risk of entering institutional care after a spouse's death appears to be higher and more long-term than the risk of death (Martikainen and Valkonen 1996a). In addition, our study indicated that the harmful effects of a spouse's death on the risk of institutional admission did not significantly vary according to the level of education or income (Nihtilä and Martikainen 2008a).

The large excess risk of admission into institutional care occurring immediately after the death of a spouse is likely to be related to the loss of social and instrumental support in the form of care and help with daily activities such as cooking, cleaning and shopping formerly shared with the deceased spouse. Furthermore, there may be nobody left to provide personal care to bereaved people with severe functional disabilities. The hypothesis on the loss of spousal support is particularly important in explaining the institutionalization risk that is even higher than the mortality risk immediately after spouses' death. However, the bereaved may also lose other social networks if they were mainly maintained by the deceased spouse.

The excess risk of admission among the bereaved may also be related to emotional stress following the death of a loved person. Grief and spousal loss may produce various symptoms, such as depression and anxiety, loss of appetite, sleep disturbance, fatigue, loss of concentration, and changes in drug-taking habits, including an increase in the use of psychotropic medicines, alcohol and tobacco (Stroebe and Stroebe 1987). Furthermore, grief may increase susceptibility to physical diseases, in terms of lowering immunity to infections and aggravating stress-related illness, including heart disease. These symptoms and their psychical and cognitive consequences may increase the risk of admission to institutions. However, a large proprtion of the bereaved are likely to recover from partner loss, given that feelings of despair and anxiety are known to diminish over time (Hyrkas et al. 1997). Emotional recovery could be one of the underlying mechanisms explaining why the very large excess risk of entering institutional care among the recently bereaved diminished over time.

Our findings on losing a spouse during follow-up (Nihtilä and Martikainen 2008a) are more accurate in assessing the causal effects of not having a spouse 
than the study on not having a spouse at baseline (Nihtilä and Martikainen $2008 \mathrm{~b}$ ) in that selection to marriage may be based on unmeasured health and wealth conditions that could also affect the risk of admission. However, according to Townsend (1962) social isolation is nevertheless an important risk factor for institutional care, and older people may be isolated in various ways. They may be socially isolated because over their lifetime they have never had close family members or friends (continuing isolation), because they have lost them due to death or for some other conclusive reason (sudden desolation), or because their relationships have been weakened by separation or infirmity (diminishing frequency of social relationships). Our study provided evidence that sudden desolation due to the death of a spouse is an important predictor of moving to an institution at older ages, especially shortly after bereavement (Nihtilä and Martikainen 2008a).

\subsubsection{Summary}

The importance of different domains of factors in explaining dependency at older ages (Arber and Ginn 1991) and the use of health services (Andersen 1968; Andersen and Newman 1973; Andersen 1995) has been conceptualized in several fields, including social sciences and health-service research. Similar to some earlier studies that apply the Anderson framework according to which need, predisposing and enabling factors explain admission to care institutions (Tomiak et al. 2000; Hancock et al. 2002), the results of this study indicated, that after age, specific medical conditions characterized as need factors were among the strongest predictors of admission (Nihtilä et al. 2008). This interpretation coincides with that of Tomiak et al. (2000) and Hancock et al. (2002) emphasizing the importance of need factors, including various health-related determinants in predicting admission. In addition, certain enabling factors such as household income and housing conditions were also important in terms of understanding why some older people move to institutions while others continue living in the community, although the net effects of low income and poor housing were smaller than those of specific medical conditions or widowhood. Our study indicated that certain predisposing factors, such as the recency of widowhood (Nihtilä and Martikainen 2008a) for both genders and living without a spouse at baseline for men (Nihtilä and Martikainen 2008b), were strongly associated with the risk of admission. Living without a spouse increased the risk among older women as well, although the net effect was smaller than among men (Nihtilä and Martikainen 2008b). These results suggest that the effect of having a spouse cannot be entirely reduced to the favorable socio-economic, housing and medical situation of those with a spouse, and that spousal caring itself is important in delaying and postponing the need for institutional care. 
As Arber and Ginn (1991) argued in their analysis of dependency in old age, all three domains of resources - health, material and caring - were important in understanding admission to institutions. Our study provided indirect evidence that the loss of caring resources due to the death of a spouse was of critical importance in explaining admission. Although higher household income was shown to be an important resource in decreasing the risk of admission in general, it did not buffer against the effects of losing a spouse.

\subsection{Methodological considerations}

\subsubsection{Strengths of the study}

\section{Date of admission}

The data that linked different administrative registers are exceptional because they contain accurate dates of admission to institutions and loss due to follow-up is minimal. This feature is an advantage of our data, because longitudinal studies on institutional care based on questionnaire surveys or population censuses may suffer from incomplete follow-up due to attrition related to severe disability or to long periods between the surveys/censuses that measure institutional residence. In the case of incomplete follow-up owing to long periods between the surveys/censuses, it would be easy to overestimate the effects of certain determinants that lead to longer periods of institutional care, such as dementia or living alone, and to underestimate the effects of certain socio-economic factors, including income, that are smaller but still important. Cross-sectional studies that tend to overrepresent the long-stayers attract similar criticism (Cohen et al. 1986), but the problem is not entirely solved in longitudinal studies with incomplete follow-up. Although, it is reasonable to use cross-sectional study designs when studying the overall use of and trends in institutional care, they are less appropriate for analyzing the determinants of institutional care. Crosssectional studies tend to reflect simultaneously both the risk of admission and the length of stay, and the determinants of institutional care cannot normally be measured prior to admission. Older people may experience rapid changes in their characteristics, especially in health and functioning, after moving into an institution, and such studies may thus give a biased picture of the reasons for admission. Accurate longitudinal studies are thus required in order to enhance understanding of the reasons for entering institutions. 


\section{Successive stays}

The data covered several types of long-term-care institutions that provided 24hour assistance, including 1) nursing and service homes, and 2) health centers and hospitals. Both public and private institutions were included. Periods of long-term institutional care that comprised several stays in a row in different institutions were also identified. This is an important aspect of long-term institutional care as older Finns often start their care episode in health centers or hospitals and then move to nursing homes. They may also move back and forth from nursing home to hospital according to the intensity of the care they need. If these successive stays are not identified the whole phenomenon of long-term institutional care would be underestimated.

Measuring socio-economic factors

The accurate measurement of various socio-economic conditions with no recall bias, especially household disposable income, is a further advantage of these data. Information on household income from the Tax Administration register is more reliable than self-reported income based on questionnaires, especially among the very old with memory difficulties. Household income in this study included pensions, wages and capital income, and was thus a rather accurate measure of consumption potential.

\section{Date of death of a spouse}

The data provided an internationally unique opportunity to study admission into institutions after the death of a spouse in relation to the duration of bereavement, in that they incorporated several exact dates: the spouse's date of death, and the study person's date of admission to institutional care and date of death.

\subsubsection{Limitations of the study}

The lack of a direct measure of functional limitations

The most obvious limitation in this study is that the administrative data did not contain direct information on functional or cognitive limitations, which are known to raise the risk of institutional care (Branch and Jette 1982; Shapiro and Tate 1988; Steinbach 1992; Wolinsky et al. 1992; Tomiak et al. 2000; Aguero-Torres et al. 2001). However, our measures of dementia, psychosis, depressive symptoms and other mental-health problems are so closely related to cognitive disability that they could serve as adequate proxies of cognitive impairment. The absence of a direct measure of functional impairment may have affected the results on the effects of socio-economic factors and those 
of having a spouse, although various socio-demographic and chronic medical conditions were controlled for. This may have led to overestimation of the effect of income on admission, if low income was strongly associated with functional impairment. Similarly, some of the unexplained, in terms of what was measured in this study, protective effect of living with a spouse could have been related to better unmeasured functional capacity. Furthermore, we were not able to examine the mechanisms, such as different aspects of functional disability, through which different medical conditions affect admission to institutional care.

\section{Measure of disease prevalence}

The second limitation of the study concerns the measurement of chronic medical conditions that lead to underestimation of some of them. Our data on disease prevalence are based on information from registers of inpatient hospital care and from two different medication registers. In general, the prevalence rates obtained were quite close to those derived from populationbased clinical examinations and other sources, e.g. diabetes, heart disease, and stroke (Aromaa and Koskinen 2004), Parkinson's disease (de Rijk et al. 2000), depression (Pahkala et al. 1995; Beekman et al. 1999) and psychosis (Ahto 1999). The two notable exceptions were dementia and osteoarthritis. Our study appears to underestimate the prevalence of dementia among those aged 65 and over, covering only about 10 percent of the prevalence obtained in clinical data sets in Finland (Sulkava 2005) and elsewhere in Europe (Lobo et al. 2000), but provided similar estimates of the prevalence of dementia that Tomiak et al. (2000) reported for older people in Manitoba, Canada. We were only able to identify those persons with dementia who had received hospital care due to dementia. Furthermore, our study appears to cover only about 15 percent of the prevalence of osteoarthritis among older Finns (Aromaa and Koskinen 2004). The prevalence of common musculoskeletal disorders that seldom lead to hospitalization or specific medicinal treatment cannot be entirely assessed from register-based data sets. The osteoarthritis cases we were able to identify were based on hospital diagnoses two years prior to baseline. The lack of association between osteoarthritis and a higher risk of institutional care could be related to the fact that older people who are hospitalized for knee or hip osteoarthritis may have endoprosthesis operations, which improve their functional capacity and decrease their need for institutional care. Furthermore, the prevalence of cancer was about 40 percent lower than indicated in the 15year cancer incidence data of the Finnish cancer registry (Moller et al. 2003). One reason for this is that the cancer cases in our study were identified from information on recently treated cancer: inpatient hospital care two years prior 
to baseline or information from medication registers. Cancers that were not actively treated or were cured were excluded. Nevertheless, having cancer was not among the strongest predictors of institutional care.

This study provided similar estimates of the prevalence of diabetes and heart disease among people aged 65 and over as compared to both survey-based and clinical data sets in Finland (Aromaa and Koskinen 2004). The prevalence of Parkinson's disease was consistent with previous findings based on clinical data sets in Europe (de Rijk et al. 2000). The prevalence of stroke in our data was somewhat lower than reported in studies based on clinical data on life-time stroke in Finland (Aromaa and Koskinen 2004). No nationally representative estimates of the prevalence of depression and of psychosis were available for older Finns at the time of this study, but regional evidence (Pahkala et al. 1995) suggests that clinical screening for depression indicates a somewhat higher prevalence of depression among older people than the register-based data we used. However, international evidence confirms that the prevalence of depression at older ages varies enormously from study to study and that no clear consensus exists regarding the correct prevalence (Beekman et al. 1999). The prevalence of psychosis we identified among older women was consistent with previous clinical findings for south-western Finland, but among older men it was somewhat higher than reported previously (Ahto 1999). Overall, despite small differences in the prevalence of certain medical conditions between our study and previous studies based on other data sources, our study provided reliable and systematic estimates of the risk of admission into institutions for the majority of the treated medical conditions used in this study.

\section{No measure of the number of children}

A further limitation was the absence of information on the number of children, which has been found to decrease the risk of institutional care among older people in the United States (Salive et al. 1993; Coward et al. 1996) and among older women in England and Wales (Grundy and Jitlal 2007). The lack of information on children outside the household may have led to an overestimation of the protective effect of having a spouse in that people with a spouse are more likely to have children than people living alone, many of whom have never been married (18 percent in this study) However, the overestimation is not certain because there are no studies on whether having children decreases the risk of moving to an institution among older Finns. Moreover, the size of the effect and the evidence in the literature strongly indicate that having a spouse is an important factor in reducing the risk of admission. 


\section{Measuring area of residence}

Due to data restrictions no detailed information was available on the area of residence, such as the municipality (NUTS 5 level of the official EU area classification). This is unfortunate as home municipalities are responsible for providing long-term institutional care for older people and the risk of admission may have been higher among those living in municipalities with a better coverage of old-age institutional care, on average, than others, such as Helsinki, Turku, and Tampere among the ten largest municipalities (derived from Official Statistics of Finland 2003). The data did contain information on region of residence, however, which was categorised into 20 official regions, NUTS 3 , and two further categories of Helsinki and the rest of the metropolitan area. There was also information on the level of urbanization in the municipality. These two variables available were adjusted to control for broad differences in the supply of and access to institutional care between the areas (Nihtilä and Martikainen 2007; Nihtilä et al. 2008; Nihtilä and Martikainen 2008b). Municipal-level information would have made it easier to control for place-specific fixed effects. However, its absence is unlikely to have markedly biased the results on the effects of socio-economic and medical conditions or the effects of having or losing a spouse, given that area of residence was controlled for on a broader level. The lack of information on the home municipality would have been a bigger problem if the analyses had been conducted by type of institution in that some municipalities provide long-term care in nursing or service homes and others more in health centres, such as large and urban municipalities (Official Statistics of Finland 2003). For more information on the risk of admission by the level of urbanization see the original publication (Nihtilä and Martikainen 2007). 



\section{CONCLUSIONS}

\section{1 Implications for future research}

The focus of this study was on entry into long-term institutional care. However, this might not be the only facet of long-term institutional care that is important. Questions that still need to be addressed include whether the lower risk of admission observed in certain groups (e.g., high-income groups) is related to postponment or total prevention of admission, and whether the length of stay following admission varies according to socio-demographic characteristics. The follow-up period in this study ended on 30 September 2003, and people who were not admitted into an institution during this time may have been admitted later. A prospective follow-up until the death of every individual or alternatively an estimation based on current admission and death rates would shed light on this question of prevention or postponement. A relatively straightforward first step was to examine whether the probability of admission among those who died during the follow-up varied according to certain baseline characteristics such as income. These preliminary results based on multivariate logistic regression models indicated that the odds of having been in long-term institutional care was 1.25-times higher among the deceased men in the lowest income quintile group than among those in the highest income group, when baseline socio-demographic and chronic medical conditions were controlled for. The corresponding figure for women was 1.18. The implication is that the lower risk of admission among those with a higher income is related not only to postponment but also partly to prevention, which was more likely among the deceased with a higher income, other things being equal. However, further research is needed in order to analyze in more detail the postponement, prevention and duration of institutional care, and the likelihood of returning back to the community (see Martikainen et al. 2009).

The emphasis in this study was on the main effects of various medical conditions, socio-economic factors, and having and losing a spouse on the risk of admission to institutions among older men and women. Less attention was given to analyzing possible interactions among these factors, with the exception of those between bereavement and the level of income and education. More research is therefore needed in order to examine whether the effects of different medical conditions vary according to socio-economic or partner status.

The death of a spouse was shown to be strongly associated with long-term institutional care, and neither a high household income nor a high level of education buffered against the effects of this loss. However, information on 
other family relationships and care outside the household was not taken into account. It has been found that having children reduces the risk of admission into institutions among older people (Salive et al. 1993; Coward et al. 1996; Grundy and Jitlal 2007), and it is likely that getting more help from children after the spouse's death could buffer against the effects of bereavement. More research is needed in order to find out whether the harmful effects of bereavement are weaker among those with living children, and whether daughters and sons play different roles in buffering the effect of spousal loss. There is also a need for more detailed research on the mechanisms that mediate the effect of bereavement on admission, preferably based on longitudinal data.

Given that the use of service housing with 24-hour care is rapidly increasing (Figure 2), further research is needed on the socio-demographic determinants of admission to different types of institutions and on the care paths between them. This would now be possible because separate information on service housing has been collected on the national level since 2000 (Official Statistics of Finland 2003). As this type of long-term care is often privately provided (Official Statistics of Finland 2006), certain socio-economic determinants such as low income may be less important in explaining admission than in the case of publicly funded nursing homes and health centers. At the time of this study analysis by type of institution was not possible because the few service homes providing 24-hour care at the end of the 1990 s were included in the same category as nursing homes. The data included both public and private institutions but nursing and service homes could not be separated in our data. There is also a need for research on how other social and health-system features such as public home-help services (Official Statistics of Finland 2007), pensioners' care allowance (Social Insurance Institution of Finland 2008), and new publicly funded vouchers for purchasing services from private-sector providers (Finlex 2009) affect the risk of admission into institutions.

There is also a need for more detailed information on the differences in the risk of admission between geographical areas in Finland and in different time periods. The preliminary results of this study indicate that the age-adjusted differences in the risk of admission between the regions are not that large, but they are different than the regional differences in mortality among communityliving Finns over 65 years of age (admission highest in Pirkanmaa and mortality highest in North Karelia and Kainuu). These differences in admission rates require further study over different time periods as the regional risks of admission are likely to be sensitive to structural changes in the provision of social and health services for older people. 


\subsection{Implications for policy}

The findings of this study indicate that the future need for institutional care will depend not only on the increasing numbers of older people but also on the future prevalence of chronic medical conditions associated with admission, and on developments in living arrangements, housing conditions and income. However, policy measures are unlikely to change most of the sociodemographic and health-related determinants of the need for institutional care on the population-level, or then they would take decades to work through. Nevertheless, there is a need for social and health-policy instruments to buffer the harmful effects of critical life-events and to postpone the onset of medical conditions associated with institutional care.

It was shown that diabetes, one of the most common chronic diseases worldwide, increased the risk of admission to institutions by 50 percent among older Finns. Given the estimated increase in the number of cases and the prevalence of diabetes (derived from Statistics Finland 2007; World Health Organization 2009), the costs of long-term institutional care related to it may also increase. Lifestyle changes that counter obesity and physical inactivity, the two major risk factors for type-2 diabetes (Alberti et al. 1997), are required to level off the potential future increase in long-term care costs associated with diabetes. In addition, the primary health care system could allocate more resources to the prevention of type-2 diabetes in order to detect those at an increased risk (Lindström and Tuomilehto 2003; Schwarz et al. 2009), to provide health counselling (Salminen et al. 2002) and to promote lifestyle interventions (Lindström et al. 2003) that are known to reduce the onset of diabetes in high-risk people. Despite the advances in medical treatments that may weaken the harmful effects of diabetes on functional status in the future, however, the fact that the number of people with type-2 diabetes in Finland is expected to increase from the current 157,000 in 2000 to 239,000 in 2030 (World Health Organization 2009) is likely to have consequences in terms of future care needs.

Neurological disorders, including dementia, Parkinson's disease and stroke were shown to be the strongest predictors of admission. Although Parkinson's disease is relatively rare in people aged 65 and over (de Rijk et al. 2000), the ageing of the older population is likely to increase the long-term-care needs associated with it as its prevalence and the severity of the symptoms are strongly age-related (Lindgren 2004). However, dementia is likely be the major driver of increases in long-term care costs among ageing populations as it is common in older people and highly disabling (Fratiglioni et al. 1999; Jonsson 2004). 
People with dementia do not only have a particularly high risk of admission, but they also tend to stay longer in institutions than those with other chronic medical conditions (results not shown). Stroke is also a major cause of admission (Nihtilä et al. 2008) and of disabilities in that the majority of people survive their first stroke, and a half of the survivors are left with permanent disabilities (Sundberg et al. 2003). However, the vast majority of permanent disabilities could be avoided if acute hospital treatment was received within three hours of the stroke (HUS 2004). It is thus of major policy importance to publicly finance the availability of acute treatment in different geographical areas in Finland, and to provide rehabilitation after stroke to counter the increasing need for long-term institutional care.

The findings in this study showed that the inverse relationship between household income and the risk of admission to institutions was partly explained by and mediated through other socio-demographic factors and chronic medical conditions. As one of the medical conditions mediating this effect was diabetes in women, it is essential to monitor the income differences in the onset and severity of diabetes in order to guarantee equal treatment regardless of income.

According to the results poor housing is associated with an increased risk of admission to institutional care at older ages. Living in a very poorly equipped dwelling raised the risk of admission by 12-14 percent, and living in a poorly equipped dwelling, lacking washing facilities or central or fixed electric heating, by 6-8 percent. These effects are of policy relevance because about 20 percent of Finnish community-living older people lived in a poorly or very poorly equipped dwelling at the time of the study. Poor housing conditions are among the few socio-economic risk factors for institutional care that could possibly be ameliorated by policy instruments such as publicly funded support for housing renovations. Renovation of dwellings, especially of bathroom facilities, could make basic bodily maintenance easier for older people and improve their chances of remaining in the community, especially for those with functional disabilities. However, this study did not produce any evidence of an association between the presence of a lift in an apartment house and a reduced risk of institutional care. This result could be related to selection into different apartment houses according to unmeasured functional disabilities: older people with more disabilities might choose to avoid apartment houses without lifts or choose to live on the ground floor.

The death of a spouse is evidently a critical moment in the life course of an individual as it strongly increased the risk of admission to institutional care. 
A particularly high risk of admission on the population-level was observed from one to two months following bereavement, and this decreased over time. These findings provide indirect evidence of the effects of the loss of social and instrumental support that is reflected in an increased need for care. Policy measures such as targeted tax reductions for purchasing private home-help services, or allocated public home-help services targeted on the bereaved soon after a spouse's death could buffer the harmful effects of widowhood. These additional services and financial support for the bereaved should be provided without the need for extensive administrative procedures. In addition, more flexibility is needed in the labor market to allow short-term family leave for adult children in order to take care of their recently widowed parents.

Given the aim in the Finnish old-age policy to shift the balance of care from institutions towards home-based services, it is of policy importance to understand that a rapid decline in the supply of long-term institutional care could lead to unmet needs unless alternative care is available, as the older population itself is ageing (Statistics Finland database 2007). In order to cut down the increasing amount of social and health-care expenditure related to an ageing population, the aim on the national policy level is to increase the proportion of older people aged 75 and over living at home from the current 90.1 percent in 2006 up to 91-92 percent by 2012 (Ministry of Social Affairs and Health 2008b). The current target is to change the structure of institutional care by dramatically decreasing the proportion of older people receiving long-term care in nursing homes and health centres, and increase the usage of service homes with 24-hour care, which are less expensive, and simultaneously extending the coverage of regular home care and support for informal care in order to support living in the community. These national targets were set in February 2008 before the deepening of the global financial crisis in September 2008 (Wikipedia 2009). Given the changed economic environment, it may be difficult to achieve the target of increasing the coverage of regular home care, the provision of which tends to decline during economic recessions, as it did the 1990s (Official Statistics of Finland 2003). Because of the growing pressure from a declining economy (Statistics Finland 2009) and an ageing population (Statistics Finland 2007) on care expenditure and use it is of major policy importance to delay the need for institutional care on the population level in order to avoid unmet care needs. The findings in this study imply that the need for institutional care at older ages depends not only on the ageing of the population but also on the future prevalence and severity of chronic medical conditions associated with institutional care, and on older people's income, housing conditions and access to informal care from their spouse. 


\section{ACKNOWLEDGEMENTS}

This study was carried out at the Population Research Unit within the Department of Sociology, University of Helsinki between 2003 and 2009. I am deeply grateful for the peaceful and supportive working environment and the excellent research facilities provided at the department. The study was financially supported by the Doctoral Programme for Population, Health, and Living Conditions, and by the Finnish Cultural Foundation. It was also part of two EU-funded research programs: Future Elderly Living Conditions In Europe, FELICIE, and Major Ageing and Gender Issues in Europe, MAGGIE.

I owe my sincere gratitude to my supervisor Professor Pekka Martikainen from the Department of Sociology for his excellent guidance over the years. I benefitted very much at every stage of this study from his extensive knowledge of population studies and his wide experience in academic research and writing, starting from his central role in obtaining the data, his help in developing the research questions, and his constructive comments on the structure of the summary. Although it is difficult to admit, this thesis would probably not have materialized without him. I greatly appreciate his efficient but calm way of commenting on manuscripts, his exceptional talent of knowing what is essential, and the diplomatic way in which he rejected ideas that were not so good. I am indeed privileged to have had such an excellent supervisor.

I am also deeply indebted to Anja Noro and Unto Häkkinen (STAKES) for their skills and guidance in negotiating and using the data on institutional care, to Seppo Koskinen and Antti Reunanen (National Public Health Institute) for their medical expertise and help in creating the variables for chronic medical conditions, to Tapani Valkonen, Eero Lahelma and Ossi Rahkonen (University of Helsinki) for their wise guidance, encouragement and humor over the years in the doctoral seminar, and to Ari Haukkala and Tuija Martelin for their constructive comments. I am grateful to Teemu Lyytikäinen (Government Institute for Economic Research) for his advices on using Stata software, to Katja Kesseli for sharing her knowledge of R software for drawing graphs, and to Sari Kauppinen (STAKES) for sharing her expertise on services for older people. My warmest appreciation goes to Timo Kauppinen, Jenni Blomgren, Karoliina Majamaa, Netta Mäki, Petteri Sipilä, Hanna Remes, Heta Moustgaard, Riikka Shemeikka and other current and former colleagues at the Population Research Unit for their support, generosity in sharing their knowledge, and excellent company over the years, and to my long-term roommate and collegue Suvi-Tuuli Waltari 
for providing a nice working atmosphere at the department. I also sincerely thank Professor Emily Grundy for her support and the provision of research facilities at the London School of Hygiene and Tropical Medicine during my research visit to England in Spring 2007.

I am indebted to the pre-examiners of my thesis, Professors Antti Karisto (Department of Social Policy, University of Helsinki) and Irma T. Elo (Population Studies Center, University of Pennsylvania, USA), for their accurate and constructive comments, and to Professor Anton Kunst (Department of Public Health, Academic Medical Centre, University of Amsterdam) for agreeing to be the opponent.

I warmly thank my mother Riitta Nihtilä for supporting me, believing in me, and taking care of our son, and my father Markku Nihtilä for his constant encouragement, his guidance in mathematics and statistics, and for always supporting my choices, with the exception of my constant attempts to drop mathematics. My most heartfelt gratitude goes to my wonderful husband Elias for his patience, constant emotional support, wise encouragement, and excellent guidance in drawing graphs. Finally, I thank our two-year old son Ilmo for keeping me busy with his cars and trains so that my work ideas and problems were seldom given a second thought at home. 


\section{REFERENCES}

Aday, Lu Ann and William C. Awe. 1997. Health Service Utilization Models, in Handbook of Health Behavior Research I: Personal and Social Determinants. New York: Plenum Press.

Aguero-Torres, H., E. von Strauss, M. Viitanen, B. Winblad, and L. Fratiglioni. 2001. Institutionalization in the elderly: the role of chronic diseases and dementia. Cross-sectional and longitudinal data from a population-based study, Journal of clinical epidemiology 54(8): 795-801.

Ahto, Merja. 1999. Coronary heart disease and quality of life among the elderly - prevalence and manifestations of coronary heart disease and its associations with physical, psychological, cognitive and social functioning. Oulu: Department of Public Health Science and General Practice, University of Oulu.

Alberti, K. G. M. M., P. Zimmet, R. A. DeFronzo, and H. Keen (eds.) 1997. International Textbook of Diabetes Mellitus, 2nd edition, New York: John Wiley \& Sons.

Andersen, Ronald. 1968. A Behavioral Model of Families' Use of Health Services. Centre for Health Administration Studies. Research Series 25. Chicago: University of Chicago.

Andersen, Ronald M. 1995. Revisiting the behavioral model and access to medical care: does it matter? Journal of health and social behavior 36: $1-10$.

Andersen, Ronald and John F. Newman. 1973. Societal and Individual Determinants of Medical Care Utilization in the United States, Milbank Memorial Fund Quarterly. Health and Society 51(1): 95-124.

Anttila, Sari. 1989. Maaseudun ikäihmisten terveydentila, sosiaali- ja terveyspalvelujen käyttö ja kuolleisuus. Tampere: Tampereen yliopisto, Acta Universitatis Tamperensis. Ser. A. vol. 277.

Arber, S. and J. Ginn. 1991. Gender and Later Life. A Sociological Analysis of Resources and Constraints. London, Newbury Park, New Delhi: Sage Publications.

Aromaa, A. and S. Koskinen (eds.) 2004. Health and functional capacity in Finland. Baseline Resuls of the Health 2000 Health Examination Survey, Helsinki: Publications of the National Public Health Insitute B12/2004.

Bajekal, M. 2002. Health Survey for England 2000: Characteristics of Care Homes and Their Residents. London: The Stationery Office.

Banaszak-Holl, J., A. M. Fendrick, N. L. Foster, A. R. Herzog, M. U. Kabeto, D. M. Kent, W. L. Straus, and K. M. Langa. 2004. Predicting nursing home admission: estimates from a 7-year follow-up of a nationally representative sample of older Americans, Alzheimer Disease and Associated Disorders 18(2): 83-89.

Beekman, A. T., J. R. Copeland, and M. J. Prince. 1999. Review of community 
prevalence of depression in later life, The British journal of psychiatry; the journal of mental science 174(4): 307-311.

Berger, K., M. M. Breteler, C. Helmer, D. Inzitari, L. Fratiglioni, C. Trenkwalder, A. Hofman, and L. J. Launer. 2000. Prognosis with Parkinson's disease in europe: A collaborative study of population-based cohorts. Neurologic Diseases in the Elderly Research Group, Neurology 54(11 Suppl 5): S24-7.

Bharucha, A. J., R. Pandav, C. Shen, H. H. Dodge, and M. Ganguli. 2004. Predictors of nursing facility admission: a 12-year epidemiological study in the United States, Journal of the American Geriatrics Society; Journal of the American Geriatrics Society 52(3): 434-439.

Bowling, A. 1987. Mortality after bereavement: a review of the literature on survival periods and factors affecting survival, Social science \& medicine (1982) 24(2): 117-124.

Branch, L. G. and A. M. Jette. 1982. A prospective study of long-term care institutionalization among the aged, American Journal of Public Health 72(12): 1373-1379.

Breeze, E., A. Sloggett, and A. Fletcher. 1999. Socioeconomic and demographic predictors of mortality and institutional residence among middle aged and older people: results from the Longitudinal Study, Journal of epidemiology and community health 53(12): 765-774.

Carrière, Y. and L. Pelletier. 1995. Factors underlying the institutionalization of elderly persons in Canada, The journals of gerontology. Series B, Psychological sciences and social sciences 50(3): S164-72.

Christensen, E. 1987. Multivariate Survival Analysis Using Cox's Regression Model, Hepatology 7(6): 1346-1358.

Cohen, M. A., E. J. Tell, and S. S. Wallack. 1986. Client-related risk factors of nursing home entry among elderly adults, Journal of gerontology 41(6): 785-792.

Couch, Kenneth A. and Duke Kao. 1998. Residential Choices and Prospective Risks of Nursing Home Entry. New York: Syracuse University.

Coward, R. T., J. K. Netzer, and R. A. Mullens. 1996. Residential differences in the incidence of nursing home admissions across a six-year period, The journals of gerontology. Series B, Psychological sciences and social sciences 51(5): S258-67.

Cox, D. 1972. Regression models and life-tables, Journal of Royal Statistical Society B 34: 187-220.

de Rijk, M. C., L. J. Launer, K. Berger, M. M. Breteler, J. F. Dartigues, M. Baldereschi, L. Fratiglioni, A. Lobo, J. Martinez-Lage, C. Trenkwalder, and A. Hofman. 2000. Prevalence of Parkinson's disease in Europe: A collaborative study of population-based cohorts. Neurologic Diseases in the Elderly Research Group, Neurology 54(11 Suppl 5): S21-3.

Desesquelles, A. and N. Brouard. 2003. The family networks of people aged 60 and over living at home or in an institution, Population 58(2): 201-227. 
Dickman, P. 2004. Population-based cancer survival analysis. Course at the University of Tampere, Finland, 3-7 May 2004.

Dolinsky, A. L. and I. Rosenwaike. 1988. The role of demographic factors in the institutionalization of the elderly, Research on aging 10(2): 235-257.

Draper, B. M., C. J. Poulos, A. M. Cole, R. G. Poulos, and F. Ehrlich. 1992. A comparison of caregivers for elderly stroke and dementia victims, Journal of the American Geriatrics Society 40(9): 896-901.

Dunkin, J. J. and C. Anderson-Hanley. 1998. Dementia caregiver burden: a review of the literature and guidelines for assessment and intervention, Neurology 51(1 Suppl 1): S53-60; discussion S65-7.

Eaker, E. D., R. A. Vierkant, and S. F. Mickel. 2002. Predictors of nursing home admission and/or death in incident Alzheimer's disease and other dementia cases compared to controls: a population-based study, Journal of clinical epidemiology 55(5): 462-468.

Evandrou, M., S. Arber, A. Dale, and G. N. Gilbert . 1986. Who cares for the elderly? Family care provision and receipt of statutory services, in Dependency and interdependency in old age. Theoretical perspectives and policy alternatives. C. Phillipson, M. Bernard and Strang P. (eds.) London: Croom Helm, pp. 150-166.

Festy, Patrick and Jitka Rychtarikova. 2008. Living conditions for the elderly in the late twentieth century, in Future Elderly Living Conditions in Europe. J. Gaymu, P. Festy, M. Poulain and G. Beets (eds.) Paris: Institut National d'Etudes Démographiques, pp. 41-67.

Finlex 2009. HE 20/2009. Hallituksen esitys Eduskunnalle laeiksi sosiaalija terveydenhuollon palvelusetelistä sekä sosiaali- ja terveydenhuollon asiakasmaksuista annetun lain 12 §:n muuttamisesta [Homepage of FINLEX, Valtion säädöstietopankki], Available: http://www.finlex.fi/fi/ esitykset/he/2009/20090020 [2009, 28 May] .

Foley, D. J., A. M. Ostfeld, L. G. Branch, R. B. Wallace, J. McGloin, and J. C. CornoniHuntley. 1992. The risk of nursing home admission in three communities, Journal of aging and health 4(2): 155-173.

Fratiglioni, L., D. De Ronchi, and H. Aguero-Torres. 1999. Worldwide prevalence and incidence of dementia, Drugs \& aging 15(5): 365-375.

Freedman, V.A. 1996. Family structure and the risk of nursing home admission, The journals of gerontology. Series B, Psychological sciences and social sciences 51(2): S61-9.

Garber, Alan and Thomas MaCurdy. 1989. Predicting Nursing Home Utilization Among the High-Risk Elderly. Cambridge, MA.

Gaugler, J. E., S. Duval, K. A. Anderson, and R. L. Kane. 2007. Predicting nursing home admission in the U.S: a meta-analysis, BMC geriatrics 7: 13.

Gaugler, J. E., F. Yu, K. Krichbaum, and J. F. Wyman. 2009. Predictors of nursing home admission for persons with dementia, Medical care 47(2): 191-198. 
Giles, L. C., G. F. Glonek, M. A. Luszcz, and G. R. Andrews. 2007. Do social networks affect the use of residential aged care among older Australians? BMC geriatrics 7: 24.

Greene, V. L., M. E. Lovely, M. D. Miller, and J. I. Ondrich. 1995. Reducing nursing home use through community long-term care: an optimization analysis, The journals of gerontology. Series B, Psychological sciences and social sciences 50(4): S259-68.

Greene, V. L. and J. I. Ondrich. 1990. Risk factors for nursing home admissions and exits: a discrete-time hazard function approach, Journal of gerontology 45(6): S250-8.

Grundy, E. M. D. 1992. Socio-Demographic Variations in Rates of Movement into Institutions among elderly People in England and Wales: An Analysis of Linked Census and Mortality Data 1971-1985, Population Studies 46(1): 65-84.

Grundy, E. and K. Glaser. 1997. Trends in, and transitions to, institutional residence among older people in England and Wales, 1971-91, Journal of epidemiology and community health 51(5): 531-540.

Grundy, E. and M. Jitlal. 2007. Socio-demographic variations in moves to institutional care 1991-2001: a record linkage study from England and Wales, Age and Ageing 36(4): 424-430.

Häkkinen, U., P. Martikainen, A. Noro, E. Nihtilä, and M. Peltola. 2008. Aging, health expenditure, proximity to death, and income in Finland, Health economics, policy, and law 3(Pt 2): 165-195.

Hancock, R., A. Arthur, C. Jagger, and R. Matthews. 2002. The effect of older people's economic resources on care home entry under the United Kingdom's long-term care financing system, The journals of gerontology. Series B, Psychological sciences and social sciences 57(5): S285-93.

Hanley, R. J., L. M. Alecxih, J. M. Wiener, and D. L. Kennell. 1990. Predicting elderly nursing home admissions. Results from the 1982-1984 National Long-Term Care Survey, Research on aging 12(2): 199-228.

Harris, Y. and J. K. Cooper. 2006. Depressive symptoms in older people predict nursing home admission, Journal of the American Geriatrics Society 54(4): 593-597.

Headen, Alvin E. Jr. 1993. Economic Disability and Health Determinants of the Hazard of Nursing Home Entry, Journal of Human Resources 28(1): 80-110.

Himes, C. L., G. G. Wagner, D. A. Wolf, H. Aykan, and D. D. Dougherty. 2000. Nursing home entry in Germany and the United States, Journal of CrossCultural Gerontology 15(2): 99-118.

Hujanen, T. 2003. Terveydenhuollon yksikkökustannukset Suomessa vuonna 2001. Aiheita 1/2003. Helsinki: Stakes.

HUS 2004. Aivohalvaus on merkittävä kansansairaus [Homepage of Hospital district of Helsinki and Uusimaa], Available: http://www.hus.fi/default.a sp?path=1,32,660,546,621,4903,5879 [2009, 8 June]. 
Hyrkas, K., M. Kaunonen, and M. Paunonen. 1997. Recovering from the death of a spouse, Journal of advanced nursing 25(4): 775-779.

Jagger, C., K. Andersen, M. M. Breteler, J. R. Copeland, C. Helmer, M. Baldereschi, L. Fratiglioni, A. Lobo, H. Soininen, A. Hofman, and L. J. Launer. 2000. Prognosis with dementia in Europe: A collaborative study of population-based cohorts. Neurologic Diseases in the Elderly Research Group, Neurology 54(11 Suppl 5): S16-20.

Jagger, C. and C. J. Sutton. 1991. Death after marital bereavement - is the risk increased? Statistics in medicine 10(3): 395-404.

Jette, A. M., L. G. Branch, L. A. Sleeper, H. Feldman, and L. M. Sullivan. 1992. High-risk profiles for nursing home admission, The Gerontologist 32(5): 634-640.

Jonsson, L. 2004. Economic evidence in dementia: a review, The European journal of health economics : HEPAC : health economics in prevention and care 5 Suppl 1: S30-5.

Joung, I. M., K. Stronks, H. van de Mheen, and J. P. Mackenbach. 1995. Health behaviours explain part of the differences in self reported health associated with partner/marital status in The Netherlands, Journal of epidemiology and community health 49(5): 482-488.

Kaplan, E. L. and P. Meier. 1958. Nonparametric Estimation from Incomplete Observations, Journal of the American Statistical Association, 53(282): 457-481.

Kaprio, J., M. Koskenvuo, and H. Rita. 1987. Mortality after bereavement: a prospective study of 95,647 widowed persons, American Journal of Public Health 77(3): 283-287.

Katz, S. J., M. Kabeto, and K. M. Langa. 2000. Gender disparities in the receipt of home care for elderly people with disability in the United States, JAMA: the journal of the American Medical Association 284(23): 3022-3027.

Kivelä, S. L. 1985. Indicators of permanent institutional care, Scandinavian journal of primary health care 3(1): 39-43.

Klein,T. 1996. Determinants of institutionalization in old age, in Long-term care: Economic issues and policy solutions. R. Eisen and F.A. Sloan (eds.) Boston / Dordrecht / London: Kluwer Academic Publishers, pp. 103-113.

Lakdawalla, D. N. and R. F. Schoeni. 2003. Is nursing home demand affected by the decline in age difference between spouses? Demographic research 2 (Published 22 May 2003. www.demographic-reasearch.org): 279-296.

Lindgren, P. 2004. Economic evidence in Parkinson's disease: a review, The European journal of health economics : HEPAC: health economics in prevention and care 5 Suppl 1: S63-6.

Lindström, J., A. Louheranta, M. Mannelin, M. Rastas, V. Salminen, J. Eriksson, M. Uusitupa, J. Tuomilehto, and Finnish Diabetes Prevention Study Group. 2003. The Finnish Diabetes Prevention Study (DPS): Lifestyle intervention and 3-year results on diet and physical activity, Diabetes care 26(12): 3230-3236. 
Lindström, J. and J. Tuomilehto. 2003. The diabetes risk score: a practical tool to predict type 2 diabetes risk, Diabetes care 26(3): 725-731.

Liu, K., T. Coughlin, and T. McBride. 1991. Predicting nursing-home admission and length of stay. A duration analysis, Medical care 29(2): 125-141.

Liu, K., T. McBride, and T. Coughlin. 1994. Risk of entering nursing homes for long versus short stays, Medical care 32(4): 315-327.

Liu, L. F. and A. Tinker. 2001. Factors associated with nursing home entry for older people in Taiwan, Republic of China, J.Interprof Care. 15(3): 245-255.

Lobo, A., L. J. Launer, L. Fratiglioni, K. Andersen, A. Di Carlo, M. M. Breteler, J. R. Copeland, J. F. Dartigues, C. Jagger, J. Martinez-Lage, H. Soininen, and A. Hofman. 2000. Prevalence of dementia and major subtypes in Europe: A collaborative study of population-based cohorts. Neurologic Diseases in the Elderly Research Group, Neurology 54(11 Suppl 5): S4-9.

Lusyne, P., H. Page, and J. Lievens. 2001. Mortality following conjugal bereavement, Belgium 1991-96: the unexpected effect of education, Population studies 55(3): 281-289.

Manor, O. and Z. Eisenbach. 2003. Mortality after spousal loss: are there socio-demographic differences? Social science \& medicine (1982) 56(2): 405-413.

Martelin, T. 1994. Differential mortality at older ages. Sociodemographic Mortality Differences among the Finnish Elderly. Helsinki: The Finnish Demographic Society.

Martikainen, P., H. Moustgaard, M. Murphy, E. K. Einiö, S. Koskinen, T. Martelin, and A. Noro. 2009. Gender, living arrangements, and social circumstances as determinants of entry into and exit from long-term institutional care at older ages: a 6-year follow-up study of older Finns, The Gerontologist 49(1): 34-45.

Martikainen, P. and T. Valkonen. 1998. Do education and income buffer the effects of death of spouse on mortality? Epidemiology (Cambridge, Mass.) 9(5): 530-534.

Martikainen, P. and T. Valkonen. 1996a. Mortality after death of spouse in relation to duration of bereavement in Finland, Journal of epidemiology and community health 50(3): 264-268.

Martikainen, P. and T. Valkonen. 1996b. Mortality after the death of a spouse: rates and causes of death in a large Finnish cohort, American Journal of Public Health 86(8): 1087-1093.

Mellström, D., A. Nilsson, A. Oden, A. Rundgren, and A. Svanborg. 1982. Mortality among the widowed in Sweden, Scandinavian journal of social medicine 10(2): 33-41.

Meriläinen,P., M. -L Perälä, and K. Virta. 1994. Vanhuksen oikeudellinen asema ja itsemäärääminen laitoshoidossa, in Muuttuva vanhuus. A. Uutela and J.-E. Ruth (eds.) Tampere: Gaudeamus, pp. 237-250. 
Mikkola, T. 2009. Sinusta kiinni. Tutkimus puolisohoivan arjen toimijuuksista (Depending on you. A study of spousal care, everyday life and agency). Helsinki: Diakonia-ammattikorkeakoulu.

Ministry of Social Affairs and Health. 1996. Komiteamietintö 1996:1. Vanhuspolitiikkaa vuoteen 2001. Suomen vanhuspoliittinen tavoite- ja strategiatoimikunnan mietintö, Helsinki.

Ministry of Social Affairs and Health. 2003. Sosiaali- ja terveydenhuollon asiakasmaksulainsäädännön muutokset 1.4.2003 (Change in the legislation concerning user charges for social and health care). Available: http:// www.stm.fi/Resource.phx/publishing/documents/1501/index.htx [2006, 6 November].

Ministry of Social Affairs and Health. 2008a. Ikäihmisten palvelut (Services for older people) [Homepage of Ministry of Social Affairs and Health], Available: http://www.stm.fi/Resource.phx/vastt/sospa/shvan/index.htx.

Ministry of Social Affairs and Health. 2008b. Ikäihmisten palveluiden laatusuositus (Recommendation for the quality of services for older people). Helsinki: Ministry of Social Affairs and Health and Federation of municipalities.

Moller, T., H. Anderson, T. Aareleid, T. Hakulinen, H. Storm, L. Tryggvadottir, I. Corazziari, E. Mugno, and EUROPREVAL Working Group. 2003. Cancer prevalence in Northern Europe: the EUROPREVAL study, Annals of Oncology : Official Journal of the European Society for Medical Oncology / ESMO 14(6): 946-957.

Mustard, C., M. Finlayson, S. Derksen, and J. M. Berthelot. 1999. What determines the need for nursing home admission in a universally insured population? Journal of health services research \& policy 4(4): 197-203.

National Agency for medicines. 1997. Lääkkeiden luokitus (ATC) ja määritellyt vuorokausiannokset (DDD). [Classification of medicines (ATC) and defined daily doses (DDD)]. Helsinki: National Agency for medicines.

National Agency for medicines. 1998. Lääkkeiden luokitus (ATC) ja määritellyt vuorokausiannokset (DDD). [Classification of medicines (ATC) and defined daily doses (DDD)]. Helsinki: National Agency for medicines.

National Center for Health Statistics. 2009. Health, United States, 2008. Hyattsville, MD: U.S. Department of health and human services, Centers for Disease Control and Prevention, National Center for Health Statistics.

Newman, S. J., R. Struyk, P. Wright, and M. Rice. 1990. Overwhelming odds: caregiving and the risk of institutionalization, Journal of gerontology 45(5): S173-83.

Nihtilä, E. and P. Martikainen. 2007. Household income and other socioeconomic determinants of long-term institutional care among older adults in Finland, Population studies 61(3): 299-314.

Nihtilä, E. and P. Martikainen. 2008a. Institutionalization of older adults after the death of a spouse, American Journal of Public Health 98(7): 1228-1234.

Nihtilä, E. and P. Martikainen. 2008b. Why older people living with a spouse 
are less likely to be institutionalized: the role of socioeconomic factors and health characteristics, Scandinavian journal of public health 36(1): 35-43.

Nihtilä, E. K., P. T. Martikainen, S. V. Koskinen, A. R. Reunanen, A. M. Noro, and U. T. Häkkinen. 2008. Chronic conditions and the risk of long-term institutionalization among older people, European journal of public health 18(1): 77-84.

Nikiforov, Oleg and Reijo Salmela. 1995. Pitkäaikaispotilaat sairaaloissa vuosina 1990-1994. Tilastotiedote 1995:42 (Long-term patients in hospital care in 1990-1994. Statistical report). Helsinki: STAKES, National Research and Development Centre for Welfare and Health.

Noro, Anja. 1998. Long-term institutional care among Finnish elderly population trends and potential for discharge. Helsinki: STAKES, National Research and Development Centre for Welfare and Health.

Nuotio, M., T. L. Tammela, T. Luukkaala, and M. Jylha. 2003. Predictors of institutionalization in an older population during a 13-year period: the effect of urge incontinence, The journals of gerontology. Series A, Biological sciences and medical sciences 58(8): 756-762.

OECD. 2005. Long-term care for older people. The OECD Health Project. Paris: Organisation for Economic Co-operation and Development.

OECD. 1982. The OECD List of Social Indicators. Paris: Organisation for Economic Co-operation and Development.

Official Statistics of Finland. 2008a. Institutional care and housing services in social care 2007. Statistical summary 25/2008. SVT: Social Security 2008. Helsinki: STAKES, National Research and Development Centre for Welfare and Health.

Official Statistics of Finland. 2008b. Statistical Yearbook on Social Welfare and Health Care 2007. Helsinki: STAKES, National Research and Development Centre for Welfare and Health.

Official Statistics of Finland. 2007. Care and Services for Older People 2005. SVT: Social Security 2007. Helsinki: STAKES, National Research and Development Centre for Welfare and Health.

Official Statistics of Finland. 2006. Institutional care and housing services in social care 2005. Statistical summary 15/2006. SVT: Social Security 2006. Helsinki: STAKES, National Research and Development Centre for Welfare and Health.

Official Statistics of Finland. 2003. Care and Services for Older People 2002. SVT: Social Security 2003:1. Helsinki: STAKES, National Research and Development Centre for Welfare and Health.

Official Statistics of Finland 2002, Statistical Yearbook on Social Welfare and Health Care 2002. SVT 2002:4. Sosiaaliturva., STAKES, National Research and Development Centre for Welfare and Health, Helsinki.

Pahkala, K., E. Kesti, P. Kongas-Saviaro, P. Laippala, and S. L. Kivela. 1995. Prevalence of depression in an aged population in Finland, Social psychiatry and psychiatric epidemiology 30(3): 99-106. 
Parkes, C. M., B. Benjamin, and R. G. Fitzgerald. 1969. Broken heart: a statistical study of increased mortality among widowers, British medical journal 1(5646): 740-743.

Pearlman, D. N. and W. H. Crown. 1992. Alternative sources of social support and their impacts on institutional risk, The Gerontologist 32(4): 527-535.

Pitkänen, K. 1994. Hylkäsivätkö perheet vanhuksensa laitoksiin? Suomalaisen laitoshoidon historiaa, in Muuttuva vanhuus. A. Uutela and J.E. Ruth (eds.) Tampere: Gaudeamus, pp. 221-236.

Puts, M. T. E., P. Lips, M. W. Ribbe, and Deeg D.J.H. 2005. The effect of frailty on residential/nursing home admission in the Netherlands independent of chronic diseases and functional limitations, European Journal of Ageing 2: 264-274.

Rintala, T. 2003. Vanhuskuvat ja vanhustenhuollon muotoutuminen 1850-luvulta 1990-luvulle. Helsinki: Stakes, Tutkimuksia 132.

Rockwood, K., P. Stolee, and I. McDowell. 1996. Factors associated with institutionalization of older people in Canada: testing a multifactorial definition of frailty, Journal of the American Geriatrics Society 44(5): 578-582.

Ross, C. E. 1995. Reconceptualizing marital status as a continuum of social attachment, Journal of Marriage and Family 57(1): 129-140.

Russell, D. W., C. E. Cutrona, A. de la Mora, and R. B. Wallace. 1997. Loneliness and nursing home admission among rural older adults, Psychology and aging 12(4): 574-589.

Salive, M. E., K. S. Collins, D. J. Foley, and L. K. George. 1993. Predictors of nursing home admission in a biracial population, American Journal of Public Health 83(12): 1765-1767.

Salminen, V., J. Lindström, A. Louheranta, and M. Rastas. 2002. Ruokavalioja liikuntaneuvonta ehkäisevät diabeteksen puhkeamista, Suomen Lääkärilehti 57(12): 1379-82.

Schaefer, C., C. P. Quesenberry Jr, and S. Wi. 1995. Mortality following conjugal bereavement and the effects of a shared environment, American Journal of Epidemiology 141(12): 1142-1152.

Schmidt, R., M. M. Breteler, D. Inzitari, L. Fratiglioni, A. Hofman, and L. J. Launer. 2000. Prognosis with stroke in Europe: A collaborative study of population-based cohorts. Neurologic Diseases in the Elderly Research Group, Neurology 54(11 Suppl 5): S34-7.

Schwarz, P. E., J. Li, J. Lindström, and J. Tuomilehto. 2009. Tools for predicting the risk of type 2 diabetes in daily practice, Hormone and metabolic research = Hormonund Stoffwechselforschung = Hormones et metabolisme 41(2): 86-97.

Shapiro, E. and R. Tate. 1988. Who is really at risk of institutionalization? The Gerontologist 28(2): 237-245.

Social Insurance Institution of Finland. 1998. Statistical Yearbook of the Social Insurance Institution, Finland, 1997, T1:33. Helsinki: Social Insurance Institution.

Social Insurance Institution of Finland, 2008. Care Allowance for Pensioners 
[Homepage of Social Insurance Institution of Finland]. Available: http://www. kela.fi/in/internet/english.nsf/NET/230708153124HS?OpenDocument [2009, 27 May]

Soldo, B. J. 1981. The Living arrangments of the elderly in the near future, in Ageing, Social Change. S.B. Kiesler, J.N. Morgan and V.K. Oppenheimer (eds.) New York: Academic Press, pp. 491-512.

Speare, A.Jr, R. Avery, and L. Lawton. 1991. Disability, residential mobility, and changes in living arrangements, Journal of gerontology 46(3): S133-42.

STAKES. 1999. Second edition of Finnish version of the International Statistical Classification of Diseases and Related Health Problems, tenth revision. Volume 1. Helsinki: STAKES.

Statistics Finland. 2009. Published 15 May 2009, Volume of total output 20032009, trend and seasonally adjusted series (Figure) [Homepage of Statistics Finland], Available: http://www.tilastokeskus.fi/til/ktkk/2009/03/ ktkk_2009_03_2009-05-15_tie_001_en.html [2009, 9 June 2009] .

Statistics Finland. 2008. Väestö iän (5-v.) ja sukupuolen mukaan koko maa 1865-2007 (Population by 5-year age and gender). Available: http:// pxweb2.stat.fi/database/StatFin/vrm/vaerak/vaerak_fi.asp [2008, 11 June].

Statistics Finland. 2007. Published 31 May 2007, Väestöennuste 20072040 (population projection 2007-2040) [Homepage of Statistics Finland], Available: http://www.tilastokeskus.fi/til/vaenn/2007/ vaenn_2007_2007-05-31_tie_001.html.

Statistics Finland database 2007. Published 31 May 2007, Tilastotietokannat: Väestöennuste 2007 iän ja sukupuolen mukaan alueittain 2006-2040 (Statistical databases) [Homepage of Statistics Finland], Available: http:// pxweb2.stat.fi/database/StatFin/vrm/vaenn/vaenn_fi.asp [2009, 7 June].

Steinbach, U. 1992. Social networks, institutionalization, and mortality among elderly people in the United States, Journal of gerontology 47(4): S183-90.

Stroebe, W. and M. S. Stroebe. 1987. Bereavement and Health: The Psychological and Physical Consequences of Partner Loss. Cambridge: Cambridge University Press.

Sulkava, Raimo. 2005. Dementia, in Health in Finland. A. Aromaa, J. Huttunen, S. Koskinen and J. Teperi (eds.) Helsinki: Kustannus Oy Duodecim, pp. 226-228.

Sundberg, G., A. Bagust, and A. Terent. 2003. A model for costs of stroke services, Health policy (Amsterdam, Netherlands) 63(1): 81-94.

Tomiak, M., J. M. Berthelot, E. Guimond, and C. A. Mustard. 2000. Factors associated with nursing-home entry for elders in Manitoba, Canada, The journals of gerontology. Series A, Biological sciences and medical sciences 55(5): M279-87. 
Townsend, P. 1965. The effects of family structure on the likelihood of admission to an institution in old age: the application of a general theory, in Social structure and the family: generational relations. E. Shanas and G.F. Streib (eds.) Englewood Cliffs, NJ: Prentice-Hall.

Townsend, P. 1962. The last refuge. A survey of residential institutions and homes for the aged in England and Wales. London: Routledge \& Kegan.

Vaarama, M., A. Hakkarainen, and S. Laaksonen. 1999. Vanhusbarometri [1998]. Helsinki: Sosiaali- ja terveysministeriö.

Valvanne, Jaakko. 1992. Ikäihmisten terveystarkastuslöydösten ennustemerkitys. Helsinkiläisten 75-, 80- ja 85-vuotiaiden yhden vuoden seurantatutkimus. Helsinki: Geriatrian yksikkö, II sisätautien klinikka, Helsingin yliopisto.

Wikipedia 2009, 8 June 2009, Financial crisis of 2007-2009 [Homepage of Wikipedia, the free encyclopedia], Available: http://en.wikipedia.org/ wiki/Financial_crisis_of_2007\%E2\%80\%932008.

Wolinsky, F. D., C. M. Callahan, J. F. Fitzgerald, and R. J. Johnson. 1992. The risk of nursing home placement and subsequent death among older adults, Journal of gerontology 47(4): S173-82.

Wolinsky, F. D. and R. J. Johnson. 1992. Widowhood, health status, and the use of health services by older adults: a cross-sectional and prospective approach, Journal of gerontology 47(1): S8-16.

Woo, J., S. C. Ho, J. Lau, and Y. K. Yuen. 1994. Age and marital status are major factors associated with institutionalisation in elderly Hong Kong Chinese, Journal of epidemiology and community health 48(3): 306-309.

Woo, J., S. C. Ho, A. L. Yu, and J. Lau. 2000. An estimate of long-term care needs and identification of risk factors for institutionalization among Hong Kong Chinese aged 70 years and over, The journals of gerontology.Series A, Biological sciences and medical sciences 55(2): M64-9.

World Health Organization 2009, , Prevalence of diabetes in the WHO European Region [Homepage of World Health Organization], Available: http://www. who.int/diabetes/facts/world_figures/en/index4.html [2009, 27 May] .

Yaffe, K., P. Fox, R. Newcomer, L. Sands, K. Lindquist, K. Dane, and K. E. Covinsky. 2002. Patient and caregiver characteristics and nursing home placement in patients with dementia, JAMA : the journal of the American Medical Association 287(16): 2090-2097.

Young, M., B. Benjamin, and C. Wallis. 1963. The Mortality of Widowers, Lancet 13: $454-456$. 


\section{APPENDICES}

Appendix 1. Distribution of the study population in 1997 and proportions entering long-term institutional care from January 1998 to September 2003 by age, living arrangements, and area characteristics, men and women aged 65 and over, Finland

\begin{tabular}{|c|c|c|c|c|c|c|}
\hline & \multicolumn{2}{|c|}{ MEN } & \multicolumn{2}{|c|}{ WOMEN } & \multirow{2}{*}{\multicolumn{2}{|c|}{$\begin{array}{l}\text { Variables included } \\
\text { in sub-studies }\end{array}$}} \\
\hline & $\begin{array}{c}\text { Distribution } \\
\%\end{array}$ & $\begin{array}{l}\text { Entering } \\
\text { institution }\end{array}$ & $\begin{array}{c}\text { Distribution } \\
\%\end{array}$ & $\begin{array}{l}\text { Entering } \\
\text { institution }\end{array}$ & & \\
\hline & & $\%$ & & $\%$ & & \\
\hline Age (years) & & & & & $\mathrm{T}$ & III IV (a) \\
\hline $65-69$ & 38,5 & 4,2 & 29,7 & 4,0 & & \\
\hline $70-74$ & 29,5 & 7,7 & 27,2 & 8,8 & & \\
\hline $75-79$ & 17,4 & 13,5 & 20,9 & 17,0 & & \\
\hline $80-84$ & 9,5 & 22,3 & 13,5 & 28,9 & & \\
\hline $85-89$ & 4,2 & 29,5 & 6,7 & 39,3 & & \\
\hline $90+$ & 1,1 & 38,6 & 1,9 & 47,0 & & \\
\hline Living arrangements & & & & & I & II III IV (b) \\
\hline Living with spouse/married & 69,7 & 7,8 & 35,1 & 8,0 & & \\
\hline Living with partner/not married & 2,4 & 7,9 & 1,4 & 10,6 & & \\
\hline Living alone / married & 1,7 & 14,2 & 0,9 & 13,6 & & \\
\hline Living alone / widowed & 10,3 & 18,8 & 34,6 & 19,2 & & \\
\hline Living alone / divorced & 4,7 & 12,6 & 6,6 & 14,7 & & \\
\hline Living alone / never married & 5,2 & 13,8 & 7,9 & 18,9 & & \\
\hline Living with others & 6,1 & 14,3 & 13,6 & 17,7 & & \\
\hline First language & & & & & & II \\
\hline Finnish & 91,2 & 9,9 & 92,3 & 14,4 & & \\
\hline Swedish & 8,4 & 10,6 & 7,4 & 16,8 & & \\
\hline Other & 0,4 & 6,0 & 0,3 & 10,0 & & \\
\hline municipality & & & & & I & III \\
\hline Urban & 51,2 & 10,4 & 55,8 & 15,0 & & \\
\hline Semi-urban & 17,1 & 9,4 & 15,9 & 14,1 & & \\
\hline Rural & 31,8 & 9,7 & 28,2 & 14,1 & & \\
\hline Region of residence & & & & & I & II III IV \\
\hline Helsinki & 8,3 & 11,6 & 10,5 & 15,7 & & \\
\hline Rest of metropolitan area & 4,3 & 9,1 & 4,1 & 13,6 & & \\
\hline Rest of Uusimaa & 5,2 & 9,8 & 5,0 & 14,8 & & \\
\hline Itä-Uusimaa & 1,7 & 9,2 & 1,6 & 14,3 & & \\
\hline Varsinais-Suomi and Aland & 10,0 & 9,9 & 10,0 & 15,0 & & \\
\hline Satakunta & 5,4 & 10,0 & 5,4 & 14,9 & & \\
\hline Kanta-Häme & 3,7 & 9,3 & 3,7 & 15,1 & & \\
\hline Pirkanmaa & 9,0 & 11,9 & 9,2 & 16,6 & & \\
\hline Päijät-Häme & 3,9 & 9,3 & 4,1 & 13,8 & & \\
\hline Kymenlaakso & 4,3 & 11,6 & 4,3 & 16,8 & & \\
\hline South Karelia & 3,1 & 9,1 & 3,2 & 13,6 & & \\
\hline Etelä-Savo & 4,1 & 10,9 & 4,0 & 15,0 & & \\
\hline Pohjois-Savo & 5,4 & 9,0 & 5,5 & 12,7 & & \\
\hline North Karelia & 3,8 & 9,0 & 3,8 & 13,8 & & \\
\hline Central Finland & 5,4 & 9,6 & 5,2 & 13,5 & & \\
\hline South Ostrobothnia & 4,7 & 8,5 & 4,5 & 13,1 & & \\
\hline Ostrobothnia & 4,1 & 10,4 & 3,7 & 16,7 & & \\
\hline Central Ostrobothnia & 1,5 & 8,1 & 1,3 & 13,9 & & \\
\hline North Ostrobothnia & 6,3 & 9,4 & 5,7 & 13,2 & & \\
\hline Kainuu & 2,1 & 8,3 & 1,9 & 10,9 & & \\
\hline Lapland & 3,9 & 9,9 & 3,5 & 12,8 & & \\
\hline All & 100,0 & 10,0 & 100,0 & 14,6 & & \\
\hline $\mathbf{N}$ & 108474 & 10823 & 172248 & 25117 & & \\
\hline
\end{tabular}

(a) 1-year age-groups in substudies I-IV

(b) less categories in sub-study III, only those with a spouse or partner included in sub-study IV 
Appendix 2. Distribution of the study population in 1997 and proportions entering long-term institutional care from January 1998 to September 2003 by socio-economic and housing characteristics, men and women aged 65 and over, Finland

\begin{tabular}{|c|c|c|c|c|c|c|c|c|}
\hline & \multicolumn{2}{|c|}{ MEN } & \multicolumn{2}{|c|}{ WOMEN } & & & & \\
\hline & $\begin{array}{c}\text { Distribution } \\
\%\end{array}$ & $\begin{array}{c}\text { Entering } \\
\text { institution }\end{array}$ & $\begin{array}{c}\text { Distribution } \\
\%\end{array}$ & $\begin{array}{c}\text { Entering } \\
\text { institution }\end{array}$ & \multicolumn{4}{|c|}{$\begin{array}{l}\text { Variables included in } \\
\text { Sub-studies }\end{array}$} \\
\hline & & & & $\%$ & & & & \\
\hline Education & & & & & $T$ & $\pi$ & IIII & IV \\
\hline Tertiary & 13,6 & 7,7 & 8,0 & 12,0 & & & & \\
\hline Intermediate & 12,3 & 9,2 & 13,6 & 12,0 & & & & \\
\hline Basic or less & 74,1 & 10,5 & 78,4 & 15,3 & & & & \\
\hline Social class & & & & & I & $\|$ & III & \\
\hline Upper white-collar & 11,2 & 7,9 & 7,4 & 12,0 & & & & \\
\hline Lower white-collar & 14,8 & 9,4 & 26,1 & 12,6 & & & & \\
\hline Worker specialized & 28,8 & 10,7 & 17,1 & 18,1 & & & & \\
\hline Worker non-specialized & 16,9 & 10,1 & 25,5 & 13,0 & & & & \\
\hline Farmer & 19,6 & 10,8 & 16,9 & 17,0 & & & & \\
\hline Self-employed & 7,5 & 8,3 & 4,6 & 13,4 & & & & \\
\hline Other & 1,3 & 13,9 & 2,3 & 21,7 & I & \| & III & \\
\hline \multicolumn{9}{|l|}{ Home ownership } \\
\hline Owner & 83,8 & 9,0 & 78,1 & 13,1 & & & & \\
\hline Renter & 12,7 & 15,7 & 18,0 & 20,8 & & & & \\
\hline Other or unknown & 3,5 & 12,4 & 3,8 & 15,7 & & & & \\
\hline House type & & & & & I & $\|$ & III & \\
\hline Detached house & 55,7 & 8,4 & 42,7 & 11,9 & & & & \\
\hline Semi-detached house & 10,7 & 11,9 & 11,9 & 16,7 & & & & \\
\hline Apartment house with lift & 16,9 & 11,9 & 23,6 & 16,5 & & & & \\
\hline Apartment house without lift & 14,5 & 12,0 & 19,7 & 15,8 & & & & \\
\hline Other & 2,2 & 13,8 & 2,2 & 23,3 & & & & \\
\hline \multicolumn{9}{|l|}{ Level of equipment in dwelling } \\
\hline Well equipped & 79,0 & 9,8 & 81,6 & 14,5 & I & $\|$ & III & \\
\hline Poorly equipped & 8,9 & 10,4 & 8,3 & 14,4 & & & & \\
\hline Very poorly equipped & 12,1 & 10,9 & 10,1 & 15,4 & & & & \\
\hline Possession of car & & & & & I & $\|$ & III & \\
\hline Yes & 58,6 & 6,1 & 8,6 & 6,1 & & & & \\
\hline No & 40,8 & 15,5 & 90,9 & 15,4 & & & & \\
\hline Missing & 0,6 & 12,7 & 0,5 & 17,1 & & & & \\
\hline \multicolumn{9}{|l|}{ Income } \\
\hline 5. Quintile (highest) & 23,9 & 7,4 & 17,5 & 10,6 & I & $\|$ & III & IV \\
\hline 4. Quintile & 23,1 & 8,1 & 18,3 & 10,5 & & & & \\
\hline 3. Quintile & 21,0 & 10,2 & 20,1 & 13,2 & & & & \\
\hline 2. Quintile & 17,3 & 12,2 & 20,8 & 16,2 & & & & \\
\hline 1. Quintile (lowest) & 14,7 & 14,2 & 23,4 & 20,5 & & & & \\
\hline All & 100,0 & 10,0 & 100,0 & 14,6 & & & & \\
\hline $\mathbf{N}$ & 108474 & 10823 & 172248 & 25117 & & & & \\
\hline
\end{tabular}


Appendix 3. Prevalence of chronic medical conditions in the study population in 1997 and proportions entering long-term institutional care from January 1998 to September 2003 by these conditions, men and women aged 65 and over, Finland

\begin{tabular}{|c|c|c|c|c|c|c|c|c|}
\hline & \multicolumn{2}{|c|}{ MEN } & \multicolumn{2}{|c|}{ WOMEN } & \multirow{2}{*}{\multicolumn{4}{|c|}{$\begin{array}{c}\text { Variables included in } \\
\text { sub-classes }\end{array}$}} \\
\hline & $\begin{array}{c}\text { Prevalence } \\
\%\end{array}$ & $\begin{array}{l}\text { Entering } \\
\text { institution }\end{array}$ & $\begin{array}{c}\text { Prevalence } \\
\%\end{array}$ & $\begin{array}{l}\text { Entering } \\
\text { institution }\end{array}$ & & & & \\
\hline Cancer & 5,1 & 13,6 & 4,1 & 17,0 & 1 & II & III & IV \\
\hline Diabetes & 10,1 & 15,2 & 10,1 & 21,7 & I & II & III & IV \\
\hline Dementia & 0,6 & 55,3 & 0,6 & 70,2 & i & II & III & IV \\
\hline Psychosis & 1,8 & 19,4 & 2,9 & 28,6 & I & II & III & IV \\
\hline Depressive symptoms & 6,5 & 21,3 & 10,7 & 27,8 & I & II & III & IV \\
\hline Other mental health disorders & 4,3 & 26,3 & 5,4 & 33,4 & I & II & III & IV \\
\hline Parkinson's disease & 1,9 & 29,5 & 1,7 & 40,0 & 1 & II & III & IV \\
\hline Other neurological diseases & 4,7 & 17,9 & 4,0 & 24,6 & I & II & III & IV \\
\hline Heart disease & 29,7 & 11,7 & 26,1 & 20,2 & I & II & III & IV \\
\hline Stroke & 2,5 & 26,6 & 1,6 & 35,2 & I & II & III & IV \\
\hline Chronic asthma and COPD* & 7,7 & 10,5 & 6,6 & 13,8 & I & II & III & IV \\
\hline Other respiratory diseases & 4,1 & 18,4 & 2,9 & 26,0 & I & II & III & IV \\
\hline Arthritis & 2,5 & 11,0 & 4,8 & 19,0 & I & II & III & IV \\
\hline Osteoarthritis & 1,9 & 11,6 & 2,9 & 17,2 & I & II & III & IV \\
\hline Hip fracture & 0,5 & 31,5 & 1,0 & 38,6 & I & II & III & IV \\
\hline Other accident or violence & 3,5 & 17,5 & 4,0 & 29,0 & I & II & III & IV \\
\hline Other hospital diagnoses & 25,5 & 14,5 & 26,1 & 22,2 & I & II & III & IV \\
\hline Other diseases & 33,9 & 10,9 & 41,9 & 16,5 & 1 & II & III & IV \\
\hline At least one of the diseases & 71,7 & 11,6 & 73,7 & 17,1 & & & & \\
\hline None of the diseases & 28,3 & 5,8 & 26,3 & 7,6 & & & & \\
\hline All & 100,0 & 10,0 & 100,0 & 14,6 & & & & \\
\hline $\mathrm{N}$ & 108474 & 10823 & 172248 & 25117 & & & & \\
\hline
\end{tabular}


ORIGINAL PUBLICATIONS 
European Journal of Public Health, Vol. 18, No. 1, 77-84

C) The Author 2007. Published by Oxford University Press on behalf of the European Public Health Association. All rights reserved. doi:10.1093/eurpub/ckm025 Advance Access published on June 11, 2007

\title{
Chronic conditions and the risk of long-term institutionalization among older people
}

\author{
Elina K. Nihtilä, Pekka T. Martikainen², Seppo V.P. Koskinen³, \\ Antti R. Reunanen ${ }^{3}$, Anja M. Noro ${ }^{4}$, Unto T. Häkkinen ${ }^{4}$
}

\begin{abstract}
Background: As the public expenditure on long-term care is likely to increase with the ageing of the population, identifying chronic medical conditions associated with the risk of long-term institutionalization is of particular interest. However, there is little systematic evidence showing how chronic medical conditions, other than dementia, affect the risk of entering into institutional care in the general older population. Methods: We used population-based follow-up data on Finnish older people aged 65 and over $(n=280722)$, to estimate the impact of different chronic conditions on the risk of long-term institutionalization. Furthermore, we analysed which chronic conditions were more strongly associated with the risk of institutionalization than with the risk of death without institutionalization. Cox proportional hazard regression models were used. Results: Our results showed that dementia, Parkinson's disease, stroke, depressive symptoms, other mental health problems, hip fracture and diabetes were strongly associated with increased risk of long-term institutionalization, independent of socio-demographic confounders and the presence of other chronic conditions. All these conditions raised the risk of institutionalization by $50 \%$ or more. Dementia, Parkinson's disease, stroke and mental health problems were more strongly associated with the risk of institutionalization than with the risk of death without institutionalization. Conclusions: Overall, these results show that the future demand for institutional care depends not only on the ageing of the population but also on the development
\end{abstract} of the prevalence and severity of chronic conditions associated with institutionalization.

Keywords: chronic disease, follow-up study, institutionalization, older adults, population based

\section{Introduction}

$\mathrm{A}^{\mathrm{s}}$ the public expenditure on long-term care is likely to $A_{\text {increase with the ageing of the population, a better }}$ understanding of the factors related to long-term institutional care is of particular interest. Several population-based prospective studies have shown that functional disability ${ }^{1-6}$ and cognitive impairment ${ }^{1,2}$ are associated with institutionalization, but systematic evidence on the effects of different chronic diseases on institutionalization is scarce. Dementia has been shown to increase the risk of institutionalization, independent of comorbid conditions ${ }^{8}$ and functional disabilities. ${ }^{5,6,9}$ Furthermore, population-based cross-sectional studies indicate that neurological diseases in general, ${ }^{10}$ and some specific neurological diseases such as Parkinson's disease $^{11}$ and stroke, ${ }^{12}$ are associated with living in an institution. However, because of the cross-sectional design of these studies it is difficult to determine whether the presence of disease predates institutional entry or not. In addition, evidence on the effects of other chronic diseases on institutionalization among general older populations is rarely available, and the effects of different diseases have seldom been studied simultaneously. Furthermore, evidence of the effect of some medical conditions, such as hip fracture, is partly inconsistent. ${ }^{5,6}$

1 Population Research Unit, Department of Sociology, University of Helsinki, Finland

2 Helsinki Collegium for Advanced Studies, University of Helsinki, Finland

3 Department of Health and Functional Capacity, National Public Health Institute (KTL), Finland

4 Centre for Health Economics (CHESS), National Research and Development Centre for Welfare and Health (STAKES), Finland Correspondence: Elina K. Nihtilä, Population Research Unit, Department of Sociology, PO Box 18, FIN-00014, University of Helsinki, tel: +358 919123882, fax: +358 919123967, e-mail: elina.k.nihtila@helsinki.fi
Using population-based survival data with continuous time scale of institutionalization, we assessed which chronic conditions were most strongly associated with long-term institutionalization. More specifically, we examined how different chronic conditions were associated with entry into institutional care, independent of socio-demographic confounders and other chronic conditions, and evaluated which chronic conditions were associated more strongly with the risk of institutionalization than with the risk of death without institutionalization.

\section{Methods}

\section{Register-based data}

The data were based on a $40 \%$ individual-level sample of the total Finnish population aged 65 and over on 31 December 1997 (301 263 persons), drawn from a population registration database at Statistics Finland using simple random sampling. These data are collected annually from different administrative records to provide Labour-Force Statistics, ${ }^{13}$ and they contain all persons living in Finland and detailed socio-demographic information. This baseline sample, already linked with dates of death, was linked with information on institutional care and prior hospital diagnoses provided by the National Research and Development Centre for Welfare and Health (STAKES), and with information from medication registers provided by the Social Insurance Institution. The data linkage was carried out at Statistics Finland using personal identification codes (TK 53-576-04 and TK 53-499-05). We excluded all those who were already institutionalized $(5.86 \%)$ or who for some other reason did not reside in private households at baseline $(0.96 \%)$. The effective study sample, representative of the total Finnish community-living older population, consisted of 280722 persons, who were followed for first entry into long-term institutional care or death from 1 January 1998 to 30 September 2003. 


\section{Long-term institutional care}

Long-term institutional care was defined as 24-hour care in nursing homes, service homes, hospitals and health centres lasting for over 90 days or confirmed by a long-term care decision. Long-term psychiatric care was included. The over90 -days criterion was met if a patient had stayed in the same institution or successively in different institutions for the time required. About $75 \%$ of first stays in long-term institutional care that started during the follow-up began in hospitals or health centres and $25 \%$ in nursing or service homes.

The information on long-term institutional care was based on the Client Censuses of Health Care (including hospitals and health centres), and on the Client Censuses of Social Care (including nursing and service homes), both of which were carried out at the end of every year from 1997 to 2003, and on the annual discharge data containing information on stays which were completed. The registers of Health Care have been collected since $1967^{14}$ and are regarded as very accurate, while those of Social Care are known to be less complete. Approximately $9 \%$ of the nursing and service homes providing 24-hour care did not participate in the Client Census of Social Care in $2003 .{ }^{15}$ However, it is very likely that the proportion of care episodes that were undetected from the Client Census is much smaller, as institutions not participating in the Census are likely to be small. It is also likely that the nursing and service home stays are somewhat better covered in the censuses than in the discharge data ${ }^{16}$ which may have underestimated the number of short stays. We used both Client Censuses and discharge data to minimize under coverage in nursing homes, but recognize that the absolute level of institutionalization may be a slight underestimate in our study.

\section{Chronic conditions}

This study used 18 dichotomous indicators of chronic medical conditions, including cancer, diabetes, dementia, psychosis, depressive symptoms, other mental health disorders, Parkinson's disease, other neurological diseases, heart disease, stroke, chronic asthma or other similar chronic obstructive pulmonary diseases, other respiratory diseases, arthritis, osteoarthritis, hip fracture, other conditions related to accident or violence, other hospital diagnoses and other chronic diseases that give the right to reimbursement for drug costs (Appendix). We mainly used three register sources to assess chronic medical conditions: (i) the principal cause of hospitalization during 1996-97, (ii) the right to reimbursement for drug costs under the Special Refund Categories due to certain diagnosed chronic medical conditions during 1997 and (iii) purchase of prescription medication during 1996-97. The persons studied were categorized as having a chronic condition if they had it according to at least one of these sources.

The principal cause of hospitalization was based on the Tenth Revision of the International classification of diseases (ICD10), ${ }^{17}$ the right to reimbursement for drug costs under the Special Refund Categories was based on the Finnish disease classification of the Social Insurance Institution, ${ }^{18}$ and purchases of prescription medication were based on the Anatomical Therapeutic Chemical Classification (ATC). ${ }^{19,20}$ The Finnish disease classification was based on the drug reimbursement system of the Social Insurance Institution. Certain chronic medical conditions were reimbursed under the Special Refund Categories which covered $75 \%$ or $100 \%$ of the costs of a single drug purchase exceeding a fixed deductible of 4.20 euros. $^{18,21}$ To receive reimbursement, the patient had to submit to the Social Insurance Institution a doctor's certificate stating the illness, its severity and the medication required to treat it. The patient's wealth, age or affiliation to other special groups did not affect reimbursement, but the severity of the illness did. ${ }^{21}$

\section{Control variables}

We used age, living arrangements, socio-economic measures, housing conditions, region of residence and urbanicity as control variables which were measured at baseline. Age and living arrangements are associated with both institutionalization $^{1}$ and health, ${ }^{22,23}$ and socio-economic characteristics and housing conditions were associated with institutionalization in our data. Region of residence and urbanicity were adjusted for to control for differences in the supply of and access to institutional care between the areas.

Living arrangement categories were: living with a spouse or partner, living alone and being married, living alone and being widowed, living alone and being divorced, living alone and being never married and living with others. The three educational categories were: tertiary education, intermediate education, and basic education or unknown. Disposable income of the household was adjusted for the number of persons in the household according to the OECD equivalence scale, ${ }^{24}$ with the exception of children who were weighted as adults because of the data restrictions. Home ownership categories were: owners, renters, and others and unknown. The possession of a car was categorized: yes, no and missing. The house type categories were: detached house, semidetached house, apartment house with lift, apartment house without lift and other. The level of equipment in a dwelling was categorized into three categories: well-equipped, poorlyequipped and very poorly-equipped. A dwelling was regarded as well-equipped if it had piped water, sewer, hot water, flush toilet, washing facilities (shower/bath/sauna) and central or fixed electric heating, as poorly-equipped if it lacked washing facilities or central or fixed electric heating, and as very poorlyequipped if it lacked piped water, sewer, hot water or flush toilet.

Region of residence was categorized into 20 official regions (NUTS3), with the exception of the region of Uusimaa which was divided into three parts (Helsinki, the metropolitan area, and the rest of Uusimaa), and the Åland Islands which were combined with Southwest Finland. The urbanicity was based on the proportion of people living in different built-up areas and the population of the largest built-up area. The municipality was categorized as urban if at least $90 \%$ of the population lived in built-up areas and the largest built-up area had at least 15000 residents, as semi-urban if $60-90 \%$ lived in built-up-areas and the largest built-up area had $4000-15000$ residents, and as rural if under $60 \%$ lived in built-up-areas and the largest built-up area had under 15000 residents or if $60-90 \%$ lived in built-up-areas and the largest built-up area had under 4000 residents. A built-up area was defined as a group of houses with at least 200 residents and where the distance between the houses did not normally exceed $200 \mathrm{~m}$. The distribution of the study cohort by the control variables (expect NUTS3) is presented in table 1.

\section{Statistical methods}

The Cox proportional hazards regression models were used to estimate the determinants of entry into institutional care. Time to first entry was measured in days. A study person was censored at the time of death or at the end of the follow-up. Separate Cox regression models were fitted to estimate the determinants of death without entering into institutional care. A study person was censored at the time of institutionalization. All statistical analyses were performed with StataSE $8^{25}$ separately for men and women, as diabetes, psychoses, 
Table 1 The distribution of Finnish community-living older women and men by socio-demographic characteristics

\begin{tabular}{|c|c|c|}
\hline & $\begin{array}{l}\text { Women } \\
\text { Distribution } \\
\text { (\%) }\end{array}$ & $\begin{array}{l}\text { Men } \\
\text { Distribution } \\
\text { (\%) }\end{array}$ \\
\hline Mean age (SD) & $74.2(6.7)$ & $72.6(6.1)$ \\
\hline \multicolumn{3}{|l|}{ Living arrangements } \\
\hline Living with spouse or partner & 36.4 & 72.0 \\
\hline Living alone/married & 0.9 & 1.7 \\
\hline Living alone/widowed & 34.6 & 10.3 \\
\hline Living alone/divorced & 6.6 & 4.7 \\
\hline Living alone/never married & 7.9 & 5.2 \\
\hline Living with others & 13.6 & 6.1 \\
\hline \multicolumn{3}{|l|}{ Income } \\
\hline 5. Quintile (highest) & 17.5 & 23.9 \\
\hline 4. Quintile & 18.3 & 23.1 \\
\hline 3. Quintile & 20.1 & 21.0 \\
\hline 2. Quintile & 20.8 & 17.3 \\
\hline 1. Quintile (lowest) & 23.4 & 14.7 \\
\hline \multicolumn{3}{|l|}{ Education } \\
\hline Tertiary & 8.0 & 13.6 \\
\hline Intermediate & 13.6 & 12.3 \\
\hline Basic or unknown & 78.4 & 74.1 \\
\hline \multicolumn{3}{|l|}{ Home ownership } \\
\hline Owner & 78.1 & 83.8 \\
\hline Renter & 18.0 & 12.7 \\
\hline Other or unknown & 3.8 & 3.5 \\
\hline \multicolumn{3}{|l|}{ Possession of car } \\
\hline Yes & 8.6 & 58.6 \\
\hline No & 90.9 & 40.8 \\
\hline Missing & 0.5 & 0.6 \\
\hline \multicolumn{3}{|l|}{ House type } \\
\hline Detached house & 42.7 & 55.7 \\
\hline Semi-detached house & 11.9 & 10.7 \\
\hline Apartment house with lift & 23.6 & 16.9 \\
\hline Apartment house without lift & 19.7 & 14.5 \\
\hline Other & 2.2 & 2.2 \\
\hline \multicolumn{3}{|l|}{ Level of equipment in dwelling } \\
\hline Well equipped & 81.6 & 79.0 \\
\hline Poorly equipped & 8.3 & 8.9 \\
\hline Very poorly equipped & 10.1 & 12.1 \\
\hline \multicolumn{3}{|l|}{ Urbanicity } \\
\hline Urban & 55.8 & 51.2 \\
\hline Semi-urban & 15.9 & 17.1 \\
\hline Rural & 28.2 & 31.8 \\
\hline All & 100.0 & 100.0 \\
\hline$N$ & 172248 & 108474 \\
\hline
\end{tabular}

Note: Finnish regions excluded from the table

depressive symptoms, other neurological diseases, stroke, chronic asthma, arthritis, and conditions related to accidents or violence were differently associated with the risk of institutionalization for the sexes.

\section{Results}

\section{The impact of chronic conditions on institutionalization}

Almost $15 \%$ of older women and $10 \%$ of older men entered into long-term institutional care during the follow-up (table 2). Entering institutional care was associated with several chronic conditions. Older people with dementia, Parkinson's disease and hip fracture had the highest rates of institutionalization (women: $70 \%, 40 \%$ and $39 \%$, men: $55 \%, 30 \%$ and $32 \%)$.

After controlling for socio-demographic confounders and other chronic conditions, several chronic conditions were still associated with institutionalization (table 2). In both men and women, dementia and Parkinson's disease raised the risk of institutionalization the most. Furthermore, psychosis, stroke, other mental health problems, depressive symptoms, hip fracture and diabetes were strongly associated with institutionalization. All these conditions raised the risk of institutionalization by $50 \%$ or more, except for psychose in men which raised the risk by $40 \%$. Also other conditions related to accidents or violence, arthritis, other neurologica diseases, cancer, respiratory diseases other than asthma, other hospital diagnoses, heart disease and other chronic diseases raised the risk of institutionalization. Chronic asthma was associated with institutionalization only among men. Osteoarthritis was not associated with institutionalization.

We further tested for proportionality of hazards over time. Parkinson's disease was the only chronic condition for which the relative risk of institutionalization rose during the follow-up. In contrast, for depression and other hospital diagnoses the relative risk of institutionalization declined during the follow-up among both men and women.

\section{Comparing relative institutionalization and mortality rates by chronic condition}

In both men and women, dementia, Parkinson's disease, psychosis, depressive symptoms, other mental health disorders and stroke were more strongly associated with the relative risk of institutionalization than with the relative risk of death without institutionalization, after controlling for sociodemographic confounders and the presence of comorbid conditions (figure 1). Our results, not shown here, indicated that the institutionalized older adults with dementia, Parkinson's disease, mental health problems or stroke stayed in institutions for longer periods than those with other conditions measured in our study. In contrast, cancer and heart diseases were more strongly associated with the risk of death without institutionalization than with the risk of institutionalization.

\section{Discussion}

\section{The impact of chronic conditions on institutionalization}

Our results indicate that dementia and Parkinson's disease were the strongest determinants of institutionalization in both genders, after adjustment for socio-demographic confounders and for other diseases. Furthermore, stroke, depressive symptoms, other mental health problems, hip fracture and diabetes were strongly associated with institutionalization. All these conditions raised the risk of institutionalization by $50 \%$ or more. Because of the large number of study subjects followed for institutionalization, many other chronic conditions were also statistically significant predictors of institutionalization despite the relative weakness of some effects.

As most previous studies on institutionalization include only older adults with certain specific disabilities, results on the effects of chronic conditions in the general older population are scarce. However, our results are consistent with the few earlier population-based findings showing that dementia is a strong predictor of institutionalization, ${ }^{5-7,9}$ and confirms findings of Banaszak-Holl et al. ${ }^{9}$ indicating that stroke, mental health problems and diabetes are associated with institutionalization, independent of various sociodemographic confounders. Furthermore, Valiyeva et al. ${ }^{26}$ found that diabetes increased the risk of institutionalization, independently of socio-demographic confounders and baseline medical conditions, especially when combined with lifestylerelated risk factors such as smoking, obesity or physical inactivity. However, Banaszak-Holl et al. ${ }^{9}$ measured date of admission into nursing home with surveys carried out every 2 or 3 year, so that nursing home stays that were completed between the surveys were not included. This could have underestimated the effects of certain diseases, such as cancer, 


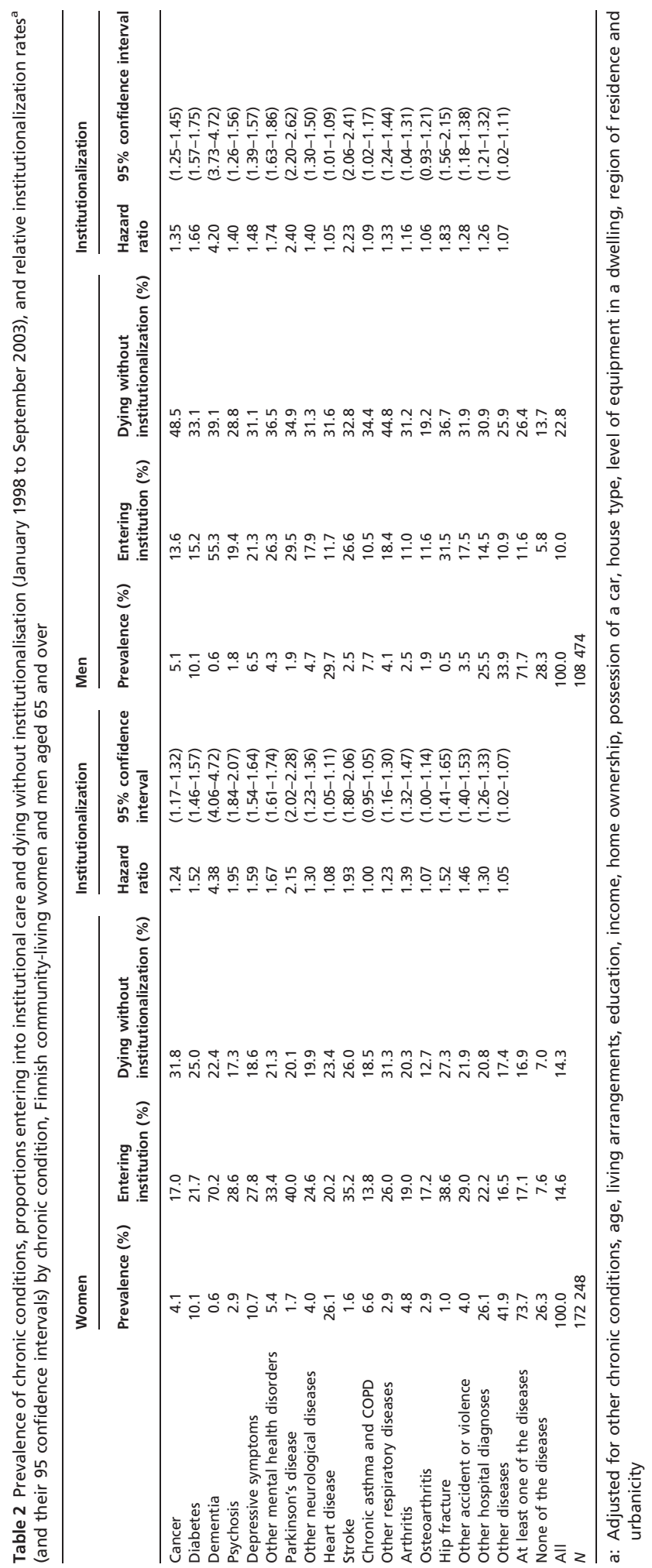



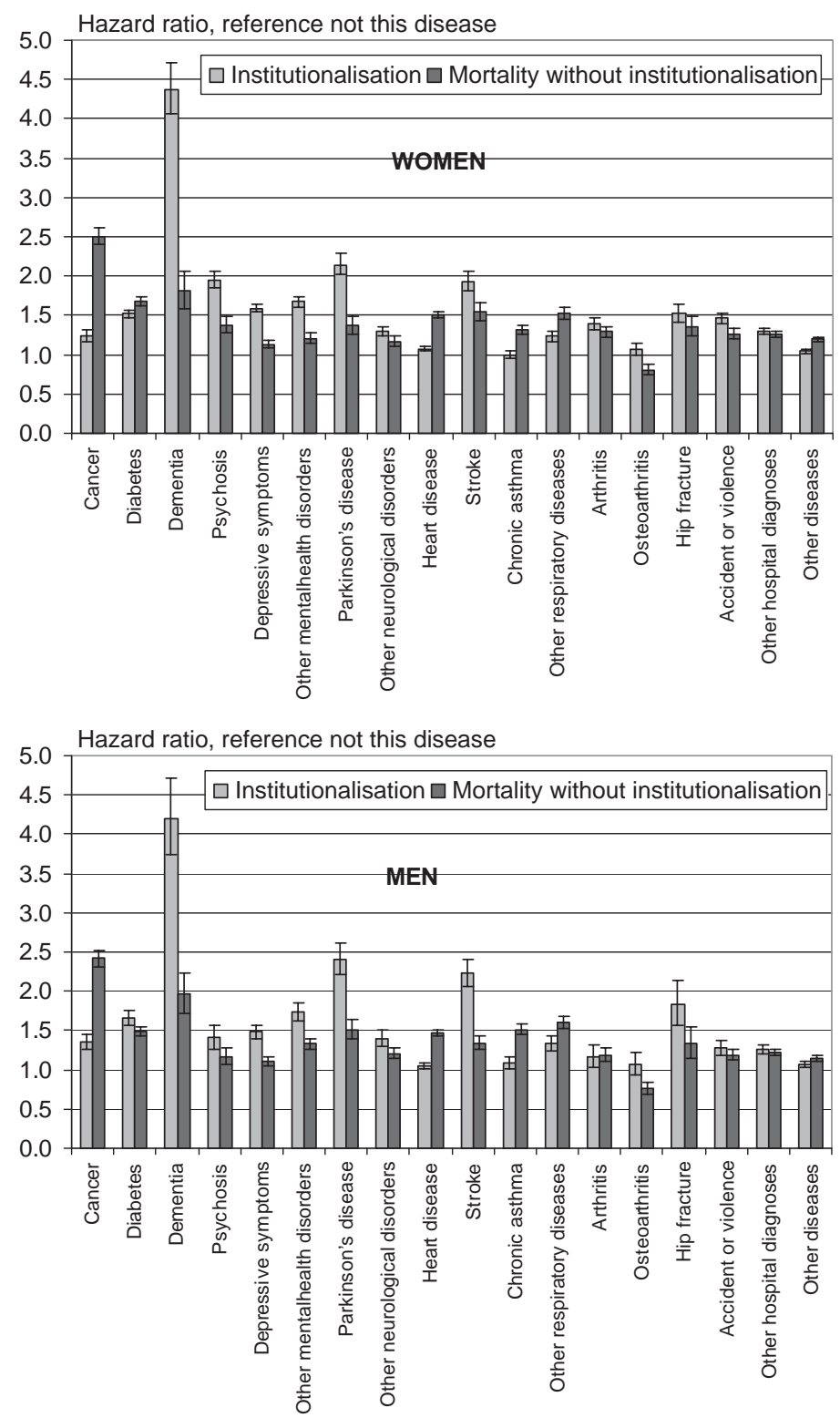

Figure 1 Relative institutionalization and mortality rates without institutionalization by chronic condition and their $95 \%$ confidence intervals, Finnish community-living women and men aged 65 and over (Adjusted for other chronic conditions, age, living arrangements, education, income, home ownership, possession of a car, house type, level of equipment in a dwelling, region of residence and urbanicity)

that cause institutionalization for shorter periods at the proximity of death. However, in a continuous follow-up study of older Canadians living in Manitoba, Tomiak et al. ${ }^{6}$ were able to detect shorter nursing home stays more accurately. Their results showed that Alzheimer's disease and dementia, and other mental disorders raised the risk of nursing home admission among both men and women, and stroke and musculoskeletal disorders only among men. However, Tomiak et al. ${ }^{6}$ analysed nursing-home admission after adjustment for functional disability which could have underestimated the effects of conditions (e.g. stroke, diabetes, hip fracture) which are likely to cause functional disability. For example, Banaszak-Holl et al. ${ }^{9}$ showed that the effects of stroke and diabetes on institutionalization disappear after controlling for functional disability. ${ }^{9}$ This indicates that the effects of stroke and diabetes are largely mediated through functional disability. In a longitudinal study of Swedes over 75 years of age living in an urban district of Stockholm, 
Aguero-Torres et al. ${ }^{5}$ showed that dementia and hip fracture raised the probability of institutionalization, independent of functional disability. This could mean that dementia and hip fracture have effects that go beyond functional disability, such as heavy care giving burden to relatives. Our study supports the Swedish result ${ }^{5}$ that hip fracture markedly increases the risk of institutionalization.

Our follow-up study supports previous cross-sectional evidence of the association between Parkinson's disease and living in an institution that has been reported for older Canadians, ${ }^{27}$ Europeans ${ }^{11}$ and Hong Kong Chinese. ${ }^{28}$ Few previous studies have examined whether cancer, ${ }^{5,6,9}$ heart disease $^{5,6,9}$ and arthritis ${ }^{6,9}$ are associated with institutionalization. Overall, previous studies have suggested that cancer and heart disease are not associated with institutionalization, after adjustment for socio-demographic confounders ${ }^{9}$ and functional disability. ${ }^{5,6}$ In contrast to previous studies, we found that cancer raised the risk of institutionalization, after adjustment for socio-demographic confounders. In addition to different modelling strategies, these differing results could be related mainly to two factors. First, we included institutional care provided in general hospitals. Cancer patients who need intensive treatment or palliative care before death are more likely to move into general hospitals than nursing homes or mental hospitals. In Finland, publicly provided palliative care is mainly given in hospitals. Second, our study identified only those cancer cases that were recently treated; untreated or cured cancers were excluded. Furthermore, in our exceptionally large data set, heart disease was a statistically significant, albeit a very weak predictor of institutionalization.

As many chronic diseases tend to cause decline in functional status, the effects of chronic diseases on entering into institutional care are likely to be mediated by the onset of functional disability. Several prospective studies have shown that stroke or transient ischaemic attack, diabetes, arthritis, hip or other fractures and hypertension are associated with decline in functional status, ${ }^{29}$ as well as dementia, ${ }^{30}$ and Parkinson's disease. $^{31}$ At older ages, admission to institutional care is in most cases preceded by a professional assessment of functional disability and thus routine adjustment for functional disability in the analyses of institutionalization tends to underestimate the effects of medical conditions that cause functional disability. As our register-based data did not contain information on functional disability, we were not able to examine the mechanisms, such as different aspects of functional disability, through which chronic conditions affect institutionalization.

Our results showed that diabetes, one of the most common chronic diseases worldwide, was strongly associated with institutionalization. As the prevalence of diabetes is estimated to increase in the future, ${ }^{32,33}$ the costs of long-term institutional care related to diabetes could also increase. The population attributable risk percentage of institutionalization due to diabetes was even higher than due to Parkinson's disease $(5.3 \%$ vs. $2.1 \%)$ because diabetes is more common. Lifestyle changes that affect obesity and physical inactivity, the two major risk factors for type 2 diabetes, ${ }^{33,34}$ are required to level off the potential future increase in long-term care expenses associated with diabetes. In addition, further research is needed to assess the effect of chronic diseases on institutionalization in different population subgroups.

\section{Comparing relative institutionalization and mortality rates by chronic condition}

Comparison of the relative institutionalization and mortality rates by chronic condition showed that mental health problems (psychosis, depressive symptoms and other mental health problems) and specific neurological disorders (e.g. dementia, Parkinson's disease, stroke) were more strongly associated with the risk of institutionalization than with the risk of death without institutionalization. That these conditions affect institutionalization more than mortality is related to two related processes. First, these conditions tend to a have long-term disability impact on older individuals' lives, and older people institutionalized with the preceding neurological or mental problems stay in institutions for longer periods than older people with other chronic conditions. Second, because of this disability impact, some of the neurological conditions, such as dementia ${ }^{35}$ and stroke, ${ }^{36}$ are known to be highly burdensome to the caregiver, which could strengthen families' intentions to seek institutional care for the older person.

\section{Considerations on data and measurement of disease prevalence}

Our data on disease prevalence are based on registration data of in-patient hospital care over a period of two years prior to baseline and on information from two different medication registers. In general, the prevalence rates obtained in this study were quite close to those derived from population-based clinical examinations and other sources (e.g. diabetes, ${ }^{37}$ heart disease, ${ }^{37}$ Parkinson's disease, ${ }^{38}$ stroke, $^{37}$ depression, ${ }^{39,40}$ psychosis, ${ }^{41}$ cancer $\left.^{42}\right)$. The two notable exceptions were dementia and osteoarthritis. Our study appears to underestimate the prevalence of dementia, covering only about $10 \%$ of the prevalence obtained in clinical data sets in Finland ${ }^{43}$ and elsewhere in Europe ${ }^{44}$ but provided similar estimates of the prevalence of dementia that Tomiak et al. ${ }^{6}$ reported for older Canadians. We were only able to identify those persons with dementia who had received hospital care due to dementia, and these cases are likely to represent the most severe forms of dementia. Furthermore, our study appears to cover only about $15 \%$ of the prevalence of osteoarthritis among Finnish older people. ${ }^{37}$ Common musculoskeletal disorders that seldom lead to hospitalization or specific medicinal treatment cannot be covered using register-based data sets. The osteoarthritis cases we were able to identify were based on hospital diagnoses. In our study, osteoarthritis was not associated with the risk of institutionalization. This could be related to the fact that those older adults hospitalized for knee or hip osteoarthritis can undergo endoprosthesis operations, which improve their functional capacity and decrease their need for institutional care.

However, nationally representative data that link different administrative registers provided several empirical and methodological advantages, as missing information and loss due to follow-up are minimal. This is unique as prospective studies on institutionalization based on questionnaires can suffer from lack of complete follow-up due to attrition related to severe disability or due to long periods between the surveys. The latter problem can easily overestimate the effects of certain conditions that cause very long periods of institutional care, such as dementia, and underestimate the effects of other important conditions, such as diabetes or cancer, that cause shorter periods of institutional care. Furthermore, our data covered several types of institutions that provided long-term care, including nursing homes, services homes, hospitals and health centres. In addition, in Finland, information on socioeconomic factors, such as disposable income, originating from the Tax Administration, is more reliable than self-reported income based upon questionnaires, especially in very old age.

\section{Conclusions}

Our study is unique in that we have systematically assessed the effects of a broad range of diseases on admission into institutional care in a nationally representative follow-up study of over 280000 older men and women. Our study was 
the first population-based follow-up study to show that Parkinson's disease, with dementia, is one of the strongest predictors of institutionalization. Furthermore, Parkinson's disease was the only chronic condition for which the relative risk of institutionalization rose during the follow-up. This is fully consistent with the nature of Parkinson's disease as a progressive disease that is likely to cause gradual decline in functional status over time. ${ }^{45}$ These results may have important implications for targeting home help services for older adults with chronic diseases to delay or prevent their institutionalization. Our results indicate that the future demand for institutional care depends not only on the ageing of the population, but also on the development of the prevalence and severity of chronic diseases among older people.

\section{Acknowledgements}

We thank Statistics Finland, the National Research and Development Centre for Welfare and Health (STAKES), and the Social Insurance Institution for making the data available to us. This study was supported by the Finnish Post-Graduate School in Social Sciences (SOVAKO) and by the Academy of Finland (210752 and 205631). This research was part of an EU-funded research programme on the Future Elderly Living Conditions In Europe (FELICIE). Earlier versions of these results were presented at the 25th International Population Conference of the International Union for the Scientific Study of Population, in Tours, France, on 8-23 July 2005.

\section{Key points}

- Systematic evidence showing how chronic conditions, other than dementia, affect the risk of entering into institutional care in the general older population is meagre.

- We assessed the effects of a broad range of diseases on admission into long-term institutional care in a nationally representative follow-up study of over 280000 Finnish older adults.

- Parkinson's disease was, after dementia, the strongest predictor of institutionalization, followed by stroke, mental health problems, hip fracture, and diabetes.

- The results have important implications for targeting home help services for older people to delay or prevent institutionalization

- The future demand for institutional care depends not only on the ageing of the population, but on the development of the prevalence of chronic diseases.

\section{References}

1 Branch LG, Jette AM. A prospective study of long-term care institutionalization among the aged. Am J Public Health 1982;72(12):1373-9.

2 Shapiro E, Tate R. Who is really at risk of institutionalization?. Gerontologist 1988;28(2):237-45.

3 Steinbach U. Social networks, institutionalization, and mortality among elderly people in the United States. J Gerontol 1992;47(4):S183-90.

4 Wolinsky FD, Callahan CM, Fitzgerald JF, Johnson RJ. The risk of nursing home placement and subsequent death among older adults. J Gerontol 1992;47(4):S173-82.

5 Aguero-Torres $\mathrm{H}$, von Strauss E, Viitanen M, et al. Institutionalization in the elderly: the role of chronic diseases and dementia. Cross-sectional and longitudinal data from a population-based study. J Clin Epidemiol 2001;54(8):795-801.
6 Tomiak M, Berthelot JM, Guimond E, Mustard CA. Factors associated with nursing-home entry for elders in Manitoba, Canada. J Gerontol A Biol Sci Med Sci 2000;55(5):M279-87.

7 Jagger C, Andersen K, Breteler MM, et al. Prognosis with dementia in Europe: a collaborative study of population-based cohorts. Neurologic Diseases in the Elderly Research Group. Neurology 2000;54:(11 Suppl 5): S16-S20.

8 Eaker ED, Vierkant RA, Mickel SF. Predictors of nursing home admission and/or death in incident Alzheimer's disease and other dementia cases compared to controls: a population-based study. J Clin Epidemiol 2002;55(5):462-8.

9 Banaszak-Holl J, Fendrick AM, Foster NL, et al. Predicting nursing home admission: estimates from a 7-year follow-up of a nationally representative sample of older Americans. Alzheimer Dis Assoc Disord 2004;18(2):83-9.

10 Liu LF, Tinker A. Factors associated with nursing home entry for older people in Taiwan, Republic of China. J Interprof Care 2001;15(3):245-55.

11 Berger K, Breteler MM, Helmer C, et al. Prognosis with Parkinson's disease in europe: a collaborative study of population-based cohorts. Neurologic Diseases in the Elderly Research Group. Neurology 2000;54:(11 Suppl 5): S24-7.

12 Schmidt R, Breteler MM, Inzitari D, et al. Prognosis with stroke in Europe: a collaborative study of population-based cohorts. Neurologic Diseases in the Elderly Research Group. Neurology 2000;54:(11 Suppl 5):S34-7.

13 Työssäkäyntitilaston laatuseloste [The quality of the Labour-Force Statistics]. Available at: http://www.stat.fi/til/tyokay/tyokay_2004-11-23_laa_001.html (accessed 12 January 2006).

14 Official Statistics of Finland. Care and Services for Older People 2002. SVT: Social Security 2003:1. Helsinki: National Research and Development Centre for Welfare and Health (STAKES), 2003.

15 Kuronen R. Telephone conversation with an expert at the National Research and Development Centre for Welfare and Health (STAKES) on data coverage in the 2003 Client Census of Social Care. 2005/6/8.

16 Sund R, Kauppinen S. Kuinka laskea ikääntyneiden pitkäaikaisasiakkaiden määriä rekisteritietojen perusteella? [How to determine the number of older people in long-term care using register-based data?]. Sosiaalilääketieteellinen Aikakauslehti 2005;25:137-44.

17 STAKES [National Research, and Development Centre for Welfare and Health]. Second edition of Finnish version of the International Statistical Classification of Diseases and Related Health Problems, tenth revision. Vol. 1:Helsinki: STAKES, 1999.

18 Social Insurance Institution. Statistical Yearbook of the Social Insurance Institution, Finland, 1997, T1:33. Helsinki: Social Insurance Institution, 1998.

19 Lääkelaitos [National Agency for medicines]. Lääkkeiden luokitus (ATC) ja määritellyt vuorokausiannokset (DDD). [Classification of medicines (ATC) and defined daily doses (DDD)]. Helsinki: Lääkelaitos, 1997.

20 Lääkelaitos [National Agency for medicines]. Lääkkeiden luokitus (ATC) ja määritellyt vuorokausiannokset (DDD). [Classification of medicines (ATC) and defined daily doses (DDD)]. Helsinki: Lääkelaitos, 1998.

21 Martikainen J, Rajaniemi S. Drug reimbursement system in EU member states, Iceland and Norway. Online publication (www.kela.fi/research) edition. Helsinki: Social Insurance Institution, 2003.

22 Vellas BJ, Albarede JL, Garry PJ. Diseases and aging: patterns of morbidity with age; relationship between aging and age-associated diseases. Am J Clin Nutr 1992;55:(6 Suppl):1225S-30.

23 Hughes ME, Waite LJ. Health in household context: living arrangements and health in late middle age. J Health Soc Behav 2002;43(1):1-21.

24 OECD. The OECD List of Social Indicators. Paris: OECD, 1982.

25 Stata Corporation. Stata Statistical Software. Release 8.0. College Station, TX: Stata Corporation, 2003.

26 Valiyeva E, Russell LB, Miller JE, Safford MM. Lifestyle-related risk factors and risk of future nursing home admission. Arch Intern Med 2006;166(9):985-90.

27 Rockwood K, Stolee P, McDowell I. Factors associated with institutionalization of older people in Canada: testing a multifactorial definition of frailty. J Am Geriatr Soc 1996;44(5):578-82

28 Woo J, Ho SC, Lau J, Yuen YK. Age and marital status are major factors associated with institutionalisation in elderly Hong Kong Chinese. J Epidemiol Community Health 1994;48(3):306-9. 
29 Stuck AE, Walthert JM, Nikolaus T, et al. Risk factors for functional status decline in community-living elderly people: a systematic literature review. Soc Sci Med 1999;48(4):445-69.

30 Aguero-Torres H, Fratiglioni L, Guo Z, et al. Dementia is the major cause of functional dependence in the elderly: 3-year follow-up data from a population-based study. Am J Public Health 1998;88(10):1452-6.

31 Spiers NA, Matthews RJ, Jagger C, et al. Diseases and impairments as risk factors for onset of disability in the older population in England and Wales: findings from the Medical Research Council Cognitive Function and Ageing Study. J Gerontol A Biol Sci Med Sci 2005;60(2):248-54.

32 Reunanen A. Diabetes. In: Aromaa A, Huttunen J, Koskinen S, Teperi J, editors. Health in Finland. Helsinki: Kustannus Oy Duodecim, 2005:222-5.

33 Boyle JP, Honeycutt AA, Narayan KM, et al. Projection of diabetes burden through 2050: impact of changing demography and disease prevalence in the U.S. Diabetes Care 2001;24(11):1936-40.

34 Björntorp P. The Relationship between Obesity and Diabetes. In: Alberti KGMM, Zimmet P, DeFronzo RA, Keen H, editors. International Textbook of Diabetes Mellitus Chichester, New York: John Wiley \& Sons, 1997;1:611-27.

35 Dunkin JJ, Anderson-Hanley C. Dementia caregiver burden: a review of the literature and guidelines for assessment and intervention. Neurology 1998;51:(1 Suppl 1):S53,60; discussion S65-7.

36 Draper BM, Poulos CJ, Cole AM, et al. A comparison of caregivers for elderly stroke and dementia victims. J Am Geriatr Soc 1992;40(9):896-901.

37 Aromaa A, Koskinen S. Health and functional capacity in Finland. Baseline Results of the Health 2000. Health Examination Survey 2004. Helsinki: Publications of the National Public Health Insitute B12/2004, 2004.
38 de Rijk MC, Launer LJ, Berger K, et al. Prevalence of Parkinson's disease in Europe: a collaborative study of population-based cohorts. Neurologic Diseases in the Elderly Research Group. Neurology 2000;54:(11 Suppl 5): S21-3.

39 Pahkala K, Kesti E, Kongas-Saviaro P, et al. Prevalence of depression in an aged population in Finland. Soc Psychiatry Psychiatr Epidemiol 1995;30(3):99-106.

40 Beekman AT, Copeland JR, Prince MJ. Review of community prevalence of depression in later life. Br J Psychiatry 1999;174:307-11.

41 Ahto M. Coronary heart disease and quality of life among the elderlyprevalence and manifestations of coronary heart disease and its associations with physical, psychological, cognitive and social functioning. Oulu: Department of Public Health Science and General Practice, University of Oulu, 1999.

42 Moller T, Anderson H, Aareleid T, et al. Cancer prevalence in Northern Europe: the EUROPREVAL study. Ann Oncol 2003;14(6):946-57.

43 Sulkava R. Dementia. In: Aromaa A, Huttunen J, Koskinen S, Teperi J, editors. Health in Finland. Helsinki: Kustannus Oy Duodecim, 2005:226-8

44 Lobo A, Launer LJ, Fratiglioni L, et al. Prevalence of dementia and major subtypes in Europe: a collaborative study of population-based cohorts. Neurologic Diseases in the Elderly Research Group. Neurology 2000;54:(11 Suppl 5):S4-9.

45 Klockgether T. Parkinson's disease: clinical aspects. Cell Tissue Res 2004;318(1):115-20.

Received 11 October 2006, accepted 26 February 2007

Appendix Classification of chronic medical conditions used in this study

\begin{tabular}{|c|c|c|c|}
\hline $\begin{array}{l}\text { Classification of } \\
\text { chronic conditions }\end{array}$ & $\begin{array}{l}\text { Hospital diagnoses } \\
\text { (ICD } 10 \text { codes in parentheses) }\end{array}$ & $\begin{array}{l}\text { Special refund category } \\
\text { (Finnish codes in parentheses) }\end{array}$ & $\begin{array}{l}\text { Prescription medication } \\
\text { (ATC codes in parentheses) }\end{array}$ \\
\hline Cancer & (CO0-C97) & $\begin{array}{l}\text { Breast cancer (115) } \\
\text { Prostatic cancer (116) } \\
\text { Gynecological cancers (128) } \\
\text { Other malignant tumors (130) } \\
\text { Melanoma and renal cancer (180) }\end{array}$ & Cancer medication (L) \\
\hline Diabetes & $(\mathrm{E} 10-\mathrm{E} 14)$ & Diabetes (103) & Diabetes medication (A10) \\
\hline Dementia & $(\mathrm{F} 00-\mathrm{F} 03, \mathrm{G} 30)$ & - & - \\
\hline Psychosis & (F20-F29, F30.2, F31.2, F31.5, F32.3, F33.3) & Psychosis (112) & - \\
\hline Depressive symptoms & $\begin{array}{l}\text { (F31.3, F31.4, F31.6, F32, F33, F34.1, } \\
\text { F38.10, F41.2, excluding F32.3, F33.3) }\end{array}$ & - & Anti-depressants (N06A) \\
\hline $\begin{array}{l}\text { Other mental health } \\
\text { disorders }\end{array}$ & (Other F00-F99) & - & $\begin{array}{l}\text { Psychosis medication (N05A) } \\
\text { if not information on } \\
\text { diagnosis of psychosis (112) }\end{array}$ \\
\hline Parkinson's disease & (G20) & Parkinson's disease (110) & Parkinsonism medication (N04) \\
\hline Other neurological diseases & (Other G00-G99) & $\begin{array}{l}\text { Epilepsy (111) } \\
\text { Multiple sclerosis (109) } \\
\text { Some apoplectic symptoms (108) } \\
\text { Trigeminusneuralgia or } \\
\quad \text { glossofaryngikusneuralgia (119) }\end{array}$ & Epilepsy medication (N03) \\
\hline Heart disease & $(100-109,120-152)$ & $\begin{array}{l}\text { Cardiac insufficiency (201) } \\
\text { Coronary heart disease (206) } \\
\text { Arrhythmia (207) }\end{array}$ & - \\
\hline Stroke & $(160-169)$ & - & - \\
\hline Chronic asthma and COPD ${ }^{a}$ & $(\mathrm{~J} 40-\mathrm{J} 45)$ & Chronic asthma and COPD (203) & - \\
\hline Other respiratory diseases & (Other J00-J99) & - & - \\
\hline Arthritis & (M05-M06) & Arthritis (202) & - \\
\hline Osteoarthritis & (M15-M19) & - & - \\
\hline Hip fracture & (S72) & - & - \\
\hline Other accidents or violence & (Other S00-T98) & - & - \\
\hline Other hospital diagnoses & (Other A00-Z99) & - & - \\
\hline Other diseases & & Other chronic conditions (Other 101-601) & \\
\hline
\end{tabular}

a: Other chronic obstructive pulmonary diseases 


\title{
Household income and other socio-economic determinants of long-term institutional care among older adults in Finland
}

\author{
Elina Nihtilä and Pekka Martikainen \\ University of Helsinki
}

\begin{abstract}
An analysis of longitudinal data on Finnish older adults shows that the probability of admission to longterm institutional care is inversely associated with household income: women in the lowest income quintile are 35 per cent more likely, and men in the lowest quintile 59 per cent more likely to be admitted than those in the highest quintile, independently of age, first language, and area characteristics. Controlling for other socio-demographic characteristics and medical conditions reduces these differences by 59 and 78 per cent, respectively. Being a renter and living in poorly equipped housing increases the probability of admission to institutional care, while the possession of a car and living in a detached house decreases it, independently of other factors. These results imply that the future need for institutional care will depend not only on the increasing numbers of older people but also on socio-economic factors and housing conditions.
\end{abstract}

Keywords: institutionalization; institutional care; income; aged; population register; prospective studies; Finland

[Submitted January 2007; Final version accepted June 2007]

\section{Introduction}

As populations continue to age, research on the determinants of receiving institutional care is expanding. Prospective studies have consistently shown that, as well as advanced age, the probability of entering institutional care is associated with the following factors among the older population: functional disabilities (Branch and Jette 1982; Shapiro and Tate 1988; Foley et al. 1992; Steinbach 1992; Wolinsky et al. 1992; Tomiak et al. 2000; Aguero-Torres et al. 2001; Nuotio et al. 2003; Banaszak-Holl et al. 2004); cognitive impairment (Branch and Jette 1982; Shapiro and Tate 1988; Foley et al. 1992); and dementia (Jagger et al. 2000; Tomiak et al. 2000; Aguero-Torres et al. 2001; Eaker et al. 2002; Banaszak-Holl et al. 2004). Research has also shown that an increased probability of admission to institutional care is also associated with certain living arrangements, such as living alone or not having a spouse (Grundy 1992; Grundy and Glaser 1997), even independently of baseline health characteristics (Branch and Jette 1982; Foley et al. 1992; Steinbach 1992; Wolinsky et al. 1992). These results indicate the importance of the social support and help in daily activities provided by the spouse or other household members in reducing the need for institutional care.

There is a general assumption that income and other socio-economic factors influence the probability of being admitted to institutional care among older adults. It has been suggested that wealthier elderly people enjoy better health, can better afford community-based formal services, and live in betterequipped apartments, all of which reduce the need for admission. However, evidence on the effect of income is still inconsistent. Many prospective studies in the USA (for a review see Miller and Weissert 2000) and Canada indicate that income has no effect on the probability of admission when baseline health and socio-demographic confounders are controlled, either among older adults in general (Speare et al. 1991; Steinbach 1992; Salive et al. 1993; Tomiak et al. 2000) or among those with certain functional disabilities (Garber and MaCurdy 1989; Greene and Ondrich 1990). Similarly, one study from the UK shows no independent effect of income on the probability of entering an institution in a rural 
town and surrounding area (Hancock et al. 2002). In contrast, other studies indicate that this probability decreases as income rises, independently of baseline health and socio-demographic confounders. This effect has been found among older adults in Manitoba, Canada (Mustard et al. 1999), and among older adults (Lakdawalla and Schoeni 2003) and chronically disabled older adults in the USA (Greene et al. 1995). Himes et al. (2000) also found similar indicative effects of income among the general older population in the USA and Germany, although the results were statistically significant only at the 10-per-cent level. Furthermore, Foley et al. (1992) indicated that low self-reported household income increased the probability of admission to institutional care among elderly people in Iowa and Washington Counties, Iowa, but not in East Boston, Massachusetts, or in New Haven, Connecticut. These divergent results from different communities could be related to missing information about income on a large number of participants. In addition, Headen (1993) indicated that having a private pension and rental income reduced the probability of receiving institutional care among older disabled Americans, but that interest or dividend income obtained from bond or stock ownership did not (Headen 1993).

Although previous studies have produced differing results on its independent effect, it is largely accepted that income level may affect health, and that health may affect the probability of being admitted to institutional care. However, there are not many studies that examine in detail which health conditions mediate the effect of income on this probability, and to what extent. Furthermore, no studies have investigated whether the inverse association between this probability and income is explained by factors that could be considered to precede income, such as living arrangements and other socio-economic characteristics, and whether it is mediated through poor housing. The low-income elderly may be less likely to live in well-equipped houses with washing facilities and central heating, which may make independent living more difficult, especially for those with health problems.

Previous studies have used various measures of socio-economic status as well as or instead of income to determine whether wealth and being well-off reduces the probability of older adults entering institutional care. The most consistent results refer to home ownership, which has been shown to be associated with a reduced probability, independently of socio-demographic characteristics, among older adults in England and Wales (Grundy 1992; Grundy and Glaser 1997; Breeze et al. 1999), and even independently of health characteristics among older adults in Manitoba, Canada (Tomiak et al. 2000), and among chronically disabled older adults in the USA (Garber and MaCurdy 1989; Greene and Ondrich 1990; Liu et al. 1991; Headen 1993; Greene et al. 1995). In contrast, findings on the effect of education on the likelihood of receiving institutional care are less consistent (Cohen et al. 1988; Greene and Ondrich 1990; Wolinsky et al. 1992; Mustard et al. 1999; Tomiak et al. 2000).

The general purpose of our study was to assess how household income and other socio-economic factors were associated with the probability of entering an institution for long-term care among older adults. We used population-based survival data on Finnish people aged 65 years and over living in the community $(n=280,722)$ with a continuous follow-up for the first entry into an institution during a 69-month period from January 1998 to September 2003. The specific aims were: (i) to estimate how household disposable income, education, occupation-based social class, housing conditions, and the possession of a car were associated with the probability of entering into long-term institutional care, independently first of age, and secondly of chronic medical conditions and other socio-economic and demographic factors; and (ii) to examine in detail whether the inverse association between household disposable income and entering an institution could be explained by living arrangements and other socioeconomic factors likely to have an effect preceding that of any effect of income, and mediated through home ownership, the possession of a car, housing conditions, and chronic medical conditions.

\section{Data and methods}

\section{Data}

The data used in this study were based on a 40-percent individual-level sample of the total Finnish population aged 65 and over on 31 December 1997 (301,263 persons), drawn from a population registration database maintained by Statistics Finland using simple random sampling. These data are collected annually from different administrative records to provide Labour-Force Statistics (Statistics Finland 2004). They cover all persons living in Finland and provide detailed demographic and socio-economic information. This baseline sample, which was already linked with dates of death, was linked also with information on institutional care and previous hospital diagnoses provided by the 
National Research and Development Centre for Welfare and Health, STAKES, and with information from medication registers provided by the Social Insurance Institution. The data linkage was carried out using personal identification codes. Permission to use the anonymous data was obtained from all three registration authorities (TK 53-576-04 and TK 53-499-05). From this linked sample, we excluded all those who were already in institutions for long-term care (5.86 per cent) or who for some other reason did not live in a private household at baseline (0.96 per cent). As a result, the effective study sample, representative of the total Finnish older population living in the community, consisted of 280,722 persons, who were observed for first entry into longterm institutional care or death from 1 January 1998 to 30 September 2003. For the sample, the rate of entry into an institution was 26 per 1,000 personyears. The population-based data used in this study are unique in containing detailed information on household income and other socio-economic characteristics and dates of first admission into long-term institutional care during the follow-up.

\section{Long-term institutional care}

In our study, long-term institutional care was defined as 24-hour care in nursing homes, service homes, hospitals, and health centres lasting for over 90 days or confirmed by a long-term care decision. The decision to admit was taken by a medical doctor. Long-term psychiatric care was also included, because long-term-care patients often require psychiatric help for their cognitive and mental health problems. Ordinary service homes providing less intensive care were not regarded as institutions in this study. The over-90-days criterion was met if a patient had stayed in the same institution or successively in different institutions for the time required.

The information on long-term institutional care was based on the Client Censuses of Health Care (including hospitals and health centres), and on the Client Censuses of Social Care (including nursing and service homes providing 24-hour care), both of which were carried out at the end of every year from 1997 to 2003, and on the annual discharge data on stays that had ended. About 75 per cent of first stays in long-term institutional care that started during the follow-up had begun in hospitals or health centres and 25 per cent in nursing or service homes providing 24-hour care. The registers of
Health Care have been collected since 1967 (Official Statistics of Finland 2003) and are currently regarded as very accurate, while those of Social Care are known to be less complete. Approximately 9 per cent of the nursing and service homes providing 24-hour care did not participate in the Client Census of Social Care in 2003 (personal communication, June 2005, from R. Kuronen, an expert at the National Research and Development Centre for Welfare and Health (STAKES) on data coverage in the 2003 Client Census of Social Care). However, it is very likely that the proportion of care episodes that could not be detected from the Client Census was much smaller, because institutions not participating in the Census were likely to be small. It is also likely that stays in nursing and service homes were somewhat better covered in the censuses than in the discharge data (Sund and Kauppinen 2005); the latter may have underreported the number of short stays that started and ended between the censuses. We used both Client Censuses and discharge data to minimize under-coverage in nursing homes, but recognize that the absolute level of residence in institutions may be a slight underestimate in our study.

\section{Other variables}

Explanatory, mediating, and control variables. Because our main focus was on understanding the relationship between income and institutional care, we categorized our other variables as explanatory, mediating, and control variables. Explanatory variables were factors that might explain the inverse association between income and admission to institutional care, such as living arrangements, and different socio-economic factors including education and occupation-based social class, the effects of which were likely to precede those of household income and to influence it. Mediating variables were factors that could mediate the effect of income on admission because the effects of income were likely to precede their effects: home ownership, house type, level of equipment in the dwelling, the possession of a car, and different chronic medical conditions. The control variables were confounders associated with both institutional care and income, but of no substantive interest to us, and adjustments were made for them before the effect of income on the probability of entering institutional care was analysed. The control variables comprised: age, first language, and area characteristics, including region of residence and 
level of urbanization. Income, and all of the explanatory, mediating, and control variables were measured at baseline at the end of 1997, with the exception of chronic medical conditions, which were defined during 1996-97, and occupation-based social class which was defined mainly according to the occupation before retirement. The classification of the explanatory and mediating factors was based on assumptions about whether their effects were likely to precede or causally follow those of household income (Figure 1).

Household disposable income. Household disposable income per consumption unit was used to measure income, which comprised all annual taxable income received by household members, including wages, capital income, pensions, unemployment benefits, and other taxable income transfers. All taxes and certain social security payments, such as income, capital, municipal and church taxes, and health-insurance and pension-insurance payments, were subtracted from household income. Disposable income was then adjusted for the number of persons in the household, with the first member weighted as 1.0 unit and any other as 0.7 of a unit. The procedure corresponds to the OECD equivalence scale for weighting income in the household (OECD 1982), except for children, who were weighted as adults because of the data restrictions. Weighting children in this way did not affect our results because there are few children in the homes of Finnish older people. Income was divided into quintiles, with the cut-off points for the quintiles calculated from the combined data for elderly men and women. The information on disposable income originated from the Tax Administration register.
Explanatory factors. Two other measures of socio-economic status were used-education and social class. Subjects were assigned to whichever of the following three educational categories was the highest level attained: tertiary, intermediate, or basic education or less. If there was no information on education the subjects were classified as having basic education or less by Statistics Finland because it was known that those for whom this information is missing were usually at the lowest level. The following occupation-based social class categories were used: upper white collar, lower white collar, worker specialized, worker non-specialized or specialization unknown, farmer, other self-employed, and others and unknown. Retired persons were categorized according to their previous occupations and positions, while former housewives were usually categorized according to the former social class of the head of the household. There were seven categories of living arrangement, which included marital status: living with a spouse, living with a partner, living alone but married, living alone and widowed, living alone and divorced, living alone and never married, and living with others.

Mediating factors. We used three categories for home ownership - owners, renters, and others and unknown - and the following categories of type of house: detached house, semi-detached house, apartment house with a lift, apartment house without a lift, and other. Dwellings were also categorized as well equipped, poorly equipped, or very poorly equipped. A dwelling was regarded as well equipped if it had all of the following: piped water, connection to sewer, hot water, a flush toilet, washing facilities (shower/bath/sauna), and central or fixed electric heating. It was poorly equipped if it lacked washing

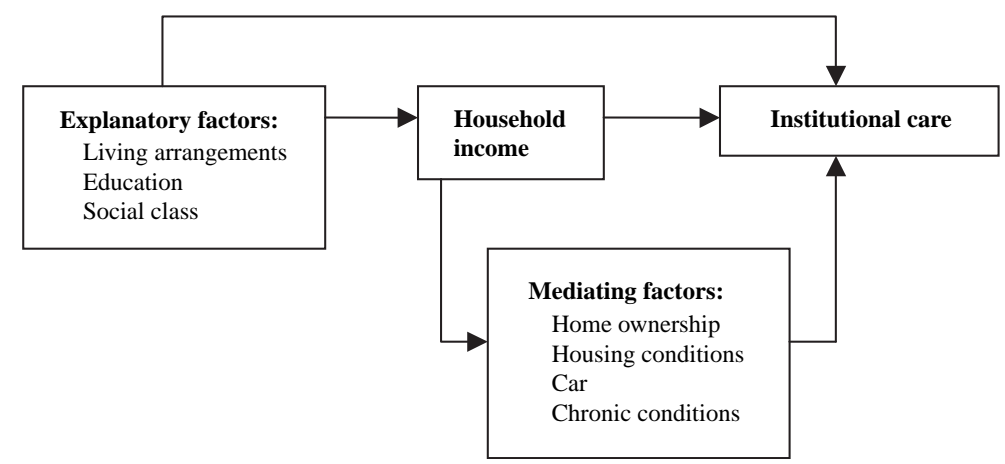

Figure 1 A schematic representation of the role of explanatory and mediating factors in the association between household income and the risk of admission to institutional care among older adults 
facilities or central or fixed electric heating, and very poorly equipped if it lacked piped water, connection to sewer, hot water, or a flush toilet. Whether or not the subject possessed a car (an individual rather than a household characteristic) was also recorded; this information was lacking for residents of the Aland Islands ( 0.55 per cent).

Eighteen dichotomous indicators of chronic medical conditions were used in analysing the relationship between income and receiving institutional care, and in order to control for health status. These conditions were: cancer, diabetes, dementia, psychosis, depressive symptoms, other mental health disorders, Parkinson's disease, other neurological diseases, heart disease, stroke, chronic asthma or other similar chronic obstructive pulmonary diseases, other respiratory diseases, arthritis, osteoarthritis, hip fracture, other conditions related to accident or violence, other hospital diagnoses, and other chronic diseases. In most instances the persons studied were categorized as having a chronic medical condition if it appeared in at least one of the following sources: (i) registers showing the principal cause of hospitalization during the 2 years preceding baseline 1996-97; (ii) registers showing the right to reimbursement for drug costs under the Special Refund Categories for certain diagnosed chronic medical conditions during 1 year before the baseline in 1997, and (iii) registers of prescription medication during the 2 years preceding baseline 1996-97. The data on the principal cause of hospitalization were based on the Tenth Revision of the International Classification of Diseases, ICD10 (STAKES 1999), that on the right to reimbursement for drug costs under the Special Refund Categories was based on the Finnish disease classification of the Social Insurance Institution (Social Insurance Institution 1998), and that on purchases of prescription medication was based on the Anatomical Therapeutic Chemical Classification, ATC (Lääkelaitos 1997, 1998). Precise definitions of the chronic medical conditions and their effects on admission to institutional care were discussed in a previous paper (Nihtilä et al. in press).

Control variables. Age was divided into 1-year age groups and added to the statistical models as separate dummies. The subject's first language was categorized as Finnish, Swedish, and other. Area characteristics, including region of residence and level of urbanization, were used as control variables to adjust for differences in the supply of and access to institutional care between the areas. Finland is divided into 20 official regions, and these were all used with the exception of Uusimaa, which was divided into three parts (Helsinki, the metropolitan area, and the rest of Uusimaa) and the Åland Islands, which were combined with Southwest Finland. The level of urbanization, which was categorized as urban, semi-urban, or rural, was based on the proportion of people living in different built-up areas in the municipality and the population of the largest built-up area. Descriptive statistics for the study cohort at baseline (excluding first language, chronic medical conditions, and regions) and the proportions entering into institutional care are presented in Table 1.

\section{Statistical methods}

The dependent variable was the time between the baseline (31 December 1997) and the first entry to long-term institutional care between 1 January 1998 and 30 September 2003. As time was measured in days we were able to use Cox proportional hazard regression models to estimate the determinants of admission. A study person was censored at the time of death or at the end of the follow-up if not previously admitted to institutional care during the follow-up. The results are presented in terms of hazard ratios. The hazard ratios for age, chronic medical conditions, first language, and regions are not shown, however. Because statistically significant interactions for age-adjusted risks of admission to institutional care were found between sex of subject and most of the socio-economic determinants, including education, social class, home ownership, and the possession of a car, all of the analyses were performed separately for men and women.

Multicollinearity between different socioeconomic measures was not a problem in the multivariate regression models. Among men, the highest Spearman rank correlations were obtained between income quintiles and occupation-based social class (Spearman's rho $=0.49, n=77,670$, including the categories higher and lower white collar and worker), and between income and education (rho $=0.40, n=108,474$ ), and among women between living in a detached house and level of equipment in the dwelling ( $r h o=0.46, n=172,248$ ), and between income and social class ( $\mathrm{rho}=0.42, n=$ 131,080). Thus multicollinearity did not bias our findings on the socio-economic determinants of admission to institutional care. 
Table 1 Characteristics of the study cohort at baseline (31 December 1997), and proportions entering long-term institutional care by these characteristics (January 1998-September 2003), women and men aged 65 years and over living in the community at baseline, Finland

\begin{tabular}{|c|c|c|c|c|}
\hline & \multicolumn{2}{|l|}{ Women } & \multicolumn{2}{|l|}{ Men } \\
\hline & Distribution \% & $\begin{array}{c}\text { Entering institution } \\
\%\end{array}$ & Distribution \% & $\begin{array}{c}\text { Entering institution } \\
\%\end{array}$ \\
\hline \multicolumn{5}{|l|}{ Income } \\
\hline 5. Quintile (highest) & 17.5 & 10.6 & 23.9 & 7.4 \\
\hline 4. Quintile & 18.3 & 10.5 & 23.1 & 8.1 \\
\hline 3. Quintile & 20.1 & 13.2 & 21.0 & 10.2 \\
\hline 2. Quintile & 20.8 & 16.2 & 17.3 & 12.2 \\
\hline 1. Quintile (lowest) & 23.4 & 20.5 & 14.7 & 14.2 \\
\hline \multicolumn{5}{|l|}{ Education } \\
\hline Tertiary & 8.0 & 12.0 & 13.6 & 7.7 \\
\hline Intermediate & 13.6 & 12.0 & 12.3 & 9.2 \\
\hline Basic or less & 78.4 & 15.3 & 74.1 & 10.5 \\
\hline \multicolumn{5}{|l|}{ Social class } \\
\hline Upper white collar & 7.4 & 12.0 & 11.2 & 7.9 \\
\hline Lower white collar & 26.1 & 12.6 & 14.8 & 9.4 \\
\hline Worker specialized & 17.1 & 18.1 & 28.8 & 10.7 \\
\hline Worker non-specialized & 25.5 & 13.0 & 16.9 & 10.1 \\
\hline Farmer & 16.9 & 17.0 & 19.6 & 10.8 \\
\hline Self-employed & 4.6 & 13.4 & 7.5 & 8.3 \\
\hline Other & 2.3 & 21.7 & 1.3 & 13.9 \\
\hline \multicolumn{5}{|l|}{ Home ownership } \\
\hline Owner & 78.1 & 13.1 & 83.8 & 9.0 \\
\hline Renter & 18.0 & 20.8 & 12.7 & 15.7 \\
\hline Other or unknown & 3.8 & 15.7 & 3.5 & 12.4 \\
\hline \multicolumn{5}{|l|}{ House type } \\
\hline Detached house & 42.7 & 11.9 & 55.7 & 8.4 \\
\hline Semi-detached house & 11.9 & 16.7 & 10.7 & 11.9 \\
\hline Apartment house with lift & 23.6 & 16.5 & 16.9 & 11.9 \\
\hline Apartment house without lift & 19.7 & 15.8 & 14.5 & 12.0 \\
\hline Other & 2.2 & 23.3 & 2.2 & 13.8 \\
\hline \multicolumn{5}{|l|}{ Level of equipment in dwelling } \\
\hline Well equipped & 81.6 & 14.5 & 79.0 & 9.8 \\
\hline Poorly equipped & 8.3 & 14.4 & 8.9 & 10.4 \\
\hline Very poorly equipped & 10.1 & 15.4 & 12.1 & 10.9 \\
\hline \multicolumn{5}{|l|}{ Possession of car } \\
\hline Yes & 8.6 & 6.1 & 58.6 & 6.1 \\
\hline No & 90.9 & 15.4 & 40.8 & 15.5 \\
\hline Missing & 0.5 & 17.1 & 0.6 & 12.7 \\
\hline \multicolumn{5}{|l|}{ Living arrangements } \\
\hline Living with spouse/married & 35.1 & 8.0 & 69.7 & 7.8 \\
\hline Living with partner/not married & 1.4 & 10.6 & 2.4 & 7.9 \\
\hline Living alone/married & 0.9 & 13.6 & 1.7 & 14.2 \\
\hline Living alone/widowed & 34.6 & 19.2 & 10.3 & 18.8 \\
\hline Living alone/divorced & 6.6 & 14.7 & 4.7 & 12.6 \\
\hline Living alone/never married & 7.9 & 18.9 & 5.2 & 13.8 \\
\hline Living with others & 13.6 & 17.7 & 6.1 & 14.3 \\
\hline \multicolumn{5}{|l|}{ Level of urbanization } \\
\hline Urban & 55.8 & 15.0 & 51.2 & 10.4 \\
\hline Semi-urban & 15.9 & 14.1 & 17.1 & 9.4 \\
\hline Rural & 28.2 & 14.1 & 31.8 & 9.7 \\
\hline All & 100.0 & 14.6 & 100.0 & 10.0 \\
\hline$N$ & 172,248 & 25,117 & 108,474 & 10,823 \\
\hline
\end{tabular}

Source: Unpublished linked registration data provided by Statistics Finland (population registers) and by the National Research and Development Centre for Welfare and Health (registers of Health and Social Care). 


\section{Analyses}

After presenting the descriptive statistics for the cohort (Table 1), we present the findings from the Cox proportional hazard models on the association between each socio-economic factor and the risk of admission to institutional care. We first adjusted for age only, and then for all other factors (Table 2). We next present more detailed results of the Cox models on the association between income and institutional care, first adjusting for control variables (basic model in Table 3, model 1), and then separately adjusting for each of the explanatory and mediating factors (Table 3 , models 2-7). These models were compared with the basic model (models 2-7 vs. model 1) in order to determine whether the inverse association between income and institutional care could be explained by or mediated through other socio-demographic factors and medical conditions.

\section{Results}

\section{Age-adjusted determinants of long-term institutional care}

Several socio-economic factors and housing conditions are associated with the probability of entering long-term institutional care independently of age (Table 2, age-adjusted model A). For both sexes, the probability is decreased by high household disposable income, tertiary education, upper-white-collar status, possession of a car, and living in a detached house, while being a renter increases the probability.

After adjustment for age alone, household income is usually inversely associated with the probability of admission to institutional care: the higher the income, the lower the probability, with the exception of those in the two lowest income quintiles, for whom the probability is the same. Men in the two lowest quintiles are about 40 per cent more likely to be admitted than those in the top quintile, independently of age. The corresponding figures for women are about 30 per cent.

The associations with certain other socioeconomic measures, including education, home ownership, and the possession of a car, are stronger for men than for women. Men with the lowest education are about 40 per cent, and women with the lowest education 15 per cent more likely to be admitted than those with the highest education. Furthermore, men renters are 90 per cent more likely, and women renters 40 per cent more likely than owner-occupiers to be admitted to institutional care. The excess risk for those not possessing a car is 110 per cent in men and 50 per cent in women.

Having a lift in an apartment house is not associated with admission to institutional care. The level of equipment in the dwelling is associated differently with the risk of institutional care for men and women independently of age. Among men, those residing in a very poorly equipped dwelling have a somewhat higher risk than those residing in one that is well equipped. Among women, those living in a well-equipped dwelling have a higher risk than those living a poorly equipped dwelling, independently of age.

In addition, men and women living with their spouse are less likely to be admitted to institutional care, even when compared with those living with a non-married partner. Former marital status continues to make a difference for those living alone: the divorced and never married are more likely to be admitted than the widowed or married. Living in an urban rather than in a rural municipality is associated with an increased probability among men and women, independently of age.

\section{The effect of controlling for all other factors on the determinants of institutional care}

The differences in institutional care by all socioeconomic characteristics and type of house are usually reduced among both sexes after simultaneous adjustment for chronic conditions, socio-economic and demographic factors, and housing conditions. However, a high household income, living in a detached house, and possessing a car are still associated with a decreased probability of entering institutional care, and being a renter with an increased probability (Table 2, fully adjusted model B). Education is associated with entry for men only. Occupation-based social class is no longer associated with entry for men, and this is almost true for women also.

The effect of poor housing conditions becomes apparent after other factors are controlled. Living in a poorly or very poorly equipped dwelling increases the probability of institutional care for both men and women. The effect of poor housing conditions was not apparent before controlling for type of house, especially for women. This is because detached houses are more likely to be poorly or very poorly equipped (details not shown) and those who live in them are, on average, less likely to be receiving 
Table 2 Age-adjusted and adjusted hazard ratios of admission to long-term institutional care from January 1998 to September 2003 (and 95\% confidence intervals), women and men aged 65 years and over living in the community at baseline, Finland

\begin{tabular}{|c|c|c|c|c|}
\hline & \multicolumn{2}{|c|}{ Women $(N=172,248)$} & \multicolumn{2}{|l|}{ Men $(N=108,474)$} \\
\hline & $\begin{array}{c}\text { Model A } \\
\text { Adjusted for age } \\
\text { Hazard ratio } \\
(95 \% \text { CI })\end{array}$ & $\begin{array}{c}\text { Model B } \\
\text { Fully adjusted }^{1} \\
\text { Hazard ratio } \\
(95 \% \mathrm{CI})\end{array}$ & $\begin{array}{c}\text { Model A } \\
\text { Adjusted for age } \\
\text { Hazard ratio } \\
(95 \% \text { CI })\end{array}$ & $\begin{array}{c}\text { Model B } \\
\text { Fully adjusted }^{1} \\
\text { Hazard ratio } \\
(95 \% \mathrm{CI})\end{array}$ \\
\hline \multicolumn{5}{|l|}{ Income } \\
\hline 5. Quintile (highest) & 1.00 & 1.00 & 1.00 & 1.00 \\
\hline 4. Quintile & $1.07(1.02-1.12)^{2}$ & $1.03(0.98-1.09)$ & $\mathbf{1 . 1 3}(1.06-1.20)^{2}$ & $1.07(1.00-1.15)^{2}$ \\
\hline 3. Quintile & $1.23(1.17-1.28)^{2}$ & $1.14(1.08-1.20)^{2}$ & $1.34(1.26-1.42)^{2}$ & $1.20(1.11-1.28)^{2}$ \\
\hline 2. Quintile & $1.28(1.22-1.33)^{2}$ & $\mathbf{1 . 1 5}(1.09-1.21)$ & $\mathbf{1 . 4 1}(1.32-1.50)$ & $1.18(1.10-1.27)$ \\
\hline 1. Quintile (lowest) & $1.28(1.23-1.34)$ & $\mathbf{1 . 1 5}(1.09-1.21)$ & $1.41(1.33-1.50)$ & $\mathbf{1 . 1 3}(1.04-1.22)$ \\
\hline \multicolumn{5}{|l|}{ Education } \\
\hline Tertiary & 1.00 & 1.00 & 1.00 & 1.00 \\
\hline Intermediate & $1.06(1.00-1.13)$ & $0.96(0.90-1.03)$ & $\mathbf{1 . 3 1}(1.20-1.42)^{2}$ & $\mathbf{1 . 1 3}(1.03-1.24)^{2}$ \\
\hline Basic or less & $1.15(1.10-1.21)^{2}$ & $0.98(0.93-1.05)$ & $\mathbf{1 . 3 9}(1.31-1.48)^{2}$ & $\mathbf{1 . 1 0}(1.01-1.19)$ \\
\hline \multicolumn{5}{|l|}{ Social class } \\
\hline Upper white collar & 1.00 & 1.00 & 1.00 & 1.00 \\
\hline Lower white collar & $\mathbf{1 . 1 4}(1.08-1.21)^{2}$ & $1.02(0.96-1.09)$ & $\mathbf{1 . 1 8}(1.09-1.28)^{2}$ & $1.01(0.93-1.11)$ \\
\hline Worker specialized & $1.30(1.22-1.37)^{2}$ & $1.06(1.00-1.14)$ & $1.41(1.31-1.51)^{2}$ & $1.03(0.94-1.13)$ \\
\hline Worker non-specialized & $1.20(1.13-1.27)^{2}$ & $1.02(0.95-1.09)$ & $1.55(1.43-1.67)^{2}$ & $1.03(0.93-1.14)$ \\
\hline Farmer & $\mathbf{1 . 1 3}(1.07-1.20)^{2}$ & $1.02(0.95-1.09)$ & $\mathbf{1 . 1 7}(1.09-1.26)^{2}$ & $0.92(0.83-1.02)$ \\
\hline Self-employed & $1.14(1.06-1.24)$ & $1.05(0.96-1.14)$ & $1.21(1.10-1.34)$ & $1.07(0.96-1.19)^{2}$ \\
\hline Other & $1.31(1.20-1.42)^{2}$ & $1.10(1.00-1.20)$ & $1.78(1.53-2.08)$ & $1.14(0.96-1.34)$ \\
\hline \multicolumn{5}{|l|}{ Home ownership } \\
\hline Owner & 1.00 & 1.00 & 1.00 & 1.00 \\
\hline Renter & $\mathbf{1 . 4 1}(1.37-1.45)^{2}$ & $\mathbf{1 . 1 9}(1.15-1.23)^{2}$ & $\mathbf{1 . 8 7}(1.78-1.96)^{2}$ & $1.23(1.16-1.30)^{2}$ \\
\hline Other or unknown & $1.02(0.96-1.08)^{2}$ & $1.00(0.94-1.06)^{2}$ & $1.20(1.09-1.31)^{2}$ & $1.08(0.98-1.19)$ \\
\hline \multicolumn{5}{|l|}{ House type } \\
\hline Detached house & 1.00 & 1.00 & 1.00 & 1.00 \\
\hline Semi-detached house & $1.27(1.22-1.32)^{2}$ & $\mathbf{1 . 0 9}(1.04-1.15)^{2}$ & $\mathbf{1 . 4 0}(1.32-1.49)^{2}$ & $\mathbf{1 . 1 2}(1.05-1.20)^{2}$ \\
\hline Apartment house with lift & $1.21(1.18-1.25)^{2}$ & $\mathbf{1 . 0 9}(1.04-1.14)$ & $\mathbf{1 . 2 9}(1.23-1.36)^{2}$ & $1.11(1.04-1.19)$ \\
\hline Apartment house without lift & $1.19(1.15-1.23)$ & $\mathbf{1 . 0 8}(1.04-1.13)$ & $\mathbf{1 . 3 6}(1.29-1.44)$ & $\mathbf{1 . 1 5}(1.07-1.22)$ \\
\hline Other & $1.62(1.51-1.74)^{2}$ & $1.22(1.13-1.31)^{2}$ & $1.62(1.45-1.81)^{2}$ & $1.07(0.95-1.21)$ \\
\hline \multicolumn{5}{|l|}{ Level of equipment in dwelling } \\
\hline Well equipped & 1.00 & 1.00 & 1.00 & 1.00 \\
\hline Poorly equipped & $\mathbf{0 . 9 3}(0.89-0.97)^{2}$ & $\mathbf{1 . 0 6}(1.01-1.11)^{2}$ & $1.00(0.93-1.06)$ & $\mathbf{1 . 0 8}(1.01-1.16)^{2}$ \\
\hline Very poorly equipped & $0.97(0.93-1.01)$ & $1.12(1.07-1.18)^{2}$ & $\mathbf{1 . 0 8}(1.02-1.14)$ & $\mathbf{1 . 1 4}(1.07-1.21)$ \\
\hline \multicolumn{5}{|l|}{ Possession of car } \\
\hline Yes & 1.00 & 1.00 & 1.00 & 1.00 \\
\hline No & $1.50(1.40-1.60)^{2}$ & $1.35(1.26-1.44)^{2}$ & $\mathbf{2 . 0 7}(1.98-2.15)^{2}$ & $1.60(1.53-1.68)^{2}$ \\
\hline Missing & $1.39(1.17-1.66)$ & $\mathbf{1 . 3 3}(1.11-1.60)$ & $1.55(1.25-1.92)^{2}$ & $\mathbf{1 . 6 5}(1.31-2.09)$ \\
\hline \multicolumn{5}{|l|}{ Living arrangements } \\
\hline Living with spouse/married & 1.00 & 1.00 & 1.00 & 1.00 \\
\hline $\begin{array}{l}\text { Living with partner/not } \\
\text { married }\end{array}$ & $\mathbf{1 . 3 8}(1.21-1.57)^{2}$ & $\mathbf{1 . 2 4}(1.09-1.41)^{2}$ & $1.26(1.10-1.45)^{2}$ & $1.12(0.97-1.29)$ \\
\hline Living alone/married & $\mathbf{1 . 3 8}(1.20-1.58)$ & $\mathbf{1 . 1 8}(1.03-1.35)$ & $\mathbf{1 . 5 8}(1.40-1.79)^{2}$ & $\mathbf{1 . 3 2}(1.16-1.49)$ \\
\hline Living alone/widowed & $1.25(1.20-1.29)$ & $\mathbf{1 . 1 5}(1.11-1.20)$ & $1.49(1.42-1.58)$ & $\mathbf{1 . 3 5}(1.28-1.42)$ \\
\hline Living alone/divorced & $1.48(1.40-1.56)^{2}$ & $1.24(1.17-1.31)^{2}$ & $\mathbf{2 . 0 5}(1.89-2.23)^{2}$ & $1.52(1.39-1.65)^{2}$ \\
\hline Living alone/never married & $1.49(1.42-1.56)$ & $\mathbf{1 . 3 8}(1.31-1.45)^{2}$ & $2.17(2.02-2.34)$ & $1.63(1.50-1.77)$ \\
\hline Living with others & $1.20(1.15-1.25)^{2}$ & $1.23(1.17-1.28)$ & $1.52(1.42-1.63)^{2}$ & $1.40(1.31-1.51)^{2}$ \\
\hline
\end{tabular}


Table 2 (Continued)

\begin{tabular}{|c|c|c|c|c|}
\hline & \multicolumn{2}{|c|}{ Women $(N=172,248)$} & \multicolumn{2}{|l|}{$\operatorname{Men}(N=108,474)$} \\
\hline & $\begin{array}{c}\text { Model A } \\
\text { Adjusted for age } \\
\text { Hazard ratio } \\
(95 \% \mathrm{CI})\end{array}$ & $\begin{array}{c}\text { Model B } \\
\text { Fully adjusted }{ }^{1} \\
\text { Hazard ratio } \\
(95 \% \mathrm{CI})\end{array}$ & $\begin{array}{c}\text { Model A } \\
\text { Adjusted for age } \\
\text { Hazard ratio } \\
(95 \% \text { CI })\end{array}$ & $\begin{array}{c}\text { Model B } \\
\text { Fully adjusted } \\
\text { Hazard ratio } \\
(95 \% \mathrm{CI})\end{array}$ \\
\hline \multicolumn{5}{|c|}{ Level of urbanization } \\
\hline Urban & 1.00 & 1.00 & 1.00 & 1.00 \\
\hline Semi-urban & $\mathbf{0 . 9 4}(0.91-0.98)^{2}$ & $\mathbf{0 . 9 3}(0.89-0.97)^{2}$ & $\mathbf{0 . 9 1}(0.87-0.96)^{2}$ & $0.96(0.91-1.03)$ \\
\hline Rural & $\mathbf{0 . 9 2}(0.90-0.95)$ & $\mathbf{0 . 9 2}(0.88-0.95)$ & $\mathbf{0 . 9 3}(0.89-0.97)$ & $0.97(0.91-1.02)$ \\
\hline
\end{tabular}

${ }^{1}$ Adjusted for all the factors in the table, and age, first language, region of residence, and chronic medical conditions. Source: Unpublished linked registration data by Statistics Finland (population registers), by the National Research and Development Centre for Welfare and Health (registers of Health and Social Care), and by the Social Insurance Institution (medication registers).

${ }^{2}$ Different from the previous category at the $5 \%$ significance level.

institutional care. The provision of a lift in apartment houses is still not associated with institutional care.

The protective effect of living with a spouse is reduced, but still persists, after adjustment for all other factors: those who live with a spouse have a lower probability of admission to institutional care than those living alone or with someone other than a spouse or partner. However, among men, there was not a statistically significant difference in the probability between those living with their spouse and those living with their partner. After adjustment for all other factors, the association between urban living and an increased probability persists only among women.

\section{Household income and the probability of admission to institutional care}

After adjustment for control variables, the hazard ratios for admission to institutional care between the highest and the lowest income quintiles are 1.35 for women and 1.59 for men (Table 3, model 1). These differences in risk by income were further analysed by adding explanatory and mediating variables to the Cox regression model.

After adjustment for living arrangements, the differences in the likelihood of admission to institutional care are reduced between the highest and the three lowest income quintiles for men and women, because the low-income elderly are less likely to live with a spouse (details not shown). Furthermore, the income differences are also reduced after adjustment for socio-economic position-simultaneous adjustment for level of education and social classespecially among men.
After adjustment for home ownership, the differences by income in the likelihood of institutional care are clearly reduced for both sexes. Furthermore, they are also somewhat reduced after adjustment for type of house and level of equipment, because the low-income elderly are more likely to live in a poorly equipped dwelling and less likely to live in a detached house (details not shown). The income differences are also reduced after adjustment for the possession of a car, particularly strongly among men. Following adjustment for the presence of chronic medical conditions, the income differences are reduced by 10-20 per cent among women (e.g., top and bottom quintiles: [(1.35-1.28)/(1.35-1) $* 100=20])$. The reduction is mainly related to the adjustment for psychoses and diabetes, chronic conditions that are more common among women with a lower rather than a higher income (details not shown). For men, controlling for chronic conditions reduces the differences in income between the bottom and the top quintiles by 15 per cent. The reduction is mainly related to psychoses and other mental health problems, as they are more common among men with a lower income (details not shown).

Overall, among women, approximately 59 per cent of the excess probability of admission to institutional care for the lowest income quintile over the highest is related to explanatory and mediating factors, while the corresponding figure for men is 78 per cent. However, a high household income is still associated with a lower rate of admission to institutional care: the elderly within the three lowest quintiles are between 13 and 20 per cent more likely to be admitted than those in the highest quintile. 


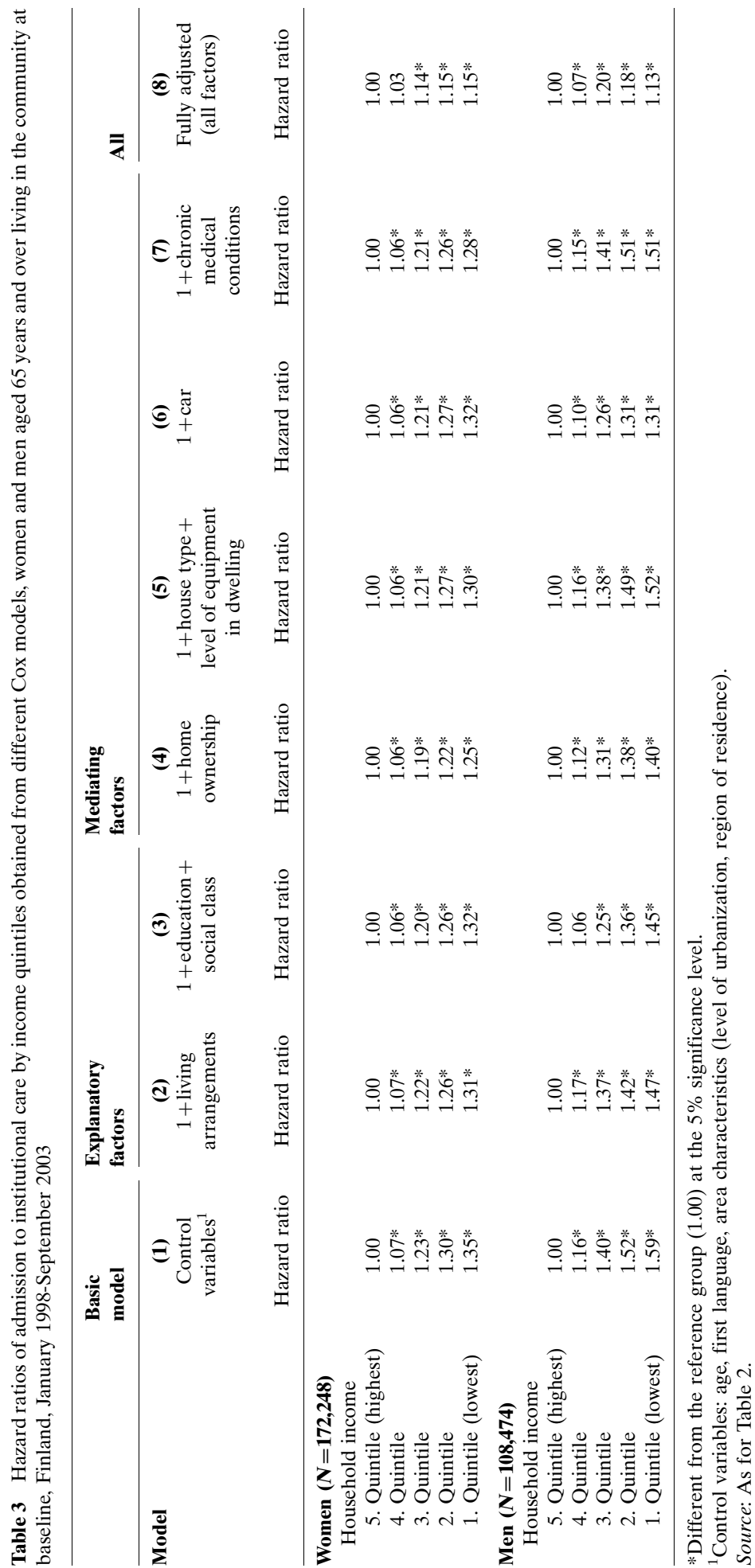




\section{Discussion}

\section{A summary of the main results and their interpretation}

Household income is inversely associated with the probability of admission to institutional care: the higher the income, the lower the probability, independently of age, first language, and area characteristics. Women in the bottom income quintile are 35 per cent more likely, and men in the bottom quintile 59 per cent more likely to be admitted than those in the top quintile. The income differences are partly explained by the fact that those with a low income are less likely to live with a spouse, and more likely to have a lower socio-economic position, and mediated by not owning a home, having poor housing conditions, not having a car, and having certain chronic medical conditions. The most important chronic conditions that mediate the effect of income on the risk of admission to institutional care are psychoses and diabetes for women and psychoses and other mental health problems for men. Controlling for all of the explanatory and mediating factors reduces the differences between the top and the bottom income quintiles by 59 per cent for women and 78 per cent for men.

The finding that income is inversely associated with the risk of admission to institutional care corresponds with the results of some earlier studies (Greene et al. 1995; Mustard et al. 1999; Himes et al. 2000; Lakdawalla and Schoeni 2003), but differs from those of other studies that show that income has no independent effect (Garber and MaCurdy 1989; Speare et al. 1991; Steinbach 1992; Tomiak et al. 2000). This difference could be the result of one or more of various factors: different national practices in providing institutional care and other services for elderly people according to their socioeconomic or family status; different definitions of the income and control variables, especially health status; and different definitions, coverage, and attrition rates in the follow-up of admission to institutional care. For the USA and Germany, Himes et al. (2000) suggested that, when independent of baseline health status, the inverse effect of income on the probability of institutional care could partly reflect the effect of policies to subsidize nursing-home costs for the low-income elderly. On the other hand, Mustard et al. (1999) found that a low income was associated with a higher probability of nursing-home entry even in the Canadian province of Manitoba, where the older population was universally insured and there were no income-related barriers to longterm nursing-home care.

In Finland, most long-term institutional care is publicly provided in nursing homes and health centres, and user charges are related to disposable income, up to a maximum of 80 per cent (Sosiaali- ja terveysministeriö 2003). Clients are allowed to keep a minimum of 20 per cent of their personal disposable income, and at least a certain fixed amount for personal use if it is very low. The highincome elderly and their families may therefore have an economic incentive to avoid long-term institutional care if the absolute level of charges would be very high, and may prefer buying home-help services and receiving less intensive care than that provided in public institutions. This could partly explain the lower rates of admission to institutional care among the high-income elderly. The ownership of property not held for profit, such as ownership of one's own home or land, does not affect user charges for institutional care. The high-income elderly may also have fewer problems in performing instrumental activities of daily living, such as shopping and housekeeping, because their greater financial recourses enables them to purchase ways of adapting to health problems (e.g., they can use ambulatory aids, taxis, and cleaning services), a factor that could also partly mediate the effects of income on the probability of receiving institutional care.

In our study, high education was associated, for men only, with a decreased probability of entering into institutional care, independently of all other factors. This is the opposite of the finding of Tomiak et al. (2000) in Manitoba, Canada, according to which it was only for women that high education was associated with a decreased probability of entering into a nursing home. One other population-based Canadian study found that a high education was independently associated with a decreased probability of nursing-home entry among older adults, but no interactions were indicated for education and sex of subject (Mustard et al. 1999). Furthermore, earlier studies from the USA indicated that education had no independent effect on nursing-home entry for the general older population (Wolinsky et al. 1992), for Medicare recipients (Cohen et al. 1988), or for older adults with disabilities (Greene and Ondrich 1990).

The results of this study confirm those of earlier ones showing that home ownership reduces the probability of entering institutional care (Garber and MaCurdy 1989; Greene and Ondrich 1990; Liu et al. 1991; Grundy 1992; Grundy and Glaser 1997; Breeze et al. 1999; Hancock et al. 2002). Home ownership could be seen as a measure of property 
and wealth that is not entirely accounted for by income. In addition, home ownership can facilitate the individual's return to the community after shortterm institutional care and thus prevent it from becoming long term. Previous studies from the USA have indicated that home ownership is associated with returning to the community from institutional care (Greene et al. 1995).

Our results on the effect of possessing a car coincide with earlier findings from England and Wales, which demonstrated that having a car in the household reduced the probability of receiving institutional care (Breeze et al. 1999). But in our study, the possession of a car was treated as an individual rather than a household characteristic, and it is the strongest socio-economic determinant of institutional care for both men and women. This could mean that, besides measuring socio-economic position and mobility as in previous studies, it also indirectly measures an individual's health. Elderly people with functional limitations or poor eyesight are likely to give up driving and even the possession of a car if their driving licence is revoked on health grounds. Another possibility is that the possession of a car could mean that somebody else in the household is healthy enough to drive it, and might also be healthy enough to take care of other household members and thereby reduce their need for institutional care.

Our study shows that very poor housing conditions, such as the lack of piped water, connection to a sewer, hot water, or a flush toilet, are significant determinants of admission to institutional care among older adults, independently of chronic medical conditions and other socio-demographic characteristics. In this respect our results differ from those of previous studies, which indicated that the lack of a flush toilet or central heating was not a significant predictor among elderly people in former West Germany (Klein 1996). In our study, living in a very poorly equipped dwelling raises the probability of entering into institutional care by $12-14$ per cent, and living in a poorly equipped dwelling, lacking washing facilities or central or fixed electric heating, by $6-8$ per cent. These effects are of major policy relevance because about 20 per cent of Finnish elderly people living in the community were in poorly or very poorly equipped dwellings at the time of data collection. Poor housing conditions are one of the few determinants of institutional care that could possibly be ameliorated by policy interventions such as publicly funded support for housing renovations. The renovation of older people's dwellings, especially of bathroom facilities, could make basic bodily maintenance easier and improve the chances of remaining in the community, especially for those with functional disabilities.

This study did not produce any evidence of an association between the presence of a lift in an apartment house and a reduced probability of admission to institutional care. One possible reason for this unexpected result is that the choice of apartment houses was made according to unmeasured functional disabilities. We also found that living in a detached house reduced the probability of admission.

Living in an urban municipality was found to be independently associated with an increased probability of admission for women only. This partly coincides with the results of earlier studies which showed that urban living was associated with an increased probability of admission among older whites in North Carolina, USA (Salive et al. 1993), and among severely disabled older adults in Southern Germany (Kliebsch et al. 1998). In our study, the rural-urban difference in institutional care for women is unlikely to be due entirely to differences in access to it. It could also be plausibly related to differences in attitudes towards death and end-oflife decision making. Rural women may see death as more natural, and thus be more resistant to moving into an institutional setting, where life could be prolonged. Earlier studies have found that in rural areas, family members of nursing-home residents are less likely than their urban counterparts to resist the approach of death or to welcome interventions that would impede death (Gessert et al. 2006).

Our results indicate that, among men, cohabiting is as protective as marriage in reducing the risk of entering institutional care, while for women, living with a spouse offered more protection than living with a partner. Furthermore, our analyses are consistent with the results of previous studies that show the importance of having a spouse in this respect (Shapiro and Tate 1988; Steinbach 1992; Grundy and Glaser 1997). Because these effects are independent of baseline socio-economic position and chronic medical conditions, it seems that elderly people living with a spouse or a partner are more likely to receive emotional and social support and help with tasks in their own household, thus reducing the need for institutional care. Our analyses show that the never married who were living alone have a higher probability of being admitted to institutional care than the widowed and the married elderly living alone. This could indicate that those who have never been married have unmeasured individual characteristics, in addition to their living arrangements, that increase the probability of ad- 
mission, such as a lower likelihood of having adult children to call upon in case of health problems.

\section{Methodological considerations}

The nationally representative data used in this study provided a continuous follow-up for first entry to long-term institutional care over a 69-month period, and also enabled us to identify periods of long-term institutional care that consisted of several stays in a row in different institutions. This is important in studying long-term care as older persons often move between hospital and nursing home according to the intensity of the care they need. The several empirical and practical advantages of the data that linked different administrative registers meant that missing information and loss due to follow-up were minimal. This feature is a unique advantage of our data sources, because prospective studies on institutional care based on questionnaire surveys may suffer from incomplete follow-up owing to attrition related to severe disability or to long periods between the surveys. In the case of incomplete follow-up owing to long periods between the surveys, it would be easy to overestimate the effects of certain determinants of institutional care that lead to longer periods of care, such as dementia, and to underestimate the effects of certain socio-economic factors, including income, that are smaller but still very important.

Information on household income that comes from the Tax Administration register is more reliable than self-reported income based on questionnaires, especially among the very old. For this study, household disposable income included pensions, wages and capital income, and was an accurate measure of consumption potential. Finnish registerbased data could also be considered more reliable than questionnaire data in terms of other socioeconomic variables and housing conditions.

The administrative data did not contain direct information on functional or cognitive impairments that are known to be associated with admission to institutional care (Branch and Jette 1982; Shapiro and Tate 1988; Foley et al. 1992; Steinbach 1992; Wolinsky et al. 1992; Tomiak et al. 2000; AgueroTorres et al. 2001). We believe, however, that our measures of dementia, psychosis, depressive symptoms, and other mental health disorders are so closely related to cognitive disability that they can serve as adequate proxies of cognitive impairment. The absence of a direct measure of functional impairment may have led to the overestimation of the independent effect of income on institutional care if low income was strongly associated with functional impairment. However, we did have detailed information on several chronic medical conditions based on registration data about the use of hospitals and medication. Many of these conditions have previously been shown to increase the risk of institutional care (e.g., dementia, Parkinson's disease, stroke, mental health disorders, hip fracture, and diabetes (Nihtilä et al. in press)) and to cause functional disabilities in old age (Aguero-Torres et al. 1998; Stuck et al. 1999; Spiers et al. 2005). In general, the prevalence rates of medical conditions obtained in our data (Nihtilä et al. in press) were quite close to those derived from other populationbased sources (e.g., diabetes, heart disease, stroke (Aromaa and Koskinen 2004), Parkinson's disease (de Rijk et al. 2000), depression (Pahkala et al. 1995; Beekman et al. 1999), psychosis (Ahto 1999), and cancer (Möller et al. 2003)). The two notable exceptions were dementia and osteoarthritis, which were underestimated in our study. Furthermore, our data did not contain information on living children or, because repeated measures of medical conditions were not available, on change in health status during the follow-up.

In our study, the causal associations between income and other socio-demographic factors and medical conditions could have been conceptualized in a somewhat different way (Figure 1). Although living arrangements are likely to influence household income (e.g., bigger households get more advantages from economics of scale, and losing a spouse may cause financial problems), income could also have an effect on living arrangements (e.g., people may have chosen a partner according to wealth). Furthermore, although income may influence the likelihood of getting chronic diseases and thus indirectly influence the risk of institutional care, chronic diseases such as mental heath disorders in people of working age may also decrease the possibilities of earning money and thus influence the size of the old-age pension. Life-course data on the explanatory and mediating factors for institutional care are needed in order to investigate these issues.

\section{Conclusions}

Our study is unique in that we were able simultaneously to use reliable information on household disposable income and a continuous follow-up for first entry to long-term institutional care in order to 
assess how different socio-economic characteristics were associated with admission to institutional care in old age. Overall, our results indicate that future demand for institutional care will depend not only on the increasing numbers of older people, but also on their income and other socio-economic characteristics and housing conditions. Material socio-economic indicators such as income, home ownership, and the possession of a car turned out to be independently more strongly associated with admission to institutional care than occupationbased social class or education among women, while for men, in addition to material socio-economic indicators, tertiary education was revealed as important in avoiding or delaying admission. Furthermore, the inverse relationship between income and the risk of admission was partly explained by living arrangements and different socio-economic factors, and mediated through home ownership, housing conditions, the possession of a car, and certain chronic conditions (mainly psychoses and diabetes for women, and psychoses and other mental health problems for men). However, those with the highest income still had a lower probability of being admitted to institutional care, independently of all other factors. More research is required to examine the mechanisms, such as the use of home-help services, through which the effect of income are mediated.

\section{Notes}

1 Elina Nihtilä is at the Population Research Unit, Department of Sociology, PO Box 18, FIN-00014 University of Helsinki, Finland. E-mail: elina.k.nihtila@helsinki.fi. Pekka Martikainen is at the Helsinki Collegium for Advanced Studies, University of Helsinki.

2 This study was supported by the Finnish Post-Graduate School of Social Sciences/Population, Health, and Living Conditions, and by the Academy of Finland. The research was part of an EU-funded research programme on Major Ageing and Gender Issues in Europe (MAGGIE). We are very grateful to Unto Häkkinen and Anja Noro from the National Development Centre for Welfare and Health (STAKES) for their guidance in designing and using the database, and for their expertise in health and social services, and to Seppo Koskinen and Antti Reunanen from the National Public Health Institute for helping us to use the hospital and medication registers. Earlier versions of these results were presented at the Twenty-Fifth International Population Conference of the International Union for the Scientific Study of Population, in Tours, France, on 23 July 2005.

\section{References}

Aguero-Torres, H., L. Fratiglioni, Z. Guo, M. Viitanen, E. von Strauss, and B. Winblad. 1998. Dementia is the major cause of functional dependence in the elderly: 3year follow-up data from a population-based study, American Journal of Public Health 88(10): 1452-1456.

Aguero-Torres, H., E. von Strauss, M. Viitanen, B. Winblad, and L. Fratiglioni. 2001. Institutionalization in the elderly: the role of chronic diseases and dementia. Cross-sectional and longitudinal data from a population-based study, Journal of Clinical Epidemiology 54(8): 795-801.

Ahto, Merja. 1999. Coronary Heart Disease and Quality of Life among the Elderly - Prevalence and Manifestations of Coronary Heart Disease and its Associations with Physical, Psychological, Cognitive and Social Functioning. Oulu: Department of Public Health Science and General Practice, University of Oulu.

Aromaa, A. and S. Koskinen (eds.). 2004. Health and Functional Capacity in Finland. Baseline Results of the Health 2000 Health Examination Survey. Helsinki: Publications of the National Public Health Institute B12/2004.

Banaszak-Holl, J., A. M. Fendrick, N. L. Foster, A. R. Herzog, M. U. Kabeto, D. M. Kent, W. L. Straus, and K. M. Langa. 2004. Predicting nursing home admission: estimates from a 7-year follow-up of a nationally representative sample of older Americans, Alzheimer Disease and Associated Disorders 18(2): 83-89.

Beekman, A. T., J. R. Copeland, and M. J. Prince. 1999. Review of community prevalence of depression in later life, The British Journal of Psychiatry; The Journal of Mental Science 174(4): 307-311.

Branch, L. G. and A. M. Jette. 1982. A prospective study of long-term care institutionalization among the aged, American Journal of Public Health 72(12): 1373-1379.

Breeze, E., A. Sloggett, and A. Fletcher. 1999. Socioeconomic and demographic predictors of mortality and institutional residence among middle aged and older people: results from the Longitudinal Study, Journal of Epidemiology and Community Health 53(12): 765-774.

Cöhen, M. A., E. J. Tell, and S. S. Wallack. 1988. The risk factors of nursing home entry among residents of six continuing care retirement communities, Journal of Gerontology 43(1): S15-S21.

de Rijk, M. C., L. J. Launer, K. Berger, M. M. Breteler, J. F. Dartigues, M. Baldereschi, L. Fratiglioni, A. Lobo, J. Martinez-Lage, C. Trenkwalder, and A. Hofman. 2000. Prevalence of Parkinson's disease in Europe: a collaborative study of population-based cohorts. Neurologic Diseases in the Elderly Research Group, Neurology 54(11 Suppl. 5): S21-S23. 
Eaker, E. D., R. A. Vierkant, and S. F. Mickel. 2002. Predictors of nursing home admission and/or death in incident Alzheimer's disease and other dementia cases compared to controls: a population-based study, Journal of Clinical Epidemiology 55(5): 462-468.

Foley, D. J., A. M. Ostfeld, L. G. Branch, R. B. Wallace, J. McGloin, and J. C. Cornoni-Huntley. 1992. The risk of nursing home admission in three communities, Journal of Aging and Health 4(2): 155-173.

Garber, Alan and Thomas MaCurdy. 1989. Predicting Nursing Home Utilization Among the High-Risk Elderly. Working Paper No. 2483. National Bureau of Economic Research, Cambridge (MA).

Gessert, C. E., B. A. Elliott, and C. Peden-McAlpine. 2006. Family decision-making for nursing home residents with dementia: rural-urban differences, The Journal of Rural Health: Official Journal of the American Rural Health Association and the National Rural Health Care Association 22(1): 1-8.

Greene, V. L. and J. I. Ondrich. 1990. Risk factors for nursing home admissions and exits: a discrete-time hazard function approach, Journal of Gerontology 45(6): S250-S258.

Greene, V. L., M. E. Lovely, M. D. Miller, and J. I. Ondrich. 1995. Reducing nursing home use through community long-term care: an optimization analysis, The Journals of Gerontology. Series B, Psychological Sciences and Social Sciences 50(4): S259-S268.

Grundy, E. M. D. 1992. Socio-demographic variations in rates of movement into institutions among elderly people in England and Wales: an analysis of linked census and mortality data 1971-1985, Population Studies 46(1): 65-84.

Grundy, E. and K. Glaser. 1997. Trends in, and transitions to, institutional residence among older people in England and Wales, 1971-91, Journal of Epidemiology and Community Health 51(5): 531-540.

Hancock, R., A. Arthur, C. Jagger, and R. Matthews. 2002. The effect of older people's economic resources on care home entry under the United Kingdom's long-term care financing system, The Journals of Gerontology. Series B, Psychological Sciences and Social Sciences 57(5): S285-S293.

Headen, Alvin E., Jr. 1993. Economic disability and health determinants of the hazard of nursing home entry, Journal of Human Resources 28(1): 80-110.

Himes, C. L., G. G. Wagner, D. A. Wolf, H. Aykan, and D. D. Dougherty. 2000. Nursing home entry in Germany and the United States, Journal of Cross-Cultural Gerontology 15(2): 99-118.

Jagger, C., K. Andersen, M. M. Breteler, J. R. Copeland, C. Helmer, M. Baldereschi, L. Fratiglioni, A. Lobo, H. Soininen, A. Hofman, and L. J. Launer. 2000. Prognosis with dementia in Europe: a collaborative study of population-based cohorts. Neurologic Diseases in the Elderly Research Group, Neurology 54(11 Suppl. 5): S16-S20

Klein, T. 1996. Determinants of institutionalization in old age, in R. Eisen and F. A. Sloan (eds.), Long-Term Care: Economic Issues and Policy Solutions. Boston/ Dordrecht/London: Kluwer Academic, pp. 103-113.

Kliebsch, U., T. Sturmer, H. Siebert, and H. Brenner. 1998. Risk factors of institutionalization in an elderly population, European Journal of Public Health 8(2): 106-112.

Lääkelaitos [National Agency for Medicines]. 1997. Lääkkeiden luokitus (ATC) ja määritellyt vuorokausiannokset $(D D D)$ [Classification of Medicines (ATC) and Defined Daily Doses (DDD)]. Helsinki: Lääkelaitos.

Lääkelaitos [National Agency for Medicines]. 1998. Lääkkeiden luokitus (ATC) ja määritellyt vuorokausiannokset $(D D D)$ [Classification of Medicines (ATC) and Defined Daily Doses (DDD)]. Helsinki: Lääkelaitos.

Lakdawalla, D. N. and R. F. Schoeni. 2003. Is nursing home demand affected by the decline in age difference between spouses?, Demographic Research 8: 279-296 (published 22 May 2003: www.demographic-reasearch.org).

Liu, K., T. Coughlin, and T. McBride. 1991. Predicting nursing-home admission and length of stay. A duration analysis, Medical Care 29(2): 125-141.

Miller, E. A. and W. G. Weissert. 2000. Predicting elderly people's risk for nursing home placement, hospitalization, functional impairment, and mortality: a synthesis, Medical Care Research and Review: MCRR 57(3): 259297.

Möller, T., H. Anderson, T. Aareleid, T. Hakulinen, H. Storm, L. Tryggvadottir, I. Corazziari, E. Mugno, and EUROPREVAL Working Group. 2003. Cancer prevalence in Northern Europe: the EUROPREVAL study, Annals of Oncology: Official Journal of the European Society for Medical Oncology/ESMO 14(6): 946-957.

Mustard, C., M. Finlayson, S. Derksen, and J. M. Berthelot. 1999. What determines the need for nursing home admission in a universally insured population?, Journal of Health Services Research \& Policy 4(4): 197-203.

Nihtilä, E. K., P. T. Martikainen, S. V. Koskinen, A. R. Reunanen, A. M. Noro, and U. T. Häkkinen. In press. Chronic conditions and the risk of long-term institutionalization among older people, European Journal of Public Health.

Nuotio, M., T. L. Tammela, T. Luukkaala, and M. Jylhä. 2003. Predictors of institutionalization in an older population during a 13-year period: the effect of urge incontinence, The Journals of Gerontology. Series A, 


\section{Elina Nihtilä and Pekka Martikainen}

Biological Sciences and Medical Sciences 58(8): 756762.

OECD. 1982. The OECD List of Social Indicators. Paris: OECD.

Official Statistics of Finland. 2003. Care and Services for Older People 2002, SVT: Social Security 2003:1. Helsinki: National Research and Development Centre for Welfare and Health (STAKES).

Pahkala, K., E. Kesti, P. Köngäs-Saviaro, P. Laippalä, and S. L. Kivelä. 1995. Prevalence of depression in an aged population in Finland, Social Psychiatry and Psychiatric Epidemiology 30(3): 99-106.

Salive, M. E., K. S. Collins, D. J. Foley, and L. K. George. 1993. Predictors of nursing home admission in a biracial population, American Journal of Public Health 83(12): 1765-1767.

Shapiro, E. and R. Tate. 1988. Who is really at risk of institutionalization?, The Gerontologist 28(2): 237-245.

Social Insurance Institution. 1998. Statistical Yearbook of the Social Insurance Institution, Finland, 1997, T1:33. Helsinki: Social Insurance Institution.

Sosiaali- ja terveysministeriö [Ministry of Social Affairs and Health]. 2003. Sosiaali- ja terveydenhuollon asiakasmaksulainsäädännön muutokset 1.4.2003 [Change in the Legislation Concerning User Charges for Social and Health Care 1.4.2003]. Available: http://www.stm.fi/Resource.phx/publishing/documents/1501/index.htx (accessed: 6 November 2006).

Speare, A., Jr., R. Avery, and L. Lawton. 1991. Disability, residential mobility, and changes in living arrangements, Journal of Gerontology 46(3): S133-S142.

Spiers, N. A., R. J. Matthews, C. Jagger, F. E. Matthews, C. Boult, T. G. Robinson, and C. Brayne. 2005. Diseases and impairments as risk factors for onset of disability in the older population in England and Wales: findings from the Medical Research Council Cognitive Function and Ageing Study, The Journals of Gerontology. Series A, Biological Sciences and Medical Sciences 60(2): 248254.

STAKES [National Research and Development Centre for Welfare and Health]. 1999. Second Edition of Finnish Version of the International Statistical Classification of Diseases and Related Health Problems, 10th revision, Volume 1. Helsinki: STAKES.

Statistics Finland. 2004. Työssäkäyntitilaston laatuseloste [The Quality of the Labour-Force Statistics]. Available: http://www.stat.fi/til/tyokay/tyokay_2004-11-23_laa_001.html (accessed: 1 December 2006).

Steinbach, U. 1992. Social networks, institutionalization, and mortality among elderly people in the United States, Journal of Gerontology 47(4): S183-S190.

Stuck, A. E., J. M. Walthert, T. Nikolaus, C. J. Bula, C. Hohmann, and J. C. Beck. 1999. Risk factors for functional status decline in community-living elderly people: a systematic literature review, Social Science \& Medicine (1982) 48(4): 445-469.

Sund, R. and S. Kauppinen. 2005. Kuinka laskea ikääntyneiden pitkäaikaisasiakkaiden määriä rekisteritietojen perusteella? [How to determine the number of older people in long-term care using register-based data?], Sosiaalilääketieteellinen aikakauslehti 42(2): 137-144.

Tomiak, M., J. M. Berthelot, E. Guimond, and C. A. Mustard. 2000. Factors associated with nursing-home entry for elders in Manitoba, Canada, The Journals of Gerontology. Series A, Biological Sciences and Medical Sciences 55(5): M279-M287.

Wolinsky, F. D., C. M. Callahan, J. F. Fitzgerald, and R. J. Johnson. 1992. The risk of nursing home placement and subsequent death among older adults, Journal of Gerontology 47(4): S173-S182. 


\title{
Why older people living with a spouse are less likely to be institutionalized: The role of socioeconomic factors and health characteristics
}

\author{
ELINA NIHTILÄ ${ }^{1} \&$ PEKKA MARTIKAINEN ${ }^{2}$ \\ ${ }^{1}$ Population Research Unit, Department of Sociology, University of Helsinki, Finland, and ${ }^{2}$ Helsinki Collegium for Advanced \\ Studies, University of Helsinki, Finland
}

\begin{abstract}
Aims: To examine whether the lower risk of institutionalization among older adults living with a spouse as compared with those living alone or with other persons could be explained by socioeconomic factors, housing, and chronic medical conditions. Methods: We used population-based follow-up data on Finnish adults aged 65 years and over $(N=280,722)$, covering the period from January 1998 to September 2003, to analyse the risk of entering into long-term institutional care by living arrangements. Kaplan-Meier estimates and Cox regression models were applied. Results: Among men, those living alone had a $70 \%$ higher risk and those living with other persons a $56 \%$ higher risk of being institutionalized than those living with a spouse, independently of age, region, and urbanicity. The corresponding figures for women were $29 \%$ and $21 \%$. Among men, the lower risk of institutionalization among those living with a spouse than among those living alone was partly explained by higher educational level, occupation-based social class, household income, home ownership, house type, better housing conditions, and lower likelihood of having depressive symptoms. Almost the same factors helped to explain the lower risk among women, except that those living with a spouse were not advantaged in terms of education or having fewer chronic diseases. Conclusions: As controlling for socioeconomic factors, housing and health characteristics explained only $35-43 \%$ of the lower risk of institutionalization among those living with a spouse as compared to those living alone, having a spouse seems to have a major independent role in preventing and delaying institutionalization among older men and women.
\end{abstract}

Key Words: Aged, Finland, institutionalization, living arrangements, population register, prospective studies

\section{Background}

As European populations continue to age, public expenditure on long-term care is likely to increase in the future [1]. Long-term institutional care is one of the most expensive forms of long-term care provided for older people needing help with their daily activities [2]. In addition, older people are likely to prefer to live in the community rather than in an institution, as long as they are able to cope with daily activities and do not feel that they are a burden to others. However, with advanced age and functional difficulties, older people who need help increasingly prefer formal services to inter-generational family care if real choices are available [3]. It is therefore important to investigate why some population subgroups are actually less likely to use intensive formal services, such as institutional care.

Previous studies have shown that advanced age, functional disabilities [4-10] and cognitive impairment $[4,5,10]$ are not the only important factors associated with entering into institutional care among older people. Research based on data from large population-based samples in England and Wales has shown that having no spouse and living alone are associated with an increased probability of institutionalization [11-13]. In addition, other studies indicate that after controlling for different

Correspondence: Elina Nihtilä, Population Research Unit, Department of Sociology, P.O. Box 18, FIN-00014 University of Helsinki, Helsinki, Finland. Tel: +35891 9123882. Fax: +35891 9123967. E-mail: Elina.k.nihtila@helsinki.fi 
sociodemographic factors and baseline health status, living alone still raises the risk of institutionalization among older populations in general $[4,6,7,14]$, and among older people with functional disabilities [1517]. These results indicate the importance of informal care and emotional support provided by household members in delaying and preventing institutionalization. Those not living with a spouse may also be disadvantaged in terms of socioeconomic status and housing conditions. However, there are few studies analysing the contribution of demographic and socioeconomic characteristics to the lower risk of institutionalization among older people living with a spouse. The aims of this study were: (a) to estimate the probabilities of survival without entering into long-term institutional care by gender and living arrangements (living with a spouse, alone, or with persons other than a spouse) among older Finnish adults followed from January 1998 until September 2003; and (b) to examine whether the differences in the risk of institutionalization by living arrangements could be explained by socioeconomic status, housing conditions, and the presence of chronic medical conditions. The analyses were performed separately for men and women using Kaplan-Meier survival estimates and Cox regression models.

\section{Methods}

Data

The data were based on a $40 \%$ random sample of the Finnish population aged 65 years and over on 31 December 1997, drawn from a population registration database held at Statistics Finland. This sample, which contained detailed sociodemographic information and dates of death, was linked with register-based information on institutional care and prior hospital diagnoses provided by the National Research and Development Centre for Welfare and Health (STAKES) and with information from medication registers provided by the Social Insurance Institution. The data linkage was carried out at Statistics Finland using personal identification codes. Permission to use the anonymous data was obtained from Statistics Finland, STAKES and the Social Insurance Institutions (permission numbers TK 53-576-04 and TK 53499-05). Those who were already institutionalized $(5.86 \%)$ or who, for some other reason, did not reside in private households at baseline $(0.96 \%)$ were excluded. The effective study sample consisted of 280,722 persons, who were followed for first entry into long-term institutional care or death from 1 January 1998 to 30 September 2003. The exact dates of entry into institutional care were available.

\section{Definition of long-term institutional care}

Long-term institutional care was defined as 24-hour care in nursing homes, service homes, hospitals and health centres lasting for over 90 days or confirmed by a long-term care decision. Long-term psychiatric care was included. Ordinary service homes providing less intensive care and not having staff on duty for 24 hours a day were not regarded as institutions. The over-90-days criterion was met if a patient had stayed in the same institution or successively in different institutions for the time required. Approximately $75 \%$ of first stays in long-term care institutions begun in hospitals or health centres and $25 \%$ in nursing or service homes.

\section{Considerations on data on long-term institutional care}

The information on institutional care held at STAKES originated from the Client Censuses of Health Care (including hospitals and health centres), and from the Client Censuses of Social Care (including nursing and service homes providing 24hour care), both of which were carried out at the end of every year from 1997 to 2003, and from the annual discharge data on care episodes that were completed. The registers of health care have been collected regularly since 1967 [18] and are currently regarded as very accurate, while those of social care were collected for the first time in 1981 (the Census of Social Care) and are known to be less complete. About $9 \%$ of the nursing and service homes providing intensive care did not participate in the Client Census of Social Care in 2003 (R. Kuronen, personal communication). However, it is likely that the proportion of care episodes that could not be detected from the Census was smaller, because institutions not participating were likely to be small. It is also likely that care episodes in social care were somewhat better covered in the censuses than in the discharge data [19]; the latter may have very slightly underestimated the number of short nursing and service home stays that started and ended between the censuses.

\section{Living arrangements}

Baseline living arrangements were divided into three categories: (a) living with a spouse (a married spouse or a partner of the opposite sex) with or without others; (b) living alone; and (c) living with persons 
other than a spouse. Older people living with adult children who have a family or a spouse of their own could not be distinguished from this group because the official definition of a family includes only one to two youngest generations [20]. The distributions by gender and living arrangements are given in Table I.

\section{Other independent variables}

Age and area characteristics, including region of residence and urbanicity, were used as control variables, which were adjusted for before the relationship between living arrangements and institutionalization was analysed. Area characteristics were adjusted for in order to control for differences in the supply of institutional care between the areas. Region of residence was categorized into 20 official regions [21], with the exception of the region of Uusimaa, which was divided into three parts (Helsinki, the metropolitan area, and the rest of Uusimaa). Urbanicity was based on the proportion of people living in built-up areas and the population of the largest built-up area. Built-up area was defined as a group of houses with at least 200 residents and where the distance between the houses did not normally exceed 200 metres. The urbanicity categories were: urban, semi-urban, and rural.

The three educational categories were based on the highest educational qualification or degree: tertiary education, intermediate education (corresponds to upper secondary or post-secondary nontertiary education), and basic education or less (corresponds to lower secondary education or less). Our data did not separate primary education from lower secondary education. If there was no administrative information on education, the subjects were classified as having basic education or less. The occupation-based social class categories were: upper white-collar, lower white-collar, worker specialized, worker non-specialized or specialization unknown, farmer, other self-employed, and others

Table I. Distribution by gender and living arrangements. Finnish older adults aged 65 years and over living in the community at the beginning of the follow-up.

\begin{tabular}{lrr}
\hline & \multicolumn{1}{c}{ Men } & Women \\
\hline Living arrangements (\%) & & \\
$\quad$ With spouse & 72.1 & 36.4 \\
Alone & 21.9 & 50.0 \\
With others & 6.1 & 13.6 \\
$N \quad 108,474$ & 172,248 \\
\hline
\end{tabular}

and unknown. Retired persons were categorized according to their last occupations and positions, and former housewives were categorized mainly according to the former social class of the head of the household.

Household disposable income per consumption unit was used to measure income. Income included all annual taxable income received by household members, including pensions, wages, capital income, unemployment benefits and other taxable income transfers. Taxes and certain social security payments, such as income, capital, municipal and church taxes, and health and pension insurance payments, were subtracted. The disposable income of a household was adjusted for the number of persons living in it. The first household member was weighted as 1.0 unit and any other as 0.7 units. This corresponds to the OECD equivalence scale [22], with the exception of children who were weighted as adults because of the data restrictions. Income was divided into quintiles. The income information originated from the tax administration. The three categories of home ownership were: owners, renters, and others and unknown.

The house-type categories were: detached house, semi-detached house, apartment building with a lift, apartment building without a lift, and other. In terms of equipment, dwellings were categorized as well equipped, poorly equipped, or very poorly equipped. A dwelling was regarded as well equipped if it had all of the following: piped water, a sewer, hot water, a flush toilet, washing facilities (shower/bath/ sauna), and central or fixed electric heating. It was regarded as poorly equipped if it lacked washing facilities or central or fixed electric heating. It was regarded as very poorly equipped if it lacked one of the following: piped water, a sewer, hot water, or a flush toilet.

We used 18 dichotomous indicators of chronic medical conditions that were based on three register sources: (a) the principal cause of hospitalization during the two years prior to baseline in 1996-97; (b) the right to reimbursement for drug costs under the Special Refund Categories for certain diagnosed chronic medical conditions during one year prior to baseline in 1997; and (c) the purchase of prescription medication during the two years prior to baseline 1996-97. The persons studied were categorized as having a chronic condition if thus indicated in at least one of these sources. The data on the principal cause of hospitalization were based on the Tenth Revision of the International Classification of Diseases (ICD10) [23], that on the right to reimbursement for drug costs under the Special Refund Categories was based on the Finnish 
disease classification of the Social Insurance Institution (FI) [24], and that on purchases of prescription medication was based on the Anatomical Therapeutic Chemical Classification (ATC) $[25,26]$. The following 18 chronic medical conditions were used: cancer (ICD10: C00-C97; FI: 115, 116, 128, 130, 180; ATC: L), diabetes (ICD10: E10-E14; FI: 103; ATC: A10), dementia (ICD10: F00-F03, G30), psychosis (ICD10: F20F29, F30.2, F31.2, F31.5, F32.3, F33.3, FI:112), depressive symptoms (ICD10: F31.3, F31.4, F31.6, F32, F33, F34.1, F38.10, F41.2, excluding F32.3 and F33.3; ATC: N06A if not FI: 112), other mental health disorders (ICD10: other F00-F99), Parkinson's disease (ICD10: G20; FI: 110; ATC: N04), other neurological diseases (ICD10: G00G99; FI: 111, 109, 108, 119; ATC: N03), heart disease (ICD10: I00-I09, I20-I52; FI: 201, 206, 207), stroke (ICD10: I60-I69), chronic asthma or other similar chronic obstructive pulmonary diseases (ICD10: J40-J45; FI: 203), other respiratory diseases (ICD10: other J00-J99), arthritis (ICD10: M05-M06; FI: 202), osteoarthritis (ICD10: M15M19), hip fracture (ICD10: S72), other accident or violence (ICD10: other S00-T98), other hospital diagnoses (ICD10: other A00-Z99), and other diseases (FI: other 101-601). Detailed definitions and prevalences of these medical conditions, and the coverage of hospital and medication registers, were discussed in a previous paper [27].

\section{Statistical methods}

Kaplan-Meier estimates were used to illustrate the unadjusted probabilities of survival without entering into institutional care by gender and living arrangements. Time to institutionalization was measured in days. A study person was censored at the time of death or at the end of the follow-up. Cox proportional hazards models were used to assess how living arrangements were associated with the risk of institutionalization, first adjusted for control variables, and then adjusted for other independent variables one after another. The order of the independent variables was determined by their hypothetical order in the life-course of a typical individual: education, occupation-based social class, household disposable income, home ownership, house type, level of equipment in the dwelling, and chronic medical conditions. A model was compared with the previous one to determine whether the lower risk of institutionalization among those living with their spouse could be explained by the socioeconomic factors, housing, and medical conditions. Because interactions were found between gender and living arrangements, analyses were performed separately for men and women using Stata/SE 9.2 [28].

\section{Results}

The unadjusted probability of survival without entering into long-term institutional care was higher among men than among women (Figure 1). Among both men and women, the probability of survival without institutionalization was highest for those living with a spouse, followed by those living with persons other than their spouse and alone. For women, the unadjusted survival was almost the same for those living with persons other than their spouse and for those living alone. However, the ageadjusted rates showed that men living with a spouse had a very low institutionalization rate, even when compared with women living with a spouse (Table II).
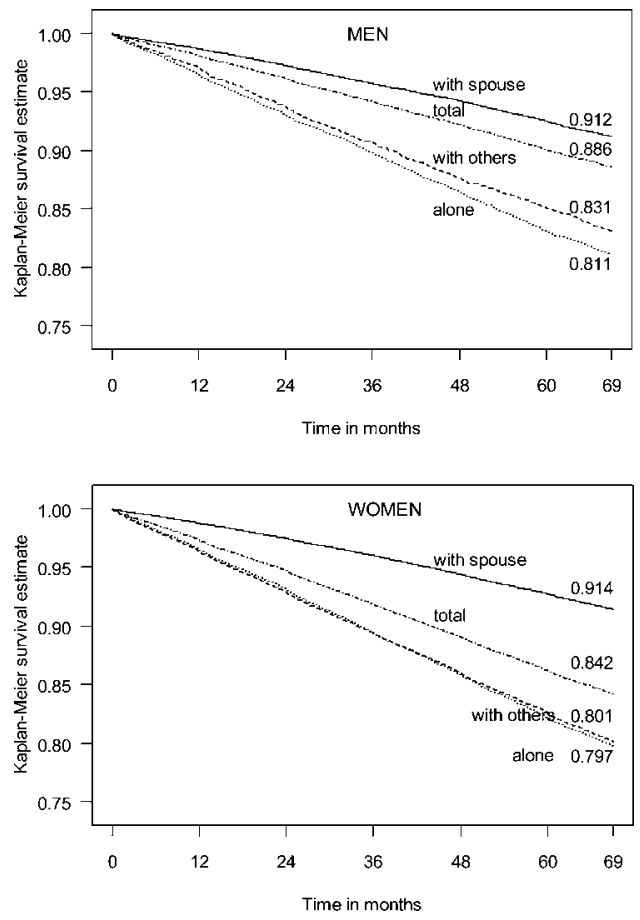

Figure 1. Probability of survival without long-term institutionalization by gender and living arrangements from January 1998 to September 2003 among Finnish older adults living in the community at the beginning of the follow-up. 


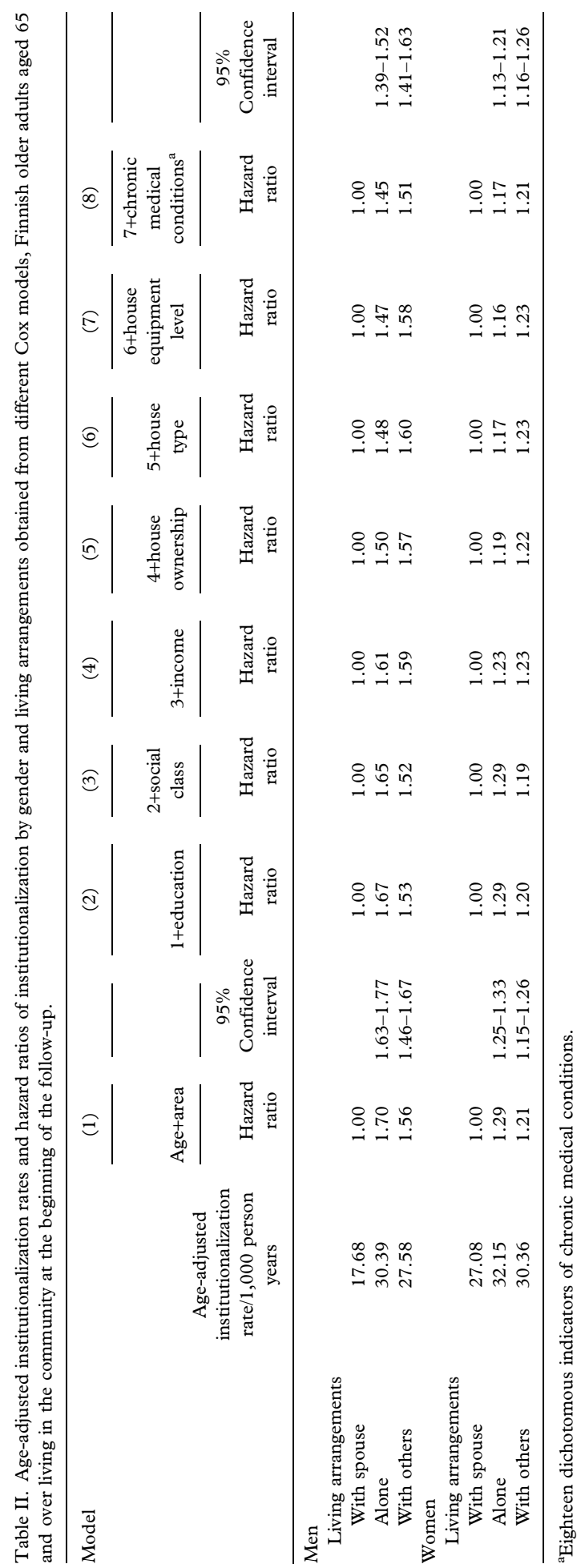


After adjustment for control variables, living with a spouse was still associated with a reduced risk of institutionalization among both men and women (Table II: model 1). However, the relative protective effect of living with a spouse was stronger among men. Among men, those living alone had a $70 \%$ higher risk and those living with persons other than their spouse had a $56 \%$ higher risk of being institutionalized than those living with their spouse. The corresponding figures for women were $29 \%$ and $21 \%$.

\section{Living alone vs. living with a spouse}

About $35 \%$ of the lower risk of institutionalization among men living with their spouse as compared to men living alone was explained by different socioeconomic factors, housing conditions, and chronic medical conditions $((1.70-1.45) /(1.70-1) \times 100)$. The most important medical conditions in terms of explaining these differences were depressive symptoms, which were more common among those living alone (results not shown). However, men living alone still had a $45 \%$ higher risk of entering into long-term institutional care as compared to men living with a spouse, independently of all other factors (Table II: model 8).

For women, almost the same factors explained the lower risk of institutionalization among those living with their spouse as compared to those living alone, with the exception that those with a spouse were not clearly advantaged in terms of education or having less chronic conditions. On the other hand, women living alone had a higher risk of institutionalization, although they were more likely to have higher education and less likely to have certain diseases, such as neurological diseases or a history of stroke, which were associated with institutionalization (results not shown). Furthermore, significant differences in the living arrangement effects between men and women were found $(p<0.001)$ : the protective effect of living with a spouse was still stronger for men than for women, even independently of all other factors.

\section{Living with other persons vs. living with a spouse}

Overall, the differences in institutionalization between those living with their spouse and those living with other persons did not clearly attenuate after adjustment for all other factors simultaneously (Table II: model 8 vs. model 1 ). However, among men, the difference was attenuated after adjustment for education, social class, home ownership, level of equipment, and chronic medical conditions. The most important medical conditions in terms of explaining the differences were psychosis and other mental health problems, excluding depressive symptoms, and conditions related to accidents or violence, all of which were more common among those living with other persons (results not shown). Household income and house type were not important in explaining the excess risk of institutionalization among those living with other persons: on the contrary, the difference was exacerbated after adjustment for these factors (Table II: model 4 vs. model 3, and model 6 vs. model 5). This is mainly related to the fact that household income was differently associated with the risk of institutionalization according to living arrangements: high household income did not reduce the risk among those living with other persons, as it did for those living with a spouse (results not shown).

Among women, almost the same factors explained the excess risk of institutionalization among those living with other persons as compared to those living with their spouse, although the level of equipment was not an important explanatory factor for these differences for women. Among women, the most important medical condition in terms of explaining the differences was psychosis, which was more common among those living with other persons (results not shown). However, both men and women living with other persons still had a higher risk of institutionalization than those living with their spouse, independently of all other factors.

\section{Discussion}

\section{Main results and explanatory framework}

Our results showed that among older men, those living alone had a $70 \%$ higher risk and those living with other persons had a $56 \%$ higher risk of being institutionalized than those living with their spouse, independently of age and area characteristics. The corresponding figures for women were $29 \%$ and $21 \%$.

Different mechanisms have been identified through which living with a spouse may lower the risk of institutionalization. First, as Freedman [29] suggested, the spouse can provide personal care directly to the older person, and give assistance in obtaining formal community-based services to delay the need for institutional care. Second, having a spouse may have beneficial effects on mental and psychological health, in that it gives more social support [30] and maintains and reinforces positive health behaviours [31], and thus indirectly affects 
the need for institutional care in old age. Third, living with a spouse may be associated with better financial and housing conditions, and thus facilitate living in the community.

\section{Living alone vs. living with a spouse}

Among men, the lower risk of institutionalization among those living with their spouse as compared to those living alone was partly explained by a higher educational level, occupation-based social class, household income, home ownership, house type, better housing conditions, and a lower likelihood of having depressive symptoms. Almost the same factors explained the lower risk among women, with the exception that those living with their spouse were not clearly advantaged in terms of education or having less chronic conditions than those living alone. Among men, adjustment for socioeconomic factors, housing conditions and chronic medical conditions explained $35 \%$ of the lower risk of institutionalization among those living with their spouse as compared to those living alone. The corresponding figure for women was $43 \%$.

Our results confirm those of earlier studies showing that older people living with a spouse have a lower risk of institutionalization than those living alone $[6,10,14]$ or without a spouse $[5,29]$, independently of health and sociodemographic factors. However, there is a lack of consistency across studies on the magnitude of risk associated with living arrangements because of methodological limitations. Studies using incomplete follow-up of institutionalization due to long periods between the surveys or censuses underreport shorter care episodes, which are likely to be more common among those having a spouse, and are thus likely to overestimate the negative effects of not having a spouse. Furthermore, divergent results can also be related to different samples and age limitations, and to different definitions of institutional care and control variables.

However, some of the unexplained protective effect of living with a spouse is likely to be related to the personal care and task support provided directly by the spouse. In our study, it could also be related to better functional capacity, which could not be directly measured in our register-based data on chronic diseases. Furthermore, those having a spouse are more likely to have adult children who could take care of them if health problems arise than those living alone, many of whom have never been married (18\%). Although having children has been shown to reduce the risk of institutionalization among older women [14], the number of children outside the household could not be measured in our study.

In contrast to some earlier studies that did not find [29] or report [6] interactions between gender and living arrangements, we found that living with a spouse protected men better than women from institutionalization, even independently of health and sociodemographic factors. Our results partly coincide, however, with earlier findings from England and Wales, not controlling for health, indicating that men seem to benefit more from the advantages of having a spouse than do women [13]. These larger benefits among men could be related, for example, to the younger age and better health of female spouses and accordingly to the lower likelihood of widowhood and better access to care within the household.

\section{Living with other persons vs. living with a spouse}

The excess risk of institutionalization among men living with persons other than their spouse were reduced modestly after controlling for all other factors simultaneously, while no overall reduction was observed among women. However, our results indicated that those living with persons other than their spouse had a higher risk of institutionalization, partly because they were more likely to have chronic medical conditions than those living with their spouse. Men living with others were more likely to have different mental health problems (excluding depressive symptoms) and conditions related to accidents or violence than those living with their spouse. Women living with others were more likely to have psychosis. Our results are in line with those of previous studies showing that people living with other persons have higher rates of certain illnesses than those living with a spouse, including limiting long-term illnesses [32]. Furthermore, our study gives indirect indications that those living with other persons, most of whom are likely to live with their adult children, are likely to have moved because of health problems. However, some of the unexplained excess risk of institutionalization among those living with others may be related to physical and cognitive disabilities, which could not be directly measured in our study. This could have somewhat overestimated the independent benefits of living with a spouse if those living with others were more likely to have psychical and cognitive disabilities. Our results did indicate that older people living with persons other than their spouse comprise a special group, because having a high household income did not reduce their relative risk of institutionalization as it did for the other living arrangement groups. Those living with 
persons other than their spouse are unlikely to benefit from the relatively high level of income in the household, most likely earned by the younger generations, in terms of reducing their risk of institutionalization.

\section{Conclusions}

Our results show that living with a spouse is an important independent factor in preventing and delaying institutionalization and that the differences in the risk of institutionalization by living arrangements could only partly be explained by socioeconomic factors, and housing and medical conditions. This indicates that the need for institutional care will depend not only on the increasing numbers of older people with disabilities but also on their living arrangements. More prospective analyses are required to examine how the health and the death of the spouse affect the risk of institutionalization.

\section{Acknowledgements}

We are grateful to Anja Noro $\mathrm{PhD}$ and Unto Häkkinen $\mathrm{PhD}$, from the National Development Centre for Welfare and Health (STAKES), for their guidance in designing and using the database, and to Seppo Koskinen $\mathrm{MD}, \mathrm{PhD}$ and Antti Reunanen $\mathrm{MD}, \mathrm{PhD}$, from the National Public Health Institute, for helping us to use the hospital and medication registers. This study was supported by the Finnish Post-Graduate School in Social Sciences/Population, Health, and Living Conditions, by the Finnish Cultural Foundation, and by the Academy of Finland. The study was part of an EU-funded research programme on Major Ageing and Gender Issues in Europe (MAGGIE). Earlier versions of these results were presented at the European Population Conference of the European Association for Population Studies, in Liverpool, UK, on 24 June 2006.

\section{References}

[1] Economic Policy Committee, Budgetary challenges posed by ageing populations: the impact on public spending, health and long-term care for the elderly and possible indicators of long-term sustainability on public spending. Brussels: Directorate General for Economic and Financial Affairs of the European Commission; 2001.

[2] Hujanen T. Terveydenhuollon yksikkökustannukset Suomessa vuonna 2001. Aiheita 1/2003. Helsinki: Stakes; 2003.

[3] Daatland SO. What are families for? On family solidarity and preferences for help. Ageing Society 1990;10:1-15.
[4] Branch LG, Jette AM. A prospective study of long-term care institutionalization among the aged. Am J Public Health 1982;72:1373-9.

[5] Shapiro E, Tate R. Who is really at risk of institutionalization? Gerontologist 1988;28:237-45.

[6] Steinbach U. Social networks, institutionalization, and mortality among elderly people in the United States. J Gerontol 1992;47:S183-90.

[7] Wolinsky FD, Callahan CM, Fitzgerald JF, Johnson RJ. The risk of nursing home placement and subsequent death among older adults. J Gerontol 1992;47:S173-82.

[8] Aguero-Torres H, von Strauss E, Viitanen M, Winblad B Fratiglioni L. Institutionalization in the elderly: the role of chronic diseases and dementia. Cross-sectional and longitudinal data from a population-based study. J Clin Epidemiol 2001;54:795-801.

[9] Tomiak M, Berthelot JM, Guimond E, Mustard CA. Factors associated with nursing-home entry for elders in Manitoba Canada. J Gerontol A Biol Sci Med Sci 2000;55:M279-87.

[10] Foley DJ, Ostfeld AM, Branch LG, Wallace RB, McGloin J, Cornoni-Huntley JC. The risk of nursing home admission in three communities. J Aging Health 1992;4:155-73.

[11] Breeze E, Sloggett A, Fletcher A. Socioeconomic and demographic predictors of mortality and institutional residence among middle aged and older people: results from the Longitudinal Study. J Epidemiol Community Health 1999;53:765-74.

[12] Grundy EMD. Socio-demographic variations in rates of movement into institutions among elderly people in England and Wales: an analysis of linked census and mortality data 1971-1985. Population Studies 1992;46:65-84

[13] Grundy E, Glaser K. Trends in, and transitions to, institutional residence among older people in England and Wales, 1971-91. J Epidemiol Community Health 1997;51 531-40.

[14] Grundy E, Jitlal M. Socio-demographic variations in moves to institutional care 1991-2001: a record linkage study from England and Wales. Age Ageing 2007;36:424-30.

[15] Greene VL, Ondrich JI. Risk factors for nursing home admissions and exits: a discrete-time hazard function approach. J Gerontol 1990;45:S250-8.

[16] Yaffe K, Fox P, Newcomer R, Sands L, Lindquist K, Dane $\mathrm{K}$, et al. Patient and caregiver characteristics and nursing home placement in patients with dementia. JAMA 2002;287:2090-7.

[17] Liu K, Coughlin T, McBride T. Predicting nursing-home admission and length of stay. A duration analysis. Med Care 1991;29:125-41.

[18] Official Statistics of Finland. Care and Services for Older People 2002. SVT: Social Security 2003:1. Helsinki National Research and Development Centre for Welfare and Health (STAKES); 2003.

[19] Sund R, Kauppinen S. Kuinka laskea ikääntyneiden pitkäaikaisasiakkaiden määriä rekisteritietojen perusteella? [How to determine the number of older people in long-term care using register-based data?]. Sosiaalilääketieteellinen aikakauslehti 2005;42:137-44.

[20] Statistics Finland, Perheasema [Family status]. Available at: http://tilastokeskus.fi/tk/tt/luokitukset/lk/perheasema_index. html (accessed 20 July 2007).

[21] Wikipedia vt. Suomen maakunnat [Finnish regions]. 1997. Available at: http://fi.wikipedia.org/wiki/Luokka:Suomen_ maakunnat (accessed 11 November 2006).

[22] OECD. The OECD list of social indicators. Paris: OECD; 1982. 
[23] STAKES [National Research and Development Centre for Welfare and Health]. Second edition of Finnish version of the International Statistical Classification of Diseases and Related Health Problems, tenth revision, Vol. 1. Helsinki: STAKES; 1999.

[24] Social Insurance Institution, Statistical Yearbook of the Social Insurance Institution, Finland, 1997, T1:33. Helsinki: Social Insurance Institution; 1998.

[25] Lääkelaitos [National Agency for medicines]. Lääkkeiden luokitus (ATC) ja määritellyt vuorokausiannokset (DDD) [Classification of medicines (ATC) and defined daily doses (DDD)]. Helsinki: Lääkelaitos; 1997.

[26] Lääkelaitos [National Agency for medicines]. Lääkkeiden luokitus (ATC) ja määritellyt vuorokausiannokset (DDD) [Classification of medicines (ATC) and defined daily doses (DDD)]. Helsinki: Lääkelaitos; 1998.

[27] Nihtilä EK, Martikainen PT, Koskinen SVP, Reunanen AR, Noro AM, Häkkinen UT. Chronic conditions and the risk of long-term institutionalization among older people. Eur J Public Health 2008 (in press).

[28] Stata Corporation. Stata statistical software. Special Edition. Release 9.2. College Station, TX: Stata Corporation; 2006.

[29] Freedman VA. Family structure and the risk of nursing home admission. J Gerontol B Psychol Sci Soc Sci 1996;51:S61-9.

[30] Ross CE. Reconceptualizing marital status as a continuum of social attachment. J Marriage Fam 1995;57: $129-40$.

[31] Joung IM, Stronks K, van de Mheen H, Mackenbach JP. Health behaviours explain part of the differences in self reported health associated with partner/marital status in The Netherlands. J Epidemiol Community Health 1995;49: 482-8.

[32] Glaser K, Murphy M, Grundy E. Limiting long-term illness and household structure among people aged 45 and over, Great Britain 1991. Ageing Society 1997;17:3-19. 



\section{Institutionalization of Older Adults After the Death of a Spouse}

| Elina Nihtilä, MSocSc, and Pekka Martikainen, PhD

Previous studies showed that older adults who live alone or without a spouse have an increased probability of entering institutional care, independent of baseline health status. ${ }^{1-4}$ These findings indicate the importance of social and instrumental support provided by a spouse in reducing the need for institutionalization. In addition, never-married, widowed, and divorced older persons have been shown to have a higher probability of institutionalization than their married counterparts., However, few studies have analyzed how the death of a spouse affects the probability of entering institutional care.

The death of a spouse has been shown to be associated with poor mental health, such as depression and anxiety, ${ }^{7.8}$ and with poor physical health. ${ }^{7}$ Because poor mental and physical health have both been found to be associated with an increased risk of institutionalization, ${ }^{1,2}$ it is likely that the death of a spouse also increases the need for institu tional care. In addition, some studies have found an association between the death of a spouse and a decline in cognitive status (e.g., memory functioning), ${ }^{9}$ which is shown to be an important risk factor for admission to institutional care. ${ }^{1,10}$ Because mental health may improve again after despair and disorganization diminish with time following bereavement, ${ }^{11}$ it is possible that the risk of institutionalization is highest immediately after the loss of a spouse and decreases over time.

One study from the United States indicated that becoming widowed during a prospective follow-up was associated with an increased probability of nursing home admission, but the recency of widowhood, measured retrospectively at the time of the baseline interviews, was not. ${ }^{12}$ The latter finding may be misleading, especially if the effect of widowhood is short term and a large proportion of the recently widowed were already institutionalized before the

Objectives. We investigated the risk of entering long-term institutional care after the death of a spouse in relation to the duration of widowhood among older Finnish men and women. We also examined whether high levels of education or household income buffered the effects of bereavement on institutionalization.

Methods. We used linked register-based data on Finnish adults 65 years or older who were living with a spouse at the beginning of the study period $\langle n=140902)$ and were followed from January 1998 to December 2002.

Results. The excess risk of institutionalization was highest during the first month following a spouse's death compared with still living with a spouse ladjusted hazard ratio $=3.31$ for men, 3.62 for womenl. This risk decreased over time among both men and women. The relative effect of the duration of widowhood on institutionalization did not significantly vary according to the level of education or income.

Conclusions. Risk of institutionalization is particularly high immediately after the death of a spouse, demonstrating the importance of loss of social and instrumental support. (Am J Public Heaith. 2008:98:1228-1234. doi:10.2105/AJPH.2007.119271)

baseline interviews. However, we know of no large-scale prospective studies testing whether the effect of a spouse's death on institutionalization varies according to the duration of widowhood, and the existence and the magnitude of these effects are unknown.

The effect of widowhood and widowerhood on mortality is well established: the recently bereaved have been shown to have a higher risk of death than the currently married, ${ }^{13-20}$ especially from alcohol-reiated diseases, suicides, and other accidents and violence. ${ }^{19} \mathrm{Be}$ cause both mortality and institutionalization are related to poor health (e.g., poor self-perceived health predicts mortality and institutionalization, ${ }^{3,21}$ depression predicts mortality, $^{22}$ and depressive symptoms predict institutionalization among $\mathrm{men}^{23}$ ), it is possible that the effect of the duration of widowhood is similar for both. Previous studies indicated that excess mortality is highest during the first weeks ${ }^{18,24}$ or months ${ }^{13,14,16,20,25}$ after a spouse's death. Some studies found that excess mortality among the bereaved decreases to the level of the married with time from bereavement among men, ${ }^{13}$ but others indicated that it continues, although at a lower level, for 10 years and longer. ${ }^{15}$
The excess risk of death among the recently bereaved may be related to psychosocial mechanisms, such as emotional stress and grief, and to the loss of social, instrumental, and material support. ${ }^{18,19,26}$ However, previous mortality studies suggested that the bereaved gradually adapt to the loss and learn to cope in their changed social environ ment. Furthermore, bereaved persons with disabilities may be more likely to be institutionalized immediately after the death of the spouse because there is no longer anybody to take care of them.

High levels of education and income, as well as other social and economic resources, may buffer against the harmful effect of spousal loss on institutionalization and mortality. However, persons with higher education $^{20.27,28}$ and income ${ }^{27}$ were not found to suffer less excess mortality after a spouse's death in previous studies. Although high socioeconomic status is associated with lower mortality, it has not been shown to prevent or even buffer the harmful effects of spousal loss. On the contrary, a study of the Israeli Jewish population indicated that the relative excess mortality among those recently bereaved was higher for men with more education. ${ }^{20}$ 
Perhaps socioeconomic buffering of the effects of bereavement is greater on institution alization than on mortality, because the loss of spousal support and access to substitute assistance, such as home help services, are likely to be more effective predictors of institutionalization than of death. However, empirical evidence for this hypothesis is not available. Because older adults with savings and higher incomes may be better able to afford home help services, a high household income at the beginning of a study could also buffer the harmful effects of spousal loss.

We used population-based survival data with a continuous time scale of institutional ization to assess the risk of entering institutional care after the death of a spouse in relation to the duration of widowhood and widowerhood among adults 65 years or older. We analyzed Finnish register-based data containing information on each individual's dates of first admission into long-term institutional care and death and on the spouse's date of death during a 5-year followup from January 1998 to December 2002. We sought to assess (1) whether recently bereaved older adults had a higher risk of entering institutional care than did those living with a spouse, independent of sociodemographic controls and preexisting medical conditions; (2) how the duration of widowhood was associated with the risk of entering institutional care; and (3) whether the relative effects of a spouse's death were smaller among persons with a higher level of education or a higher household income. The first 2 analyses were performed separately for men and women.

\section{METHODS}

\section{Data}

We analyzed a $40 \%$ individual-level random sample of the Finnish population 65 years or older on December 31, 1997, drawn from a population registration database at Statistics Finland. These data, which contain detailed sociodemographic information, are collected annually from different administrative records to provide labor-force statistics. ${ }^{29}$ Already linked with dates of death and dates of spousal death, these data were further linked with register-based information on institutionalization and hospital diagnoses provided by the National Research and Development Centre for Welfare and Health and with medication registers provided by the Social Insurance Institution. The linkage was carried out with personal identification codes.

We included all those who were living in private households with a partner $(\mathrm{N}=$ 140902), including a married spouse $(96.4 \%)$ and a nonmarried partner (3.6\%), at the beginning of the study period. This sample was followed for first admission into longterm institutional care, death, and spousal death from January 1, 1998, to December 31,2002 . The data were unique in that they covered a large number of persons bereaved during the follow-up and gave the dates of bereavement and of first admission into institutional care. Furthermore, missing information and loss to follow-up were minimal in these nationally representative data that linked various administrative registers.

\section{Long-Term Institutional Care and Bereavement}

Long-term institutional care was defined as 24-hour care in nursing homes and service homes and as inpatient care in hospitals and health centers lasting more than 90 days or confirmed by a long-term-care decision. Longterm psychiatric care was included. The more-than-90-days criterion was met if a patient had stayed in the same institution or successively in different institutions for that period. We used care episodes in nursing and service homes (social care) as well as those in hospitals and health centers (health care) to identify periods of long-term institutional care that consisted of several stays in a row in different institutions. This is important in studying long-term care because elderly persons often move between hospital and nursing home according to the intensity of the care they need. Furthermore, in many individual cases of long-term care in Finland it is often difficult or arbitrary to define which of these care types is primary or predominant, because, for example, long-term institutiona care often starts in hospitals or health centers, where disabled elderly persons wait to get a place in a nursing home. More information on institutional care for older persons in Finland is available elsewhere. ${ }^{30,31}$
A person was considered bereaved if the spouse (a married spouse or cohabiting part ner of the opposite gender) had died 1 day or more prior to his or her own date of institutionalization or death. We divided the time since the bereavement into 7 categories: 0 to 1 month (1-30 days), 1 to 2 months ( $31-60$ days), 2 to 6 months ( $61-180$ days), 6 to 12 months ( $181-360$ days), 12 to 24 months ( $361-720$ days), 24 to 36 months (721-1080 days), and more than 36 months $(>1081$ days); for the analyses of socioeconomic interactions, we used 4 categories: 0 to 2 months, 2 to 6 months, 6 to 12 months, and more than 12 months.

\section{Socioeconomic and Control Variables}

Education and household disposable income were the socioeconomic variables, and age, region of residence, and chronic medical conditions were control variables. Household size was excluded from the models because adding it did not improve the fit. The socioeconomic and control variables were mea sured at the beginning of the follow-up at the end of 1997, with the exception of medical conditions, which were defined during 1996 and 1997. Education and household income were adjusted to control for a shared socioeconomic environment that could affect both the spouse's probability of death and study participant's probability of institutionalization. These variables were also used to analyze whether a higher socioeconomic status buffered the effects of bereavement.

The educational categories were determined by the highest educational qualification. The 2 categories were tertiary or intermediate education and basic education or less. If there was no information on education, the participants were classified as having basic education or less by Statistics Finland.

Household disposable income per consumption unit was used to measure income, meaning all annual taxable income received by household members, including pensions, wages, capital income, unemployment benefits, and other taxable income transfers. Taxes and certain social security payments, such as income, capital, municipal and church taxes, and health and pension insurance payments were subtracted. Disposable income of a household was adjusted for the number of 


\section{RESEARCH AND PRACTICE}

persons in the household: the first member was weighted as 1.0 unit and any other as 0.7 units. This corresponds to the Organisation for Economic Co-operation and Development Equivalence Scale, ${ }^{32}$ with the exception of children who were weighted as aduits because of the data restrictions. This did not affect our results, because the inclusion of children in this study population was very rare. Income was divided into quintiles: the cut-off points for the quintiles were calculated from the combined data for older men and women living with a spouse.

Region of residence was adjusted to control for difference in the supply of and access to institutional care between the areas. It was categorized into the 20 official regions of Finland, ${ }^{33}$ with the exception of Uusimaa, which was divided into 3 parts: Helsinki, the metropolitan area, and the rest of Uusimaa.

Eighteen dichotomous indicators of chronic medical conditions were used to control for preexisting health status: cancer, diabetes, dementia, psychosis, depressive symptoms, other mental heaith disorders, Parkinson's disease, other neurological diseases, heart disease, stroke, chronic asthma or other similar chronic obstructive pulmonary diseases, other respiratory diseases, arthritis, osteoarthritis, hip fracture, other conditions related to accident or violence, other hospital diagnoses, and other chronic diseases. The study participants were categorized as having a medical condition if it appeared in 1 or more of the following sources: (1) registers showing the principal cause of hospitalization in 1996 to 1997 ; (2) registers showing the right to reimbursement for drug costs under the special refund categories for certain diagnosed chronic conditions in 1997, and (3) registers of prescription medication in 1996 to 1997.

The data on the principal cause of hospitalization were derived from the Finnish Version of the International Classification of Diseases, 10th Revision. ${ }^{34}$ Data on the right to reimbursement for drug costs under the special refund categories were derived from the Finnish disease classification of the Social Insurance Institution, ${ }^{35}$ and data on purchases of prescription medication were derived from the Anatomical Therapeutic Chemical Classification: ${ }^{36,37}$ Precise definitions, coverage, and effects of these conditions were discussed in a

\begin{tabular}{|c|c|c|}
\hline & $\begin{array}{c}\text { Men }(n=78151) \\
\% \text { or mean }(S D)\end{array}$ & $\begin{array}{c}\text { Women ( } n=62751 \text { ), } \\
\text { \% or mean (SD) }\end{array}$ \\
\hline Age, $y$ & $72.0(5.6)$ & $71.2(5.0)$ \\
\hline \multicolumn{3}{|l|}{ Education } \\
\hline Tertiary or intermediate & 28.3 & 23.7 \\
\hline Basic or less & 71.7 & 76.3 \\
\hline \multicolumn{3}{|l|}{ Household income } \\
\hline Fifth quintile (highest) & 21.0 & 18.5 \\
\hline Fourth quintile & 20.5 & 20.0 \\
\hline Third quintile & 19.2 & 19.8 \\
\hline Second quintile & 19.9 & 20.9 \\
\hline First quintile (lowest) & 19.4 & 20,8 \\
\hline \multicolumn{3}{|c|}{ Prevalence of chronic medical conditions } \\
\hline Cancer & 5.1 & 4.0 \\
\hline Diabetes & 10.0 & 9.4 \\
\hline Dementia & 0.5 & 0.4 \\
\hline Psychosis & 1.3 & 2.2 \\
\hline Depressive symptoms & 5.9 & 9.1 \\
\hline Other mental health disorders & 3.7 & 3.9 \\
\hline Parkinson's disease & 1.8 & 1.4 \\
\hline Other neurological diseases & 4.7 & 3.7 \\
\hline Heart disease & 29.8 & 21.7 \\
\hline Stroke & 2.5 & 1.3 \\
\hline Chronic asthma or COPD & 7.7 & 6.8 \\
\hline Other respiratory diseases & 3.7 & 2.0 \\
\hline Arthritis & 2.5 & 4.8 \\
\hline Osteoarthritis & 1.9 & 2.8 \\
\hline Hip fracture & 0.4 & 0.6 \\
\hline Other accident or violence & 3.0 & 2.9 \\
\hline Other hospital diagnoses & 24.5 & 22.3 \\
\hline Other diseases & 34.7 & 40.7 \\
\hline
\end{tabular}

Note. COPD = chronic obstructive puimonary disease.

previous study. ${ }^{31}$ The distribution of the control variables, excluding Finnish regions, is shown in Table 1.

\section{Statistical Methods}

Cox proportional hazards regression models were used to assess how a spouse's death was associated with the risk of institutionalization. The outcome was the time from the start of the study until the first entry into long-term institutional care. Censoring occurred at the time of death or at the end of the follow-up. Bereavement or its duration was considered a time-varying covariate, and the reference category comprised those who had a spouse. The results were presented as hazard ratios (HRs). The controls were considered as time-invariant variables. We used Stata/SE 9.2 (StataCorp LP, College Station, $\mathrm{TX)}$ for all the analyses.

\section{RESULTS}

\section{Duration of Widowhood}

Among men, we observed a $71 \%$ higher risk of institutionalization for the bereaved than for persons living with a spouse, independent of the socioeconomic and control variables. The corresponding figure for women was $49 \%$ (Table 2). The excess risk 
RESEARCH AND PRACTICE

\begin{tabular}{|c|c|c|}
\hline \multicolumn{3}{|c|}{$\begin{array}{l}\text { TABLE 2-Adjusted Hazayd Ratios of } \\
\text { Institutionalization Among Finnish Men } \\
\text { and Women } 65 \text { Years or Older Living } \\
\text { With a Spouse at the Beginning of } \\
\text { Follow-Up, by Bereavement Status: } \\
\text { Finland, 1998-2002 }\end{array}$} \\
\hline & $\begin{array}{c}\text { Men } \\
(n=78151)\end{array}$ & $\begin{array}{c}\text { Women } \\
(n=62751)\end{array}$ \\
\hline Institutionalized, \% & 6.8 & 7.0 \\
\hline Bereaved, $\%$ & 7.1 & 21.0 \\
\hline \multicolumn{3}{|c|}{ Bereavement, HR ( $95 \% \mathrm{Cl}$ ) } \\
\hline Not bereaved (Ref) & 1.00 & 1.00 \\
\hline Bereaved & 1.71 & 1.49 \\
\hline & $(1.55,1.87)$ & $(1.38,1.61)$ \\
\hline
\end{tabular}

Note. $\mathrm{HR}=$ hazard ratio; $\mathrm{Cl}=$ confidence interval. Models included age, region of residence, education, household income, and chronic medical conditions as control variables.

of institutionalization was highest during the first month after the spouse's death: $231 \%$ among men $(\mathrm{HR}=3.31)$ and $262 \%$ among women ( $\mathrm{HR}=3.62$; Figure 1 ). This excess risk decreased with time from the spouse's death among both men and women, dropping to approximately $40 \%$ to $50 \%$ among men and $20 \%$ to $30 \%$ among women 1 year after bereavement. Although the overall excess risk of institutionalization among the bereaved stabilized at a somewhat higher level among men than among women after 1 year, the interaction between gender and the duration of widowhood was not statistically significant in the combined model for men and women.

\section{Buffers Against the Effects of} Bereavement

Although high household income (fifth quintile [highest, reference category]; fourth quintile: $\mathrm{HR}=1.08 ; 95 \%$ confidence interval $[\mathrm{CI}]=1.00,1.16$; third quintile: $\mathrm{HR}=1.21 ; 95 \% \mathrm{CI}=1.12,1.30$; second quintile: $\mathrm{HR}=1.30 ; 95 \% \mathrm{CI}=1.21,1.40$ first quintile: $\mathrm{HR}=1.29 ; 95 \% \mathrm{CI}=1.20$, 1.38 ) and more education (reference category; less education: $\mathrm{HR}=1.07 ; 95 \% \mathrm{CI}=$ $1.01,1.12)$ were associated with a lower risk of institutionalization, the overall effect of bereavement did not significantly vary according to the level of income or education

a

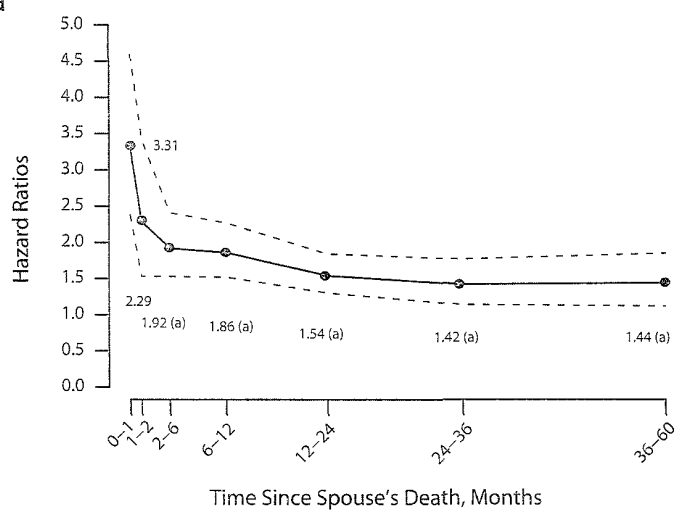

$\mathrm{b}$

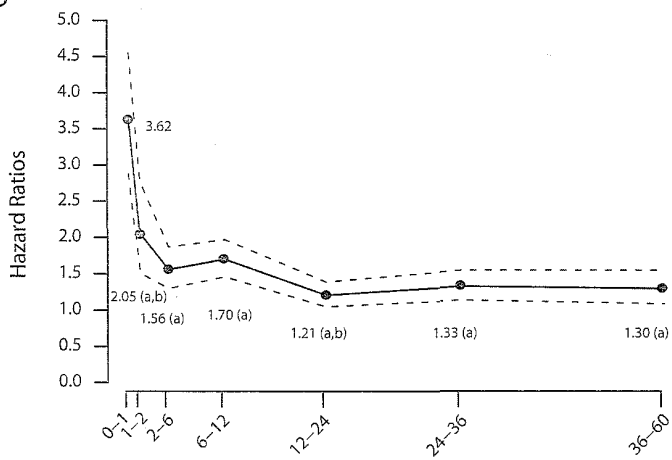

Time Since Spouse's Death, Months

Note. Models included age, region of residence, education, househoid income, and chronic medical conditions. Difference from duration category of 0 to 1 month at the $5 \%$ significance level (a); difference from previous duration category at the $5 \%$ significance level (b).

FIGURE 1-Adjusted hazard ratios and $95 \%$ confidence intervals of institutionalization in relation to duration of bereavement (not bereaved: hazard ratio $=1$ ) among men and women 65 years and older living with a spouse at the beginning of the follow-up study: Finland, 1998-2002.

(Table 3). Furthermore, the effect of the duration of widowhood was similar regardless of income.

However, we detected a slightly different effect of duration of widowhood on institutionalization among more- and less-educated persons, although the difference was not significant. The excess risk of institutionalization seemed to be lower among the more versus the less educated immediately after the spouse's death (first 2 months: $H R=2.02$ vs 3.03 ), but in the longer term, the more educated seemed to have a higher excess risk (e.g. after 1 year: $H R=1.56$ vs 1.31). Overall, we found no evidence of strong interactions between bereavement and education and income when these were assessed as rate differences (on the absolute scale; results not shown). 
TABLE 3-Adjusted Hazard Ratios of Institutionalization in Relation to Duration of Bereavement Among Adults 65 Years or Older Living With a Spouse at the Beginning of Follow-Up, by Level of Education and Househoid income: Finland, 1998-2002

\begin{tabular}{|c|c|c|c|c|}
\hline & \multicolumn{2}{|c|}{ Education } & \multicolumn{2}{|c|}{ Household Income } \\
\hline & $\begin{array}{c}\text { Tertiary of } \\
\text { Intermediate } \\
(n=36984)\end{array}$ & $\begin{array}{c}\text { Basic } \\
\text { or Less } \\
(n=103918)\end{array}$ & $\begin{array}{c}\text { Highest } \\
\text { Quintile } \\
\text { (n=27958) }\end{array}$ & $\begin{array}{c}\text { Lower } \\
\text { Quintiles } \\
(n=112944)^{\mathrm{a}}\end{array}$ \\
\hline Institutionalized, \% & 5.8 & 7.3 & 5.0 & 7.3 \\
\hline Bereaved, $\%$ & 10.8 & 14.2 & 9.9 & 14.2 \\
\hline \multicolumn{5}{|c|}{ Duration of bereavement, $\mathrm{HR}(95 \% \mathrm{Cl})$} \\
\hline Not bereaved (Ref) & 1.00 & 1.00 & 1.00 & 1.00 \\
\hline $0-2$ mo & $2.02(1.33,3.08)$ & $3.03(2.58,3.56)$ & $2.77(1.78,4.32)$ & $2.88(2.46,3.37)$ \\
\hline $2-6 \mathrm{mo}$ & $1.83(1.33,2.53)$ & $1.67(1.43,1.95)$ & $1.89(1.28,2.80)$ & $1.68(1.44,1.95)$ \\
\hline $6-12$ mo & $2.14(1.66,2.77)$ & $1.69(1.47,1.93)$ & $1.69(1.19,2.39)$ & $1.78(1.57,2.03)$ \\
\hline$>12 \mathrm{mo}$ & $1.56(1.32,1.84)$ & $1.31(1.20,1.42)$ & $1.45(1.18,1.78)$ & $1.34(1.23,1.45)$ \\
\hline$P$ for interaction & \multicolumn{2}{|c|}{.056} & \multicolumn{2}{|c|}{.635} \\
\hline Total bereaved, HR $(95 \% \mathrm{Cl})$ & $1.73(1.52,1.98)$ & $1.54(1.44,1.64)$ & $1.63(1.38,1.92)$ & $1.57(1.47,1.67)$ \\
\hline$P$ for interaction & \multicolumn{2}{|c|}{.143} & \multicolumn{2}{|c|}{.194} \\
\hline
\end{tabular}

Note. $\mathrm{HR}=$ hazard ratio; $\mathrm{Cl}=$ confidence interval. All models included gender, age, region of residence, education, household income, and chronic medical conditions as control variables. "Four lowest income quintiles.

\section{DISCUSSION}

\section{Duration of Widowhood}

We found that the risk of entering longterm institutional care was higher among older adults who had lost their spouse than among those living with their spouse. The excess risk of institutionalization was highest during the first month after the spouse's death-more than 3 times among both men and women-and decreased with time from bereavement, stabilizing at approximately $20 \%$ to $50 \%$ higher over 1 to 5 years. Our results cannot be compared with those of previous studies because no other large-scale prospective studies analyzing institutionalization in relation to the duration of widowhood are available. However, our findings are similar to those reported in mortality studies showing a larger immediate effect of bereave ment that decreased with time from the spouse's death. ${ }^{13,15,16,18-20,24,26-28}$ In Finland, however, the excess risk of institutionalization after the death of a spouse seems to be higher and more long term than the risk of death. ${ }^{18}$

The large excess risk of institutionalization occurring immediately after a spouse's death may be related to the loss of social and instrumental support, ${ }^{19}$ in the form of care and help with daily activities such as help in cooking, cleaning, and shopping formerly shared with the deceased spouse. Furthermore, there may be nobody to provide personal care for bereaved persons with severe functional disabilities, and family members and medical professionals may recommend institutional care. Those most vulnerable to entering institutional care are likely to do so immediately after their spouse's death; the risk of institutionalization is, on average, more moderate among those surviving longer after bereavement. The bereaved may also lose other social networks if these were mainly maintained by the spouse. The death of a spouse could also cause a fall in income, which may complicate living in the community.

The excess risk of institutionalization among the bereaved may also be related to emotional stress following the death of a loved partner. Grief and spousal loss may cause various symptoms, such as depression and anxiety, loss of appetite, sleep disturbances, fatigue, retardation of thought, loss of concentration, and changes in drug-taking habits, including an increase in the use of psychotropic medicines, alcohol, and tobacco. ${ }^{7}$ Furthermore, grief may cause increased susceptibility to physical diseases, for example, by lowering immunity to infections or aggravating stress-related diseases, including heart disease. These symptoms and their behavioral, psychic, and cognitive consequences may increase the risk of institutionalization.

Fortunately, a large proportion of the widowed are likely to recover from partner loss, and feelings of despair and anxiety diminish over time. "Emotional recovery could be one of the underlying mechanisms explaining why the very large excess risk of entering institutional care among those recently bereaved dropped with time from the spouse's death.

It has been suggested that the stronger short-term effects of widowhood on mortality may be caused by emotional stress and grief and the more moderate long-term effects by the loss of social, instrumental, and material support. ${ }^{18,19}$ However, the loss of spousal support in daily activities may be an important risk factor for institutionalization, even immediately after the spouse's death, because eating properly and housekeeping are crucial in maintaining an independent life in the community.

Unfortunately, we were not able to directly investigate the mechanisms that mediated the effects of losing a spouse on institutionalization because of data limitations. For example we did not have information on the role of the main caregiver or on change in chronic medical conditions during the follow-up. Furthermore, the data did not contain direct information on functional disabilities ${ }^{1,3,4,10,38,39}$ or childlessness, ${ }^{6}$ conditions that have been shown to be associated with institutionalization. The absence of a measure of childlessness may have led to the overestimation of the overall effect of widowhood on institutionalization if being childless was strongly associated with becoming widowed. However, the very large immediate short-term effect of widowhood that decreased with time was unlikely to be biased because of the absence of information on certain baseline characteristics.

\section{Buffers Against the Effects of} Bereavement

Our results indicated that neither high household income nor education buffered against the harmful effects of spousal loss. The lack of interactions between income and 
spousal loss could be related to the fact that, in Finland, publicly provided institutional care is equally accessible to all older persons regardless of income. Although user charges are tied to income, income is unlikely to influence bereaved persons' decisions on institutional care. Clients in institutions are allowed to keep a minimum of $20 \%$ of their disposable income, or if income is very low, a fixed amount, for personal use.

The duration of widowhood had a slightly different association with the relative risk of institutionalization among more- and less-educated persons, although in an unexpected way. The harmful effects of bereavement seemed to be weaker among the more educated during the first 2 months after bereavement but became stronger as more time elapsed. How ever, the differences were not statistically significant. These results partly agree with a study on mortality in Israel indicating that the relative effect of bereavement is greater among more-educated men. ${ }^{20}$ However, Lusyne et al. indicated that more-educated persons in Belgium seemed to have relatively more excess mortality during the period immediately following the spouse's death. ${ }^{28}$

Manor and Eisenbach suggested that highly educated men may have more to lose in bereavement because they enjoy several roles, including the head of the household and the main breadwinner. ${ }^{20}$ Furthermore, individuals with the most educational and financial resources and with more control over their circumstances may be emotionally more vulnerable to spousal loss. However, our results did not support the idea that persons with more education are emo tionally more vulnerable to their spouse's death, because they indicated a smaller short-term relative effect of bereavement.

Because having children, ${ }^{6}$ especially daughters, ${ }^{40}$ is known to reduce the probability of entering institutional care among older adults, it is likely that getting more help from children after a spouse's death buffers the effects of bereavement on institutionalization, even in Finland, where contacts between older parents and their children are less frequent than in southern European countries. ${ }^{41}$ Further research is needed to examine whether the harmful effects of bereavement are smaller among those who have living children and whether daughters and sons play different roles in buffering the effects of spousal loss. More research is also needed to assess the effects of bereavement according to the disability status of the bereaved and to investigate in detail the mechanisms that mediate the effect of bereavement on institutionalization.

\section{Conclusions}

The follow-up data we used contained information on the dates of spousal death and admission into institutional care, providing a unique opportunity to study institutionalization after the death of a spouse. Our study showed a particularly high risk of institutionalization immediately after bereavement, which decreased over time. These results provide indirect evidence of the effect of the loss of social and instrumental support on the risk of institutionalization. Furthermore, we found that high levels of education and income did not buffer the effects of bereavement. Because long-term institutional care is extremely expensive for society, community-based home help services could be targeted to the bereaved immediately after a spouse's death to reduce the need for institutional care.

\section{About the Atithors}

The authors are with the Population Research Unit, Department of Sociology, University of Helsinki, Helsinki. Finland.

Requests for reprints should be sent to Elina Nihtitä, Population Research Unit, Department of Sociology, PO Box 18, FIN-00014 University of Helsinki, Helsinki, Finland (e-mail: elina.knihtila@helsinkifi).

This article was accepted September 17, 2007.

\section{Contributors}

Both authors designed the study. E. Nihtilly led the writing and completed the aralyses. P. Martikainen superrised the study and reviewed drafts of the article.

\section{Acknowledigneris}

This work was stipported by the Finnish Post-Graduate School of Social Sciences/Population, Health, and Living Conditions; the Finnish Cultural Foundation; and the Academy of Finland (grant 213060). It was part of a European Union-funded research program on Major a European Union-funded research program on

We thank Anja Noro and Unto Häkkinen, National Research and Development Centre for Welfare and Health, for their guidance in designing and using the database and Seppo Koskinen and Anti Reunanen, National Public Health Institute, for helping us with the hospital and medication registers.

\section{Human Participant Protection}

Permission to use the register-based data was obtained from all register authorities involved, including Statistic
Finland, the National Research and Development Centre for Wellare and Health (STAKES), and the Social Insurance Institution (pertnission TK 53-576-04 and TK 53-499-05)

\section{Feferences}

1. Branch LG, Jette AM, A prospective study of longterm care institutionalization among the aged. Am I Public Health. 1982;72:1373-1379.

2. Foley DJ, Ostfeld AM, Branch LG, Wallace RB, McGioin J. Cornoni-Huntley IC. The risk of nursing home admission in three communities. I Aging Healt h 1992;4:155-173.

3. Steinbach U. Social networks, institutionalization, and mortality among elderly people in the United States. J Gerontol. 1992;47(4):S183-S190.

4. Wolinsky FD, Callahan CM, Fitzgerald JF, Johnson RJ. The risk of nursing home placement and subse quent death among older adults. I Gerontol. 1992; 47(4):S173-S182

5. Grundy E, Glaser K. Trends in, and transitions to, institutional residence among older people in England and Wales, 1971-91. J Epidemiol Community Health. $1997 ; 51: 531-540$

6. Grundy E., Jitlal M. Socio-demographic variations in moves to institutional care 1991-2001: a record linkagc study from England and Wales. Age Ageing. 2007:36: $424-430$.

7. Stroebe W, Stroebe MS. Berecwement and Health: The Psychological and Physical Consequences of Partner Loss. Cambridge, England: Cambridge University Loss. Cambri 1987.

8. Bruce ML, Kim K, Leaf PJ, Jacobs S. Depressive episodes and dysphoria resulting from conjugal bereavement in a prospective community sample. $A n J$ $P_{\text {sychiatry. 1990;147:608-611 }}$

9. Aartsen MJ, Van Tilburg T, Smits CH, Comijs HC, Knipscheer KC. Does widowhood affect memory performance of older persons?. Psychol Med. 2005;35: 217-226.

10. Shapiro E. Tate R. Who is really at risk of institutionalization? Gerontologist. 1988:28:237-245.

11. Hyrkäs K, Kaunonen M, Paunonen M. Recovering from the death of a spouse. I Adv Nurs. 1997:25: $775-779$.

12. Wolinsky FD, Johnson RJ. Widowhood, health status, and the use of health services by older aduits: cross-sectional and prospective approach. J Gerontol. 1992;47(1):S8-\$16

13. Young M, Benjamin B, Wallis $C$. The mortality of widowers. Lancet. 1963;454-456

14. Parkes CM, Benjamin B, Fitzgerald RG. Broken heart: a statistical stucily of increasec mortality among widowers. Br Med J. 1969;1:740-743

15. Meliström D, Nilsson A, Oden A, Rundgren A, Svanborg A. Mortality among the widowed in Sweden. Scand j Soc Med. 1982;10:33-41.

16. Jagger C, Sutton CJ. Death after marital bereavement-is the risk increased? Stat Med. $1991 ; 10$ 395-404.

17. Schaefer C, Quesenberry CP Jr, Wi S. Mortality following conjugal bereavement and the effects of a shared environment. Am J Epidemiol. 1995;141: 1142-152 
18. Martikainen P, Valkonen T. Mortality after death of spouse in relation to duration of bereavement in Finland. J Epidemiol Community Health. 1996;50 264-268.

19. Martikainen P, Valkonen T. Mortality after the death of a spouse: rates and causes of death in a large Finnish cohort. Am J Public Health 1996.86 1087-1093.

20. Manor O, Eisenbach Z Mortality after spousal loss: are there socio-demographic differences? Soc Sci Med. 2003:56:405-413.

21. Wolinsky FD, Johnson RJ. Perceived health status and mortality among older men and women. J Gerontol. 1992;47(6):S304-S312.

22. Kiecolt-Glaser JK, Glaser R. Depression and immune function: central pathways to morbidity and mortality. J Psychosom Res. 2002;53:873-876.

23. Nuotio M, Tammela TL, Luukkaala T, Jylhä M. Predictors of institutionalization in an older population during a 13-year period: the effect of urge incontinence. J Gerontol A Biol Sci Med Sci. 2003.58: 756-762.

24. Kaprio J, Koskenvuo M, Rita H. Mortality after bereavement: a prospective sudy of 95647 widowed persons. Am J Public Health. 1987;77:283-287.

25. Jones DR. Cancer mortality following widow(er)hood: some further results from the office of population censuses and surveys longtudinal study. Stress Med. 1986;2:129-140.

26. Bowling A. Mortality after bereavement: a review of the literature on survival periods and factors affecting survival. Soc Sci Med. 1987;24:117-124.

27. Martikainen $P$, Valkonen T. Do education and in come buffer the effects of death of spouse on mortality? Epidemiology. 1998;9:530-534.

28. Lusyne P, Page H, Lievens J. Mortality following conjugal bereavement, Belgium 1991-96: the unexpected effect of education. Popul Stud (Camb). 2001; $55: 281-289$.

29. Statistics Finland. Työssäkäyntitilaston laatuseloste [The quality of the labour force statistics]. Available at http://www.stat.fi/til/tyokay/tyokay_2004-11-23_laa 001.html. Accessed December 1, 2006.

30. Official Statistics of Finland. Care and Services for Older People 2002. SVT: Social Security 2003:1. Helsinki, Finland: National Research and Development Centre for Welfare and Health; 2003.

31. Nihtilä EK, Martikainen PT, Koskinen SV, Reunanen AR, Noro AM, Häkkinen UT. Chronic conditions and the risk of long-term institutionalization among older people. Eur J Public Health. 2008;18:77-84 32. Organisation for Economic Co-operation and Development. The OECD List of Social Indicators. Paris, France: Organisation for Economic Co-operation and Development; 1982

33. Suomen maakunnat [Finnish regions]. Available at: http://fi.wikipedia.org/wiki/Luokka:Suomen_maakunnat. Accessed November 11, 2006

34. Sosiaali- ja terveysalan tutkimus- ja kehittämiskeskus [National Research and Development Centre for Welfare and Health]. Tautiluokitus ICD-10 [Finnish version of the International Statistical Classification of Diseases and Related Health Problems, 10th revision]. 2nd ed. Vol 1: Helsinki, Finland: Sosiaali- ja terveysalan tutkimus- ja kehittämiskeskus; 1999.
35. Kansaneläkelaitos [Social instrance Institution]. Kansaneläkelaitoksen tilastollinen vuosikirja 1997 [Statistical Yearbook of the Social Insurance Institution Finland, 1997], T1:33. Helsinki. Finland: Kansaneläkelaitos; 1998

36. Lääkelaitos [National Agency for Medicines]

Lääkkeiden luokitus (ATC) ja määritellyt vuorokausiannok set (DDD) [Classification of medicines (ATC) and defined daily doses (DDD)]. Helsinki, Finland: Lääkelaitos; 1997

37. Lääkelaitos [National Agency for Medicines]. Lääkkeiden luokitus (ATC) ja määritellyt vuorokausiannokset (DDD) [Classification of medicines (ATC) and defined daily doses (DDD). Helsinki, Finland: Lääkelaitos; 1998

38. Aguero-Torres $\mathrm{H}$, von Strauss $\mathrm{E}$, Viitanen $\mathrm{M}$, Winblad B, Fratiglioni L. Institutionalization in the elderly: the role of chronic diseases and dementia. Crosssectional and longitudinal data from a populationbased study. J Clin Epidemiol. 2001;54:795-801.

39. Tomiak M, Berthelot JM, Guimond E, Mustard CA. Factors associated with nursing-home entry for elders in Manitoba, Canada. J Gerontol A Biol Sci Med Sci. 2000;55(5):M279-M287.

40. Freedman VA. Family structure and the risk of nursing home admission. J Gerontol B Psychol Sci Soc Sci. 1996;51(2):S61-S69.

41. Tomassini C, Kalogirou S, Grundy E, et al. Contacts between elderly parents and their children in four European countries: current paiterns and future prospects. Eur J Ageing. 2004:1:54-63.

\section{Public Health and Podiatric Medicine}

Principles and Practice, 2nd Edition Arthur E. Helfand, DPM, Ed.

This new 2 nd edition has been developed as a text for practitioners, students, and individuals in both the podiatric and public healt professions. It is intended to serve as a model for the future, so that the public can be assured of their foot health and that as ciety ages, patients can retain their mobility, minimize complications related

to chronic diseases, and retain their health and vigor late in life. This presentation has been authored by a group of professionals with a long history of involvement in the professions of podiatric medicine and in public health. The health care delivery system is ever changing. There is a need to focu concern in the future quality of podiatric medical care, the delivery of care and availability of podiatric care for generations to come.

\begin{tabular}{|c|c|}
\hline & ORDER TODAY! \\
\hline APHA & $\begin{array}{l}\text { IBSN } \mathbf{0 - 8 7 5 5 3 - 0 7 1 \cdot 0} \\
608 \text { pages } \cdot \text { softcover } \cdot 2006 \\
\$ 39.19 \text { APHA Members (plus s\&h) }\end{array}$ \\
\hline & $\$ 55.95$ Nonmembers (plus s\&h) \\
\hline & $\begin{array}{l}\text { American Public Health Association } \\
\text { PUBLICAIION SALES } \\
\text { WEB: Www.apha.org E-MAIL APHA@pbd.com } \\
\text { TEL: 888-320-APHA FAX: 888-361-APHA }\end{array}$ \\
\hline
\end{tabular}


